\title{
Challenges in prevention, diagnosis and treatment of abdominal wall hernias
}

Citation for published version (APA):

Bloemen, A. (2020). Challenges in prevention, diagnosis and treatment of abdominal wall hernias.

[Doctoral Thesis, Maastricht University]. Ipskamp. https://doi.org/10.26481/dis.20201204ab

Document status and date:

Published: 01/01/2020

DOI:

10.26481/dis.20201204ab

Document Version:

Publisher's PDF, also known as Version of record

\section{Please check the document version of this publication:}

- A submitted manuscript is the version of the article upon submission and before peer-review. There can be important differences between the submitted version and the official published version of record.

People interested in the research are advised to contact the author for the final version of the publication, or visit the DOI to the publisher's website.

- The final author version and the galley proof are versions of the publication after peer review.

- The final published version features the final layout of the paper including the volume, issue and page numbers.

Link to publication

\footnotetext{
General rights rights.

- You may freely distribute the URL identifying the publication in the public portal. please follow below link for the End User Agreement:

www.umlib.nl/taverne-license

Take down policy

If you believe that this document breaches copyright please contact us at:

repository@maastrichtuniversity.nl

providing details and we will investigate your claim.
}

Copyright and moral rights for the publications made accessible in the public portal are retained by the authors and/or other copyright owners and it is a condition of accessing publications that users recognise and abide by the legal requirements associated with these

- Users may download and print one copy of any publication from the public portal for the purpose of private study or research.

- You may not further distribute the material or use it for any profit-making activity or commercial gain

If the publication is distributed under the terms of Article $25 \mathrm{fa}$ of the Dutch Copyright Act, indicated by the "Taverne" license above, 


\section{Challenges in prevention, diagnosis and treatment of abdominal wall hernias}

Arthur Bloemen 

Challenges in prevention, diagnosis and treatment of abdominal wall hernias 
Copyright (C) Arthur Bloemen 2020

All right reserved. No part of this thesis may be reproduced or distributed in any form or by any means, without the prior written permission of the author or the publisher.

Cover: 'the ascent' by Fons Bloemen

Layout: Tiny Wouters

Printing: Ipskamp bv

ISBN: 978-94-6421-092-7 


\title{
Challenges in prevention, diagnosis and treatment of abdominal wall hernias
}

\author{
PROEFSCHRIFT \\ ter verkrijging van de graad van doctor aan de Universiteit Maastricht, \\ op gezag van de Rector Magnificus, Prof. dr. Rianne M. Letschert, \\ volgens het besluit van het College van Decanen, \\ in het openbaar te verdedigen op \\ vrijdag 4 december 2020 om 14.00 uur \\ door
}

Arthur Bloemen

Geboren 14-07-1985 te Sittard 


\section{Promotor}

Prof. dr. N.D. Bouvy

\section{Copromotores}

Dr. A.G.M. Hoofwijk (Zuyderland Medisch Centrum, Sittard-Geleen)

Dr. F. Aarts (VieCuri Medisch Centrum, Venlo)

\section{Beoordelingscommissie}

Prof. dr. L.P.S. Stassen, voorzitter

Prof. dr. M. van Kleef

Prof. dr. N. Komen (Universitair Ziekenhuis Antwerpen België)

Dr. S.W. Nienhuijs 
Voor mijn dochters 



\section{Table of contents}

Chapter 1 Introduction and outline of the thesis 9

Part A Prevention and treatment of iatrogenic abdominal wall hernias $\quad 19$

Chapter 2 Laparotomy closure techniques: do surgeons follow the latest 21 guidelines? Results of a questionnaire

Chapter 3 Randomized clinical trial comparing polypropylene or

polydioxanone for midline abdominal wall closure

Chapter 4 Evaluation of a new elastic ostomy appliance to decrease skin complications: results of a pilot study

Part B Diagnosis and treatment of abdominal wall hernias

Chapter 5 Comparison of ultrasonography and physical examination in the diagnosis of incisional hernia in a prospective study

Chapter 6 Pitfalls and clinical recommendations for the primary lumbar hernia based on a systematic review of the literature

Chapter 7 Clinical image internal herniation of the abdominal wall

Chapter 8 Incidence of arcuate line hernia in patients with abdominal complaints: radiological and clinical features

Chapter 9 Discussion and future perspectives

Chapter 10 Summary

Samenvatting

Valorisation

Dankwoord

Curriculum Vitae

List of publications 



\section{Chapter 1}

General introduction and outline of the thesis 

Surgery is the medical specialty that focuses on the treatment of injuries or diseases by surgically opening (parts) of the body and removing or repairing the damaged part. Surgery has been performed since before recorded history and treatment of abdominal wall hernias has been a major part of a general or abdominal surgeon's work since ancient times. ${ }^{1,2}$

Ancient Greeks and Phoenicians already described the treatment of abdominal wall hernias. With the advent of the Renaissance and Enlightenment era came an increased interest and understanding of human anatomy. ${ }^{3}$ This led to improved understanding of the pathophysiology and treatment principles of abdominal wall hernias. In the $19^{\text {th }}$ century the discovery of reliable anaesthesia and aseptic methods by Morton and Semmelweis respectively meant that increasingly complex (abdominal wall) surgery became possible. ${ }^{4,5}$

In the $20^{\text {th }}$ century, great progression in knowledge and treatment of abdominal wall hernias was made, which to date have culminated in multiple evidence based guidelines on the prevention and treatment of different types of abdominal wall hernias. $^{6-8}$

This thesis explores current aspects and challenges in preventative measures, diagnostics and treatment of both common and rare abdominal wall hernias.

\section{Anatomy}

The abdominal wall consists of skin, nerves, blood vessels, subcutaneous fat and muscles, that are encased in aponeurotic fibrous sheaths, the fasciae. ${ }^{9}$ Together, these tissues encase the intra-abdominal organs like a corset and provide strength and flexibility during movement. The abdominal wall muscles and aponeurotic sheaths provide the most strength and stability in the abdominal wall (Figure 1.1). The abdominal wall can be divided into an anterolateral part and a posterior part. The anterolateral abdominal wall is bordered by the $7^{\text {th }}$ to $10^{\text {th }}$ ribs and xiphoid process of the sternum cranially and by the inguinal ligament and pelvic bones caudally. There are five muscles of the anterolateral wall: two vertical muscles in the midline (the rectus abdominis and pyramidalis muscle) and three flat muscles on either side (the external oblique, internal oblique and transverse abdominal muscles), whose fibres contract inferomedially, obliquely upward and transversomedially, respectively. The rectus muscle is encased in the aponeurotic fascia of the lateral muscles; in the upper abdomen this encasement is both anterior and posterior of the muscle fibers and in the lower abdomen the encasement is only on the anterior side. The level of delineation of 
posterior fascia is called the arcuate line. The central part of this aponeurotic fascia between the two rectus muscles is called the linea alba or midline.

The posterior abdominal wall is bordered cranially by the ribs and caudally by the iliac crest. It is bordered medially by the lumbar vertebrae and laterally by the anterolateral abdominal wall. The lumbar vertebrae and the five posterior abdominal wall muscles (the psoas, quadratus lumborum, iliacus and the transversus and oblique muscles) provide strength and stability of the posterior abdominal wall.
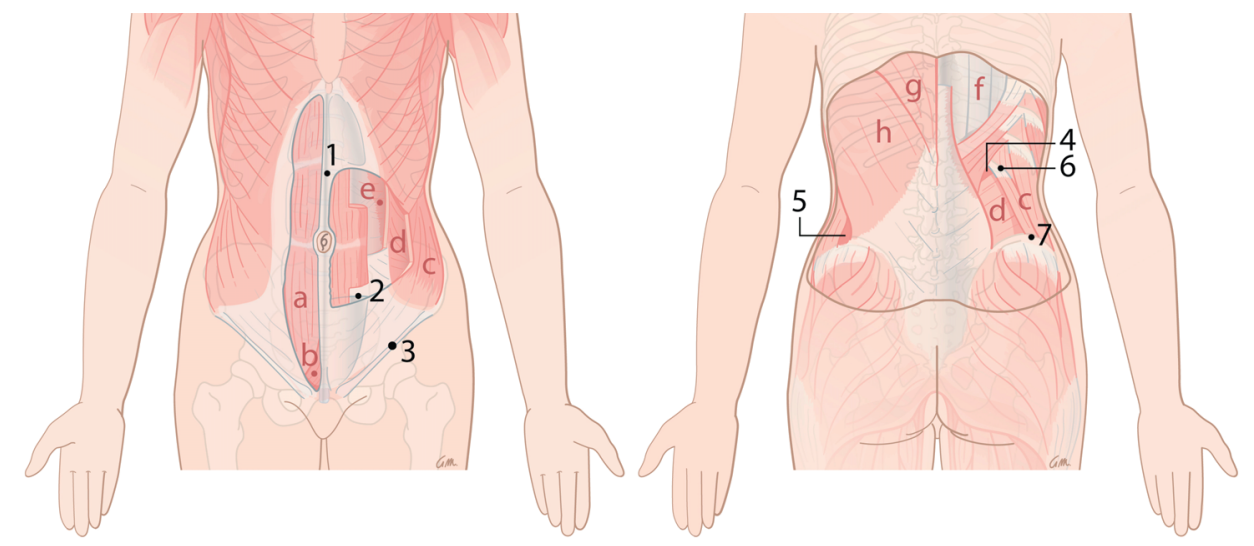
a. rectus abdominis muscle
b. pyramidalis muscle
c. external oblique muscle
d. internal oblique muscle
e. transverse abdominal muscle
f. erector spinae muscle
g. trapezius muscle
h. latissimus dorsi muscle

1. linea alba

2. arcuate line/ semicircular line

3. inguinal ligament

4. Superior lumbar triangle/Grynfeltt-Lesshaft triangle

5. Inferior lumbar triangle/Petit triangle

6. 12 th rib

7. iliac crest

Figure 1.1 Anatomy of the anterior and posterior abdominal wall.

\section{Abdominal wall hernias}

An abdominal wall hernia is a gap in the abdominal wall muscles or aponeurotic sheaths, through which abdominal contents, such as omentum or bowel, can protrude. $^{10} \mathrm{~A}$ visible bulge on the exterior abdomen may result. Presence of an abdominal wall hernia may cause complaints and negatively impact quality of life. ${ }^{11,12}$ If strangulation of the hernia occurs, serious morbidity and mortality may follow. Surgical treatment of abdominal wall hernias is one of the most common operations performed 
worldwide; inguinal hernia repair is performed on more than 20 million people annually. ${ }^{13}$ Treatment of abdominal wall hernias put a significant financial burden on health care systems. ${ }^{14}$

Abdominal wall hernias can be present at birth, be acquired or develop after surgery. Congenital and acquired hernias are called primary hernias and iatrogenic hernias are classified as secondary hernias.

\section{Incisional hernia}

One of the most common types of secondary hernia is the incisional hernia. Although a trend towards minimal invasive laparoscopic and robot assisted surgical procedures can be discerned during the last decades, the abdominal wall still has to be incised in order to access the intra-abdominal organs. Abdominal fascia that has lost structural integrity after a surgical incision needs to recover resistance to traction through wound healing. ${ }^{15}$ Initially, only sutures provide support to the approximated fascial edges. With time and wound healing the musculotendineous layers of the abdominal wall recover structural integrity. If the abdominal wall cannot resist intra-abdominal pressure, an incisional hernia may form. The incidence of an incisional hernia after midline laparotomy ranges from 2 to $20 \%$ in available literature ${ }^{13,16-21}$ In the past, much research focussed on identifying risk factors for incisional hernia development, both patient and surgery related. ${ }^{6,15,22-29}$

One aspect of surgical technique, which can influence the risk of incisional hernia development, is the type of suture material used for closure of the aponeurotic fascia after a laparotomy. Suture materials can be divided into monofilament or braided materials and also classified according to their lasting properties over time. Nonabsorbable sutures that stay in situ permanently, slow absorbable sutures gradually dissolve over a timespan of months and fast absorbable sutures dissolve quickly over the course of several weeks.

Detection of incisional hernias during postoperative follow up is essential in both research setting and in clinical practice. Several diagnostic modalities for diagnosing an incisional hernia are available. Physical examination is usually the diagnostic method of choice, but if uncertainty exists, other modalities such as ultrasonography, computed tomography scanning or magnetic resonance imaging can be used. 


\section{Parastomal hernia}

A stoma is an artificial (surgically created) opening in the abdominal wall, through which a hollow abdominal organ, such as the bowel or urinary tract exits. One of the most frequent complications after stoma formation is peristomal skin irritation, which can occur in up to one in three patients with a stoma. ${ }^{30}$ This skin irritation can range from mild erythema to erosions and ulcerations of the skin. Peristomal skin complications negatively impact the quality of life of patients and lead to increased health care costs. ${ }^{31}$

Presence of a parastomal hernia can cause pain, obstipation and exacerbate peristomal skin irritation. Previous studies found that in patients with permanent stomas approximately fifty percent of patients eventually develop a parastomal hernia. ${ }^{32}$ After surgical creation of the stoma, besides surgical revision, little can be done to influence the location and protrusion of the stoma. Recent guidelines recommend placement of a prophylactic mesh augmentation around the stoma at the time of creation in order to prevent parastomal hernia formation. ${ }^{7}$ Unfortunately, implementation of this guideline has not been ubiquitous.

\section{Outline of the thesis}

The thesis is divided into two parts. The first part explores preventive strategies of two common iatrogenic types of abdominal wall hernias: incisional hernia and parastomal hernia. The second part concerns two more rare types of abdominal wall hernia: the lumbar and arcuate line hernia.

\section{Part A Prevention and treatment of iatrogenic abdominal wall hernias}

Little is known on the application of current evidence to prevent incisional hernia formation in clinical practice. Therefore a national survey among Dutch surgeons was performed to investigate both the awareness and knowledge on this topic. Chapter 2 describes the results of this survey.

Chapter 3 describes a randomised controlled trial, which was performed to investigate the incidence of incisional hernia in patients who had a midline laparotomy. In the trial the abdominal fascia was closed either with a non-absorbable suture (polypropylene) or a slow absorbable suture (polydioxanone).

Chapter $\mathbf{4}$ describes a safety and feasibility study on a new stoma appliance for patients with peristomal skin complications and parastomal hernias. 


\section{Part B Diagnosis and treatment of abdominal wall hernias}

Diagnosis and treatment of abdominal wall hernias can be challenging when the symptoms are not specific or the hernia is a rare entity. The second part of the thesis focuses on diagnostic and treatment aspects of various abdominal wall hernias; Incisional hernias and two more rare types of abdominal wall hernias are discussed.

Chapter $\mathbf{5}$ describes a comparison of physical examination and ultrasonography for the detection of incisional hernia in the setting of the prospective trial, described in chapter 3.

The lumbar hernia is an abdominal wall hernia of the posterior abdominal wall, which can be congenitally present or can be acquired. Chapter 6 describes a literature review of the existing literature and makes clinical recommendations for proper diagnosis and treatment of the primary lumbar hernia.

Another little-known abdominal wall hernia is the arcuate line hernia. An arcuate line hernia can occur if a sharp delineation of the arcuate line occurs and a peritoneal fold develops at this location. This abdominal wall hernia is an internal herniation, ie no full defect of the abdominal wall occurs. Chapter 7 describes a case-report of this rare type of abdominal wall hernia. Little is known on the clinical relevance and incidence of this type of abdominal wall hernia. Chapter 8 reports a retrospective study on the incidence of arcuate line hernia in patients presenting to the emergency department with abdominal complaints in which no initial diagnosis was found. 


\section{References}

1. Sanders DL, Kingsnorth AN. From ancient to contemporary times: A concise history of incisional hernia repair. Hernia. 2012;16(1):1-7

2. Dobanovački D, Milovanović L, Slavković A, Tatić M, Mišković SS, Škorić-Jokić S, et al. Surgery before common era (B.C.E.*). Arch Oncol. 2012;20(1-20):28-35.

3. Toledo-Pereyra LH. Medical renaissance. J Invest Surg. 2015;28(3):127-30

4. Noakes TD, Borresen J, Hew-Butler T, Lambert MI, Jordaan E. Semmelweis and the aetiology of puerperal sepsis 160 years on: An historical review. Epidemiol Infect. 2008;136(1):1-9.

5. Robinson DH, Toledo AH. Historical development of modern anesthesia. J Invest Surg. 2012;25(3): 141-9.

6. Muysoms FE, Antoniou SA, Bury K, Campanelli G, Conze J, Cuccurullo D, et al. European Hernia Society guidelines on the closure of abdominal wall incisions. Hernia. 2015;19(1):1-24

7. Antoniou SA, Agresta F, Garcia Alamino JM, Berger D, Berrevoet F, Brandsma HT, et al. European Hernia Society guidelines on prevention and treatment of parastomal hernias. Hernia. 2018;22(1):183-198.

8. Simons MP, Smietanski M, Bonjer HJ, Bittner R, Miserez M, Aufenacker TJ, et al. International guidelines for groin hernia management. Hernia. 2018;22(1):1-165.

9. Moore KL, Dalley AF, Agur AMR. Clinically Oriented Anatomy (Seventh Edition). Lippincott Williams \& Wilkins, a Wolters Kluwer business. 2014. doi: 10.1017/СBO9781107415324.004

10. Slater NJ, Montgomery A, Berrevoet F, Carbonell AM, Chang A, Franklin M, et al. Criteria for definition of a complex abdominal wall hernia. Hernia. 2014;18(1):7-17.

11. Nieuwenhuizen J, Kleinrensink GJ, Hop WCJ, Jeekel J, Lange JF. Indications for incisional hernia repair: An international questionnaire among hernia surgeons. Hernia. 2008;12(3):223-5.

12. Van Ramshorst GH, Eker HH, Hop WCJ, Jeekel J, Lange JF. Impact of incisional hernia on health-related quality of life and body image: A prospective cohort study. Am J Surg. 2012;204(2):144-50.

13. Gillion JF, Sanders D, Miserez M, Muysoms F. The economic burden of incisional ventral hernia repair: a multicentric cost analysis. Hernia. 2016;20(6):819-30.

14. Franz MG. The Biology of Hernia Formation. Surg Clin North Am. 2008 Feb;88(1):1-15, vii.

15. Hodgson NCF, Malthaner RA, $\varnothing$ stbye T. The search for an ideal method of abdominal fascial closure: A meta- analysis. Ann Surg. 2000;231(3):436-42.

16. Kingsnorth A, LeBlanc K. Hernias: Inguinal and incisional. Lancet. 2003;362(9395):1561-71

17. Höer J, Lawong G, Klinge U, Schumpelick V. Influencing factors on the causes of incisional hernia. A retrospective study of 2983 laparotomy patients over a period of 10 years. Chirurg. 2002;73(5):474-80.

18. Israelsson LA, Jonsson T. Incisional Hernia after Midline Laparotomy: A Prospective Study. Eur J Surg. 1996;162(2):125-9.

19. Mudge M, Hughes LE. Incisional hernia: A 10 year prospective study of incidence and attitudes. British Journal of Surgery. 1985;72(1):70-1.

20. Osther PJ, Gjøde P, Mortensen BB, Mortensen PB, Bartholin J, Gottrup F. Randomized comparison of polyglycolic acid and polyglyconate sutures for abdominal fascial closure after laparotomy in patients with suspected impaired wound healing. Br J Surg. 1995;82(8):1080-2.

21. Bosanquet DC, Ansell J, Abdelrahman T, Cornish J, Harries R, Stimpson A, et al. Systematic review and meta-regression of factors affecting midline Incisional hernia rates: Analysis of 14618 Patients. Vol. 10, PLoS ONE. 2015. doi: 10.1371/journal.pone.0138745

22. Israelsson LA, Millbourn D. Prevention of incisional hernias. How to close a midline incision. Surg Clin North Am. 2013'93:1027-40.

23. Deerenberg EB, Harlaar JJ, Steyerberg EW, Lont HE, Van Doorn HC, Heisterkamp J, et al. Small bites versus large bites for closure of abdominal midline incisions (STITCH): A double-blind, multicentre, randomised controlled trial. Lancet. 2015;386(10000):1254-60.

24. Israelsson LA, Jonsson T. Physical properties of self locking and conventional surgical knots. Eur J Surg. 1994;160(6-7):323-7.

25. Thorup T, Tolstrup MB, Gögenur I. Reduced rate of incisional hernia after standardized fascial closure in emergency laparotomy. Hernia. 2019;23(2):341-6. 
26. Franz MG. The biology of hernias and the abdominal wall. Hernia. 2006;10:462-71.

27. Yahchouchy-Chouillard E, Aura T, Picone O, Etienne JC, Fingerhut A. Incisional hernias: I. Related risk factors. Vol. 20, Digestive Surgery. 2003;20:3-9.

28. Junge K, Klinge U, Rosch R, Mertens PR, Kirch J, Klosterhalfen B, et al. Decreased collagen type I/III ratio in patients with recurring hernia after implantation of alloplastic prostheses. Langenbeck's Arch Surg. 2004;389(1):17-22.

29. Klinge U, Si ZY, Zheng H, Schumpelick V, Bhardwaj RS, Klosterhalfen B. Abnormal collagen I to III distribution in the skin of patients with incisional hernia. Eur Surg Res. 2000;32(1):43-8.

30. Malik TAM, Lee MJ, Harikrishnan AB. The incidence of stoma related morbidity - A systematic review of randomised controlled trials. Ann R Coll Surg Engl. 2018;100(7):501-508.

31. Taneja C, Netsch D, Rolstad BS, Inglese G, Eaves D, Oster G. Risk and Economic Burden of Peristomal Skin Complications Following Ostomy Surgery. J wound, ostomy, Cont Nurs Off Publ Wound, Ostomy Cont Nurses Soc. 2019;46(2):143--9.

32. Carne PWG, Robertson GM, Frizelle FA. Parastomal hernia. Br J Surg. 2003;90(7):784-93. 



\section{Part A}

Prevention and treatment of iatrogenic abdominal wall hernias 



\title{
Chapter 2
}

Laparotomy closure techniques:

do surgeons follow the latest guidelines?

Results of a questionnaire

\author{
Bloemen A \\ De Kleijn RJCMF \\ Van Steensel S \\ Aarts $\mathrm{F}$ \\ Schreinemacher M \\ Bouvy ND
}

International Journal of Surgery. 2019:71:110-116 


\section{Abstract}

\section{Purpose}

Incisional hernias after laparotomy are associated with significant morbidity and increased costs. Recent research on prevention of incisional hernia formation suggests a laparotomy closure technique using a slowly absorbable monofilament suture with small fascial steps and bites in a continuous, single layer with a suture length to wound length (SL/WL) ratio at least 4:1. Little is known about application of this evidence in daily practice. Therefore, a survey was performed among Dutch surgeons.

\section{Methods}

All members of the Dutch Surgical Society were invited to participate in a 24-question online survey on techniques and materials used for abdominal wall closure after midline laparotomy. Subgroup analysis based on surgical subspecialty, type of hospital and experience was performed.

\section{Results}

Response rate was 26\% (402 respondents), representing $97 \%$ of all Dutch surgical departments. More than $90 \%$ of participants close the abdominal wall in a single mass layer, using a monofilament slowly absorbable running suture The SL/WL ratio of $>4: 1$ is practiced by only $35 \%$ of participants. Preferred suture size is variable among participants. Risk factors for incisional hernia development are generally identified correctly but more than half of the participants were unaware of the incidence and time of occurrence of incisional hernia. Subgroup analysis found that gastrointestinal and oncologic surgeons preferred smaller diameter sutures and higher suture-length to wound-length ratios. Trauma, vascular and pediatric surgeons had lower estimates of incidence of incisional hernia than other subspecialties. Surgeons employed in academic hospitals are more likely to use small fascial steps and smaller suture sizes than their colleagues in non-academic hospitals. Correct estimates of incisional hernia incidence decreased when surgeons perform less than 10 laparotomies annually.

\section{Conclusion}

Adoption of techniques to close the abdominal wall to the latest evidence is not widespread. Surgical trainees, gastrointestinal and oncological surgeons are most familiar with the technique and use it in their daily practice. Efforts should be directed at improving spreading of this technique. 


\section{Introduction}

The midline laparotomy is a common technique for fast and avascular open access to the abdominal cavity. Optimal closure of the abdominal wall after laparotomy is essential to prevent short-term complications such as surgical site infections or wound dehiscence (burst abdomen) and formation of incisional hernias during long-term follow-up. These complications cause both increased morbidity and mortality, and increased health care costs due to increased length of hospital stay, re-admissions and re-interventions. ${ }^{1}$

Over the last decades, various groups have published a significant amount of research on optimal closure techniques and materials of the abdominal wall after midline laparotomy to prevent incisional hernia formation. As first described by Israelsson et al. and later confirmed in other randomized clinical trials, a continuous, single layer suturing technique with a suture length to wound length (SL/WL) ratio at least 4:1, using a slowly absorbable monofilament suture with small fascial steps and bites and a self-locking knot appears to minimize the risk of incisional hernia development. ${ }^{2-5}$ Based on available evidence, the European Hernia Society (EHS) published a guideline on abdominal wall closure in 2015 , which recommends using this technique in elective settings. ${ }^{6}$ Two recent retrospective cohort studies also found a decrease in wound dehiscence and incisional hernia when a similar structured closure technique is adopted in emergency laparotomies. ${ }^{7,8}$ Since publication of the guideline, additional research has been published on the optimal technique for abdominal wall closure which further supports the small bites technique using a smaller suture size (2-0) and which suggest using prophylactic mesh reinforcement in high risk patients. ${ }^{4,9,10}$

Little is known on the implementation of these techniques and evidence in daily surgical practice. Previous surveys investigating this were generally small, reported in the author's native languages and were published before the guideline of 2015. ${ }^{11-13}$ We therefore conducted a national survey among Dutch surgeons in order to investigate current knowledge and techniques of abdominal wall closure used in relation to the current best available evidence and the EHS guideline. The secondary purpose of the survey was to perform subgroup analysis to investigate possible differences in practice between surgical subspecialties, between the type of hospital and between the number of laparotomies performed annually. 


\section{Methods}

\section{Design}

A web-based survey was constructed using professional survey software (Surveymonkey, Palo Alto, USA). The survey questions were designed by two independent authors ( $A B$ and $R K$ ) and edited by a third author (NB). The survey was in the Dutch language. The translated questions are listed in Appendix 2.A. In the web survey, each question was listed on a separate page. Participants were able to review and change their answers before finalizing their responses.

Prior to distribution, five surgical trainees tested the survey for unambiguity and their feedback was incorporated in the survey. The survey was in concordance with the CHERRIES checklist, which is a checklist to ensure quality of the reporting of web-based surveys, analogous to the CONSORT and QUORUM checklists for reporting randomized trials and systematic reviews. ${ }^{14}$

No approval from an Institutional Review Board was needed for this study. Participants were informed about the goals, expected time to complete the questions and identity of the research group before starting the survey. This study was registered in the publicly accessible database of the United States National Library of Medicine (accessible at www.ClinicalTrials.gov, identifier NCT04013009).

The survey consisted of 24 multiple choice and open questions on experience, technique and suture materials used for closure after a laparotomy. Questions on technique focused on layers of closure, type of knot used to secure the suture, the size of fascial bites and steps between consecutive bites of the sutures. A fascial bite is the distance from fascial edge to where the needle pierces through the tissue. The size of bites and steps was defined as small ( $<5$ millimeters), intermediate (6-10 millimeters) or large (>10 millimeters). Four questions were asked to test the surgeon's knowledge on risk factors and incidence of incisional hernia. Participants were not queried on the use of prophylactic mesh placement in high-risk patients because the evidence became available after distribution of this survey. ${ }^{9}$ Based on current available evidence in the literature, the following statements were considered correct:

- A transverse incision has the lowest risk of incisional hernia development, when compared to oblique and midline incisions ( $\mathrm{RR}=1.77 ; 95 \% \mathrm{Cl}: 1.09-2.87) .{ }^{15}$

- The incidence of incisional hernia is highest in the second postoperative year. ${ }^{2,16}$

- $\quad$ The weighted mean incisional hernia rate is $13 \%$ at 2 years after surgery. ${ }^{17}$

- The following patient related risk factors have been identified to increase the development of an incisional hernia: Postoperative surgical site infection, obesity, abdominal aortic aneurysm, male gender and age. ${ }^{6,16}$ 


\section{Participants}

A database was created of all listed members of the Dutch Society for Surgery (Nederlandse Vereniging voor Heelkunde) containing both surgeons and surgical trainees. We excluded surgeons registered outside the Netherlands, surgeons without contact details and members who were retired or changed professions. Subsequently, we excluded surgeons who, after a prior survey using the same database requested not to be contacted again for future surveys. ${ }^{18}$

Following this exclusion we sent a participation request by e-mail to the remaining members. Responses were collected over a period of 6 weeks during which reminder emails to non-respondents were distributed. In order to stimulate response, ten portable smartphone chargers were raffled among respondents. After this period the online survey was no longer accessible and the recorded responses anonymized. Responses were protected from unauthorized access by password control.

Respondents were asked to provide their subspecialty and the main type of hospital in which they work, as well as the estimated number of annual laparotomies performed. The following subspecialties were available for choice: surgical trainee, general surgeon or one of the following subspecialties: gastrointestinal, oncologic, trauma, vascular or pediatric surgeon. Later, gastrointestinal and oncologic surgeons were grouped together because both subspecialties perform abdominal surgery in the Netherlands. Likewise, trauma surgeons, vascular surgeons and pediatric surgeons were grouped together because of expected less affinity or experience with abdominal wall surgery. Participants chose the following type of hospital: academic (university) hospital, nonacademic teaching hospital and non-academic non-teaching hospital.

\section{Analysis}

Surveys that were completed for more than eighty percent were included in the analysis. Reported data is based on the answers of the survey, missing values were excluded. Subgroup analysis was performed to investigate differences between surgical subspecialties, type of hospital in which the respondent works and between the number of laparotomies performed each year.

In categorical data, Pearson's Chi-squared test and Fisher's exact test were used. Due to plurality of questions in the study, a Bonferroni correction was applied, the cutoff value for assessing statistical significance was set at $24 / 0.05=0.002$. If a significant difference was found, multinomial logistic regression analysis was performed.

Percentages are reported in rounded figures. Statistical analysis was performed using the SPSS software package ${ }^{\circledR}$, version 22 for Windows (SPSS Inc., Chicago, IL, USA). 


\section{Results}

\section{Participants}

A total of 1577 surgeons and trainees were invited by e-mail in July 2016. After six weeks and three reminder e-mails, 402 complete responses (26\%) were received. The respondents represent $97 \%$ of all hospitals in the Netherlands. The participant characteristics are listed in Table 2.1.

The largest group of participants was gastro-intestinal and oncologic surgeons (38\%), followed by trauma, vascular and pediatric surgeons (27\%), surgical trainees (19\%) and general surgeons (15\%). Most respondents (57\%) were employed in a non-academic teaching hospital. Median work-experience of the participants was 7 years (interquartile range 4-15). Most respondents (89\%) performed more than 10 laparotomies annually.

Table 2.1 Characteristics of participants.

\begin{tabular}{lccccc}
\hline & $\begin{array}{c}\text { Surgical } \\
\text { trainee }\end{array}$ & $\begin{array}{c}\text { Gastrointestinal / } \\
\text { oncologic surgeon }\end{array}$ & $\begin{array}{c}\text { Trauma / vascular / } \\
\text { pediatric surgeon }\end{array}$ & $\begin{array}{c}\text { General } \\
\text { surgeon / other }\end{array}$ & Total \\
\hline $\begin{array}{l}\text { Number of respondents (\%) } \\
\text { Median work experience in }\end{array}$ & $58(19)$ & $153(38)$ & $110(27)$ & $61(15)$ & $402(100)$ \\
years (interquartile range) & & $8(4-15.5)$ & $10(5-17)$ & $15(6.5-29.5)$ & $7(4-15)$ \\
Type of hospital (\%) & & & & & \\
- academic & $25(32)$ & $23(15)$ & $28(26)$ & $5(9)$ & $81(21)$ \\
- non-academic teaching & $52(67)$ & $92(52)$ & $57(52)$ & $27(49)$ & $228(58)$ \\
- non-teaching & $1(1)$ & $24(22)$ & $24(22)$ & $23(42)$ & $85(22)$ \\
Number of laparotomies & & & & & \\
annually (\%) & & & & & \\
$-<10$ & $13(17)$ & $11(7)$ & $38(35)$ & $25(46)$ & $181(46)$ \\
-10 to 30 & $41(53)$ & $62(41)$ & $53(49)$ & $16(30)$ & $136(35)$ \\
$->30$ & $24(31)$ & $78(52)$ & $18(17)$ & & \\
\hline
\end{tabular}

\section{Abdominal wall closure technique and materials}

Responses to the questionnaire on the technique used to close of the abdominal fascia after midline incision are shown in Table 2.2. The majority of respondents (96\%) indicated that they used a single mass closure of the abdominal fascia. Most respondents (98\%) routinely use running sutures for closure of the abdominal fascia and $68 \%$ use a surgical knot to secure the fascial suture. 
Table 2.2 Responses on technique of abdominal wall closure after midline laparotomy.

\begin{tabular}{|c|c|c|c|c|c|c|}
\hline & Trainee & $\begin{array}{c}\text { Gastrointestinal/ } \\
\text { oncologic } \\
\text { surgeon }\end{array}$ & $\begin{array}{l}\text { Trauma/ } \\
\text { vascular/ } \\
\text { pediatric } \\
\text { surgeon }\end{array}$ & $\begin{array}{l}\text { General } \\
\text { surgeon/ } \\
\text { other }\end{array}$ & Total & P-value \\
\hline \multicolumn{7}{|c|}{ Peritoneal closure (\%) } \\
\hline -yes & $6(8)$ & $11(7)$ & $12(11)$ & $8(17)$ & $37(10)$ & 0.259 \\
\hline -no & $68(92)$ & $137(93)$ & $93(89)$ & $40(83)$ & $375(90)$ & \\
\hline \multicolumn{7}{|l|}{ Layers of closure (\%) } \\
\hline - one & $70(93)$ & $146(98)$ & $100(95)$ & $46(96)$ & $362(96)$ & 0.310 \\
\hline - two & $5(7)$ & $3(2)$ & $5(5)$ & $2(4)$ & $15(4)$ & \\
\hline \multicolumn{7}{|l|}{ Running suture (\%) } \\
\hline -yes & $75(100)$ & $146(99)$ & $104(98)$ & $47(96)$ & $372(98)$ & 0.332 \\
\hline -no & $0(0)$ & $2(1)$ & $2(2)$ & $2(4)$ & $6(2)$ & \\
\hline \multicolumn{7}{|l|}{ Type of knot (\%) } \\
\hline - surgical & $52(69)$ & $101(68)$ & $70(67)$ & $34(70)$ & $275(68)$ & 0,72 \\
\hline - aberdeen & $16(21)$ & $24(16)$ & $23(22)$ & $7(15)$ & 70 (19) & \\
\hline - other self-locking & $7(9)$ & $23(16)$ & $12(11)$ & $7(15)$ & $49(13)$ & \\
\hline \multicolumn{7}{|l|}{ Fascial bite (\%) } \\
\hline$-0-5 \mathrm{~mm}$ & $13(17)$ & 28 (19) & $14(13)$ & $7(14)$ & $62(17)$ & 0.407 \\
\hline$-6-10 \mathrm{~mm}$ & $52(69)$ & $98(67)$ & $66(62)$ & $30(63)$ & $246(65)$ & \\
\hline$-11-20 \mathrm{~mm}$ & $10(13)$ & $20(13)$ & $22(21)$ & $10(21)$ & $62(17)$ & \\
\hline$->20 \mathrm{~mm}$ & $0(0)$ & $1(1)$ & $4(4)$ & $1(2)$ & $6(1)$ & \\
\hline \multicolumn{7}{|l|}{ Fascial steps (\%) } \\
\hline$-0-5 m m$ & $27(36)$ & $36(24)$ & $22(21)$ & $7(15)$ & $92(24)$ & 0.005 \\
\hline$-6-10 m m$ & $45(60)$ & $89(61)$ & $61(57)$ & $30(62)$ & $225(60)$ & \\
\hline - large (>10mm) & $3(4)$ & $22(15)$ & $23(22)$ & $11(23)$ & $59(16)$ & \\
\hline \multicolumn{7}{|c|}{$\begin{array}{l}\text { Preferred suture-length: } \\
\text { wound-length ratio (\%) }\end{array}$} \\
\hline - none & $36(48)$ & $42(29)$ & $64(60)$ & $20(41)$ & $162(43)$ & 0.001 \\
\hline$-1: 1$ & $1(1)$ & $5(3)$ & $5(4)$ & $1(2)$ & $12(3)$ & \\
\hline$-2: 1$ & $8(11)$ & $9(6)$ & $7(7)$ & $4(8)$ & $28(7)$ & \\
\hline$-3: 1$ & $7(10)$ & $20(14)$ & $6(6)$ & $6(12)$ & $39(10)$ & \\
\hline$-4: 1$ & $22(29)$ & $69(47)$ & $24(23)$ & $18(37)$ & $133(35)$ & \\
\hline$-5: 1$ & $1(1)$ & $1(1)$ & $0(0)$ & $0(0)$ & $2(1)$ & \\
\hline \multicolumn{7}{|c|}{$\begin{array}{l}\text { Technique changed since } \\
\text { training (\%) }\end{array}$} \\
\hline -Yes & $7(9)$ & $49(37)$ & $32(33)$ & $26(55)$ & $114(32)$ & $<0.001$ \\
\hline -no & $71(91)$ & $82(63)$ & $66(66)$ & $21(45)$ & $240(68)$ & \\
\hline
\end{tabular}

Responses to questions on the size of fascial bites and steps used and the resultant suture-length to wound-length ratio varied more. Most (65\%) participants reported an intermediate fascial bite size and $60 \%$ use steps of 6-10 millimeters between fascial bites. $43 \%$ of the participants did not prefer a suture length to wound length ratio and $35 \%$ seek a ratio of $4: 1$. Other participants prefer other ratios. $68 \%$ of participants reported that they did not change technique and materials for closure of the abdominal wall since surgical training. 
Concerning the material used for closure of the abdominal wall, nearly all (93\%) respondents preferred a slowly absorbable suture. 96\% preferred a monofilament, rather than a braided, multifilament suture thread and most participants (81\%) preferred a sharp-tipped needle for closure of the fascia and all participants used a curved needle (Table 2.3). The preferred suture size for closure of the abdominal fascia was variable among respondents: Suture size 1 is most often used (42\%), followed by 0 $(23 \%)$ and $2-0(18 \%)$. The majority of participants (62\%) use a loop suture. Nearly half of the participants $(47 \%)$ reported using two suture threads and the other half $(53 \%)$ used one suture thread for closure of the abdominal wall.

Table 2.3 Responses on material used for abdominal wall closure after midline laparotomy.

\begin{tabular}{|c|c|c|c|c|c|c|}
\hline & Trainee & $\begin{array}{l}\text { Gastrointestinal/ } \\
\text { oncologic } \\
\text { surgeon }\end{array}$ & $\begin{array}{l}\text { Trauma/ } \\
\text { vascular/ } \\
\text { pediatric } \\
\text { surgeon }\end{array}$ & $\begin{array}{l}\text { General } \\
\text { surgeon } \\
\text { /other }\end{array}$ & Total & P-value \\
\hline \multicolumn{7}{|c|}{ Number of sutures (\%) } \\
\hline - one & $38(51)$ & $77(42)$ & $59(57)$ & $24(51)$ & $198(53)$ & 0.715 \\
\hline - two & 27 (49) & $72(48)$ & $44(43)$ & $23(49)$ & $176(47)$ & \\
\hline \multicolumn{7}{|l|}{ Loop suture (\%) } \\
\hline - yes & $48(64)$ & $95(64)$ & $76(74)$ & $30(64)$ & $249(67)$ & 0.715 \\
\hline - no & $27(36)$ & $54(36)$ & $17(26)$ & $17(36)$ & $125(33)$ & \\
\hline \multicolumn{7}{|l|}{ Type of suture (\%) } \\
\hline - slowly absorbable & $65(87)$ & $140(94)$ & $102(96)$ & $47(96)$ & $354(93)$ & 0.092 \\
\hline - non-absorbable & $10(13)$ & $9(6)$ & $4(4)$ & $2(4)$ & $25(7)$ & \\
\hline \multicolumn{7}{|l|}{ Type of suture (\%) } \\
\hline - monofilament & $75(100)$ & $146(98)$ & $98(93)$ & $43(90)$ & $362(96)$ & 0.003 \\
\hline - braided & $0(0)$ & $3(2)$ & $8(7)$ & $5(10)$ & $16(4)$ & \\
\hline \multicolumn{7}{|l|}{ Needle tip (\%) } \\
\hline - sharp & $70(93)$ & $134(90)$ & $86(83)$ & $36(74)$ & $326(87)$ & 0.006 \\
\hline - blunt & $5(7)$ & $15(10)$ & $18(17)$ & $13(26)$ & $51(13)$ & \\
\hline \multicolumn{7}{|l|}{ Suture size (\%) } \\
\hline-2 & $8(11)$ & $13(9)$ & $12(12)$ & $5(10)$ & $38(10)$ & 0.168 \\
\hline-1 & 25 (34) & $66(44)$ & $52(51)$ & 27 (55) & $170(45)$ & \\
\hline-0 & 22 (29) & $44(29)$ & $16(15)$ & $10(21)$ & $92(25)$ & \\
\hline$-2-0$ & $19(26)$ & 25 (17) & $21(20)$ & $7(14)$ & 72 (19) & \\
\hline$-3-0$ & $0(0)$ & $1(1)$ & $2(2)$ & $0(0)$ & $3(1)$ & \\
\hline
\end{tabular}

\section{Incisional hernia knowledge}

The responses to the questions on opinions on incisional hernia are summarized in Table 2.4. The majority of respondents (79\%) correctly indicated a midline laparotomy to be most at risk for incisional hernia development. $32 \%$ of participants correctly estimated the risk of incisional hernia to be $11-15 \%$. 
Just over half the participants (52\%) estimated the time till diagnosis of incisional hernia to be within the first postoperative year and most other (46\%) participants estimated this to be within five years after surgery. Almost no participants $(2 \%)$ thought that an incisional hernia could develop more than five years after surgery. The five factors deemed to be most important for the development of incisional hernia were: surgical site infection, obesity, COPD, steroid use and impaired nutritional state (Figure 2.1). The responses are summarized in Figure 2.1.

Table 2.4 Incisional hernia knowledge.

\begin{tabular}{|c|c|c|c|c|c|c|}
\hline & Trainee & $\begin{array}{l}\text { Gastrointestinal/ } \\
\text { oncologic } \\
\text { surgeon }\end{array}$ & $\begin{array}{l}\text { Trauma/ } \\
\text { vascular/ } \\
\text { pediatric } \\
\text { surgeon }\end{array}$ & $\begin{array}{l}\text { General } \\
\text { surgeon/ } \\
\text { other }\end{array}$ & Total & P-value \\
\hline \multicolumn{7}{|c|}{$\begin{array}{l}\text { Incision most at risk for } \\
\text { development of incisional } \\
\text { hernia (\%) }\end{array}$} \\
\hline -midline laparotomy & $57(80)$ & $131(93)$ & $89(86)$ & $42(88)$ & $319(88)$ & 0.04 \\
\hline -transverse & $8(11)$ & $2(1)$ & $5(5)$ & $1(2)$ & $16(4)$ & \\
\hline -oblique & $6(9)$ & $8(6)$ & $10(9)$ & $5(10)$ & $29(8)$ & \\
\hline \multicolumn{7}{|c|}{$\begin{array}{l}\text { Estimate of incidence of } \\
\text { incisional hernia }\end{array}$} \\
\hline$-1-5 \%$ & $4(6)$ & $2(1)$ & $12(11)$ & $2(4)$ & $20(5)$ & $<0.001$ \\
\hline$-6-10 \%$ & $15(21)$ & $17(12)$ & $34(33)$ & $7(15)$ & $23(20)$ & \\
\hline$-11-15 \%$ & $27(39)$ & $35(25)$ & $33(32)$ & $20(42)$ & $115(32)$ & \\
\hline$-16-20 \%$ & $16(23)$ & $50(36)$ & $14(13)$ & $14(29)$ & $94(26)$ & \\
\hline$-20-25 \%$ & $8(11)$ & $25(18)$ & $8(8)$ & $2(4)$ & $43(12)$ & \\
\hline$->25 \%$ & $0(0)$ & $11(8)$ & $3(3)$ & $3(6)$ & $17(5)$ & \\
\hline \multicolumn{7}{|c|}{$\begin{array}{l}\text { Time of diagnosis of incisional } \\
\text { hernia }\end{array}$} \\
\hline$-<6$ weeks postop & $2(3)$ & $2(1)$ & $3(3)$ & $0(0)$ & $7(2)$ & 0.668 \\
\hline - 1st year & $30(42)$ & $74(53)$ & $53(51)$ & $25(52)$ & $182(50)$ & \\
\hline$-1-5$ years & $35(49)$ & $62(44)$ & $45(44)$ & $23(48)$ & $165(46)$ & \\
\hline$->5$ years & $4(6)$ & $3(2)$ & $2(2)$ & $0(0)$ & $9(2)$ & \\
\hline
\end{tabular}

\section{Subgroup analysis}

Subgroup analysis of the surgical subspecialties found significant differences in responses on SL/WL ratio and estimated incidence of incisional hernia (Table 2.2 and 2.4). 


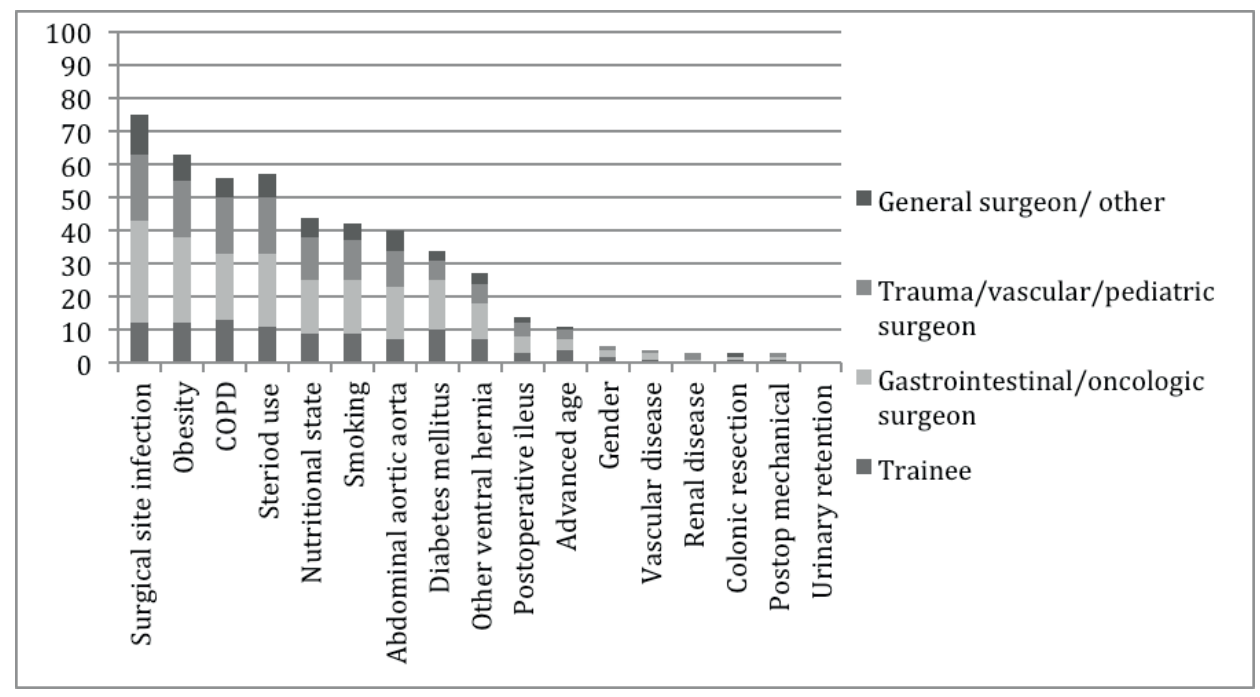

Figure 2.1 Reported risk factors for development of incisional hernia in percentages.

Multinomial logistic regression analysis with the gastro-intestinal and oncologic surgeons as reference group found that the odd's ratio for preference of SL/WL ratio of 4:1 for trainees was 0.37 [95\% confidence interval 0.19-0.72]. In trauma, vascular and pediatric surgeons the odd's ratio was 0.23 [95\% $\mathrm{Cl} 0.13-0.42]$ and in general surgeons this was 0.55 [95\% $\mathrm{Cl} 0.26-1.15]$. In other words; when compared with gastrointestinal and oncological surgeons, trainees are three times less likely to use a SL/WL ratio of 4:1. Trauma, vascular and pediatric surgeons are four times less likely to use this ratio and the odds of a general surgeon preferring the $4: 1$ ratio are half those of gastrointestinal and oncologic surgeons.

Responses between the subspecialties on incidence of incisional hernia were significantly different $(P<0.001)$; General surgeons were most likely to reply the correct incisional hernia incidence (42\%). Multinomial logistic regression analysis defining the general surgeons as reference group found that the odd's ratio for correct estimation of incisional hernia was 1.17 [95\% $\mathrm{Cl} 0.46-2.46]$ for trainees, 0.39 [95\% Cl 0.18-0.81] for gastro-intestinal and oncologic surgeons and 1.25 [95\% $\mathrm{Cl} 0.56-2.83]$ for trauma, vascular and pediatric surgeons. Gastro-intestinal and oncologic surgeons were more likely to estimate a higher incidence of incisional hernia while trauma, vascular and pediatric surgeons were more prone to lower estimations. No significant differences in responses on type of incision, time of occurrence or risk factors for development of incisional hernia were found. 
Multinomial regression analysis was performed to detect differences between subspecialties in changes in technique during the active career of participants. Since $91 \%$ of trainees did not change their technique during their career, they were excluded from this analysis. No significant difference was between subspecialties in this analysis ( $P=0.027)$.

After Bonferroni correction, no significant differences were found during subgroup analysis of preferences of material between the subspecialties.

Subgroup analysis based on the type of hospital in which participants work found differences in responses on the questions on fascial step size $(P=0.001)$ and suture size $(P=0.001)$. The responses to the other questions on technique, materials and incisional hernia knowledge did not vary among the type of hospital.

Multinomial logistic regression analysis with the participants from academic hospitals as reference group found that the odd's ratio for preference of small fascial step size ( $<5 \mathrm{~mm}$ ) was 0.39 for participants from teaching hospitals (95\% confidence interval 0.14-1.04) and for participants from non-academic non-teaching hospitals the odd's ratio was 0.10 [95\% $\mathrm{Cl} 0.03-0.32]$. Participants from academic hospitals were 2.5 to 8 times more likely to prefer small steps than participants from other hospitals.

When compared with participants from academic hospitals at multinomial logistic regression analysis, the odd's ratio for participants from teaching hospitals to use a suture size other than $2-0$ was 3.17 (95\% Cl 1,75-5.74) and 3.64 (95\% Cl 1.67-8.00) for non-academic, non-teaching hospitals. Surgeons working in non-academic hospitals are more likely to use sutures other than 2-0 for closure of the abdominal wall.

When participants were grouped according to the annual number of midline laparotomies performed, a significant difference was detected in the estimation of the incidence of incisional hernias $(P<0.002)$.

Multinomial logistic regression analysis found that the odd's ratio for participants who perform less than 10 laparotomies to estimate the correct incidence of incisional hernia was 1.05 (95\% Cl 0.24-4.57), when compared with participants performing more than 30 laparotomies yearly as reference. The odd's ratio for participants performing 10-30 laparotomies was $0.82(95 \% \mathrm{Cl} 0.25-2.55)$. These findings suggest that an increased number of laparotomies is associated with better knowledge on incisional hernia incidence. 


\section{Discussion}

The surgical technique used for closure after laparotomy is one of the most important risk factors for development of incisional hernia. Unlike other patient related factors, it is also one of the few factors that can be influenced by the surgeon in order to decrease the incidence of incisional hernia. Previously, little was known on the acceptance and implementation of current evidence on this subject among surgeons.

This survey provides insight in current practice patterns of abdominal wall closure of different surgical subspecialties. The main findings are that most interviewed surgeons use a single layer mass closure technique with a running slow absorbable suture. Only $35 \%$ of surgeons close the abdominal fascia using a SL/WL ratio of $4: 1$ and $19 \%$ use a size 2-0 suture. Gastro-intestinal and oncologic surgeons are two to four times more likely to use the 4:1 ratio and surgeons in academic hospitals are more likely to use small steps and a 2-0 suture. Over two thirds of participants did not change this technique since training. Risk factors for incisional hernia development are generally identified correctly but the correct incidence of incisional hernia was known by only $32 \%$ of participants. Also, while evidence suggest that most incisional hernias develop during the second postoperative year, half of the participating surgeons thought most incisional hernias develop within the first postoperative year. This suggests that surgeons may be insufficiently vigilant for later development of incisional hernias.

Previous studies on implementation of evidence for incisional hernia prevention found similar results to our survey. In 2009, Rahbari et al. reported a lack of consensus of abdominal wall closure in a cohort analysis of 157 patients. ${ }^{11}$ Pereira et al. found similar results in a Spanish survey among 131 surgeons and surgical trainees in $2013 .{ }^{12}$ More recently, Fischer et al. reported on a web-based survey among members of hernia societies and found that, in this selected population of 'abdominal wall enthusiasts' $63 \%$ of participants practiced but not measured the suture length to wound length ratio of $4: 1$ and only $15 \%$ of participants currently use prophylactic mesh reinforcement of the abdominal wall in high risk patients. ${ }^{20}$ Although in their survey more surgeons use incisional hernia prevention techniques when compared to the present study, even among this targeted population of surgeons, adaptation to best practice is still not ubiquitous.

There are several possible explanations for the discrepancy in findings between literature recommendations and reported current practice:

First, probably not all surgeons are aware of current findings. Surgeons who perform less laparotomies were found to be more likely to estimate the rate of incisional hernia formation incorrectly. This may reflect a lower affinity with techniques of closure of the 
abdominal wall for these surgeons. If these specialists do not encounter incisional hernias (because these patients are referred to other colleagues), they may not feel the need to change their current technique since it seems to be sufficient.

Secondly, it is possible that not all surgeons are convinced by the literature. Two recent meta-analyses on abdominal wall closure concluded that available evidence is of moderate quality and the Cochrane analysis by Patel et al. advised larger, higher quality trials. $^{21,22}$ In this survey, over half of the respondents did not change their technique of closure of the abdominal wall since their surgical training. Perhaps the respondents feel that the available evidence does not balance out against years of personal experience. Adoption of new techniques by individual surgeons may also be hindered by intercollegiate agreements to have all team members in a hospital use identical techniques and materials. Because responses were anonymized to ensure participants privacy, no analysis could be performed to investigate this.

A third explanation is that the results of this survey represent a snapshot of current practice and does not show changes in practice over the years. It is possible that the new evidence has yet to be incorporated in daily practice and that this is an ongoing process. Historical techniques of abdominal wall closure, such as interrupted sutures in separate layers, which are almost gone in this survey, used to be standard practice in previous decades and have since changed. ${ }^{23} \mathrm{~A}$ repeat of this survey in 10 years could find very different results in practice than the current survey.

Notable is that, although the 'small step, small stitch'-technique has not yet been universally adopted, the gastro-intestinal and oncologic surgeons do seem to use these techniques and materials relatively more often than the other participants. These 'early adopters' of new techniques could be the catalysts to introduce these new insights in their local surgical departments and stimulate their colleagues to adjust their technique. Surgeons who work in academic (university) hospitals also seem to be adapting to this technique, as evidenced by the increased percentage of participants from these hospitals who use smaller suture sizes and smaller fascial steps. This offers a good opportunity for implementing evidence-based closure techniques in practice; as these surgeons are involved in training future surgeons, a trickle-down effect may follow.

Grol and Grimshaw studied strategies for successful implementation of new evidence in medical practice and found many different approaches, ranging from financial interventions, audit and feedback strategies to distribution of educational materials. ${ }^{19}$ None of the available strategies appeared superior to others in all situations. The authors concluded that, in order to effectively change practice and implement evidence, a strategy should be tailor-made, well prepared in advance with clear 
indicators for measurement of success. The approach should be feasible within available budgets and possibilities. Relevant people should be involved early and progress should be monitored regularly.

Surgeons operating on patients with increased risk of incisional hernia development should be a focus for these strategies. One subspecialty at which efforts should be directed is vascular surgery. Patients with aortic aneurysms are considered to have an impaired connective tissue turnover and at increased risk of incisional hernia development. Bariatric surgeons and other surgeons operating on obese patients are another group, which should be encouraged to adopt evidence-based techniques, because obesity is another risk factor for incisional hernia development.

There are some limitations to this survey. The response rate of $26 \%$ is relatively low and a selective response bias might have occurred because of this. However, the 402 completed surveys represent $97 \%$ of all surgical departments in the Netherlands. The completed surveys therefore seem to reflect current practice in the Netherlands adequately. Although this survey was conducted in the Netherlands, the results are likely to be generalizable to surgeons worldwide because the materials and techniques discussed for abdominal wall closure and incisional hernia treatment are widely available and midline laparotomy is a common approach for access to the abdominal cavity. Finally, a survey is inherently a snapshot if the current practice and does not show changes in practice over time.

\section{Conclusions}

In this survey, which evaluates current practice of abdominal wall closure after midline laparotomy among Dutch surgeons with incisional hernia prevention in mind, most participants prefer a single layer mass closure with a running slow absorbable suture. Only $35 \%$ of surgeons close the abdominal fascia using a suture length to wound length ratio of 4:1. Gastro-intestinal and oncologic surgeons are most likely to use this technique. Over two-thirds of participants did not change their abdominal closure technique since training. Risk factors for incisional hernia development are generally identified correctly but knowledge on incidence and time of occurrence of incisional hernia is lacking. Efforts should be directed at improved adoption of the evidence based technique. 


\section{Acknowledgements}

F. Van Osch. PhD (department of clinical epidemiology, VieCuri Medical Centre, Venlo, The Netherlands) provided statistical assistance. 


\section{References}

1. Gillion JF, Sanders D, Miserez M, Muysoms F. The economic burden of incisional ventral hernia repair: a multicentric cost analysis. Hernia. 2016;20(6):819-30.

2. Bloemen A, Van Dooren P, Huizinga BF, Hoofwijk AGM. Randomized clinical trial comparing polypropylene or polydioxanone for midline abdominal wall closure. Br J Surg. 2011;98(5):633-9.

3. Israelsson LA, Millbourn D. Prevention of incisional hernias. How to close a midline incision. Surg Clin North Am. 2013; 93(5):1027-40.

4. Deerenberg EB, Harlaar JJ, Steyerberg EW, Lont HE, Van Doorn HC, Heisterkamp J, et al. Small bites versus large bites for closure of abdominal midline incisions (STITCH): A double-blind, multicentre, randomised controlled trial. Lancet. 2015;386(10000):1254-60.

5. Israelsson LA, Jonsson T. Physical properties of self locking and conventional surgical knots. Eur J Surg. 1994;160(6-7):323-7.

6. Muysoms FE, Antoniou SA, Bury K, Campanelli G, Conze J, Cuccurullo D, et al. European Hernia Society guidelines on the closure of abdominal wall incisions. Hernia. 2015;19(1):1-24.

7. Thorup T, Tolstrup MB, Gögenur I. Reduced rate of incisional hernia after standardized fascial closure in emergency laparotomy. Hernia. 2019;23(2):341-346

8. Tolstrup MB, Watt SK, Gögenur I. Reduced rate of dehiscence after implementation of a standardized fascial closure technique in patients undergoing emergency laparotomy. Ann Surg. 2017;265(4): 821-826

9. Jairam AP, Timmermans L, Eker HH, Pierik REGJM, van Klaveren D, Steyerberg EW, et al. Prevention of incisional hernia with prophylactic onlay and sublay mesh reinforcement versus primary suture only in midline laparotomies (PRIMA): 2-year follow-up of a multicentre, double-blind, randomised controlled trial. Lancet . 2017;390(10094):567-76.

10. Muysoms FE, Detry O, Vierendeels T, Huyghe M, Miserez M, Ruppert $M$, et al. Prevention of incisional hernias by prophylactic meshaugmented reinforcement of midline laparotomies for abdominal aortic aneurysm treatment: A randomized controlled trial. Ann Surg. 2016;263(4):638-45

11. Rahbari NN, Knebel P, Diener MK, Seidlmayer C, Ridwelski K, Stöltzing H, et al. Current practice of abdominal wall closure in elective surgery - Is there any consensus? BMC Surg [Internet]. 2009;9:8. [cited 2019 Jul 14] available from: http://www.biomedcentral.com/1471-2482/9/8 DOI: 10.1186/14712482-9-8

12. Pereira JA, Lopez-Cano M, Marsal F, Feliu X. [Results of a national survey on abdominal wall closure]. Cir Esp. 2013;91(10):645-50.

13. Dabrowiecki S. [Abdominal wall closure techniques--the results of the Polish surgeons' survey]. Pol Merkur Lekarski. 2005 ;19(113):646-50.

14. Eysenbach G. Improving the quality of web surveys: The Checklist for Reporting Results of Internet ESurveys (CHERRIES). J Med Internet Res. 2004; 29;6(3):e34

15. Bickenbach KA, Karanicolas PJ, Ammori JB, Jayaraman S, Winter JM, Fields RC, et al. Up and down or side to side? A systematic review and meta-analysis examining the impact of incision on outcomes after abdominal surgery. Am J Surg. $2013 ; 206(3): 400-9$

16. Höer J, Lawong G, Klinge U, Schumpelick V. Factors influencing the development of incisional hernia. A retrospective study of 2,983 laparotomy patients over a period of 10 years. Der Chir. 2002;73(5): 474-80.

17. Bosanquet DC, Ansell J, Abdelrahman T, Cornish J, Harries R, Stimpson A, et al. Systematic review and meta-regression of factors affecting midline Incisional hernia rates: Analysis of 14618 Patients. PLoS One. 2015;10(9): e0138745

18. Schreinemacher MHF, Ten Broek RP, Bakkum EA, Van Goor H, Bouvy ND. Adhesion awareness: A national survey of surgeons. World J Surg. 2010;34(12):2805-12.

19. Grol R, Grimshaw J. From best evidence to best practice: Effective implementation of change in patients' care. Lancet. 2003; 362(9391):1225-30.

20. Fischer JP, Harris HW, López-Cano M, Hope WW. Hernia prevention: practice patterns and surgeons' attitudes about abdominal wall closure and the use of prophylactic mesh. Hernia. $2019 ; 23(2): 329-334$ 
21. Patel S V., Paskar DD, Nelson RL, Vedula SS, Steele SR. Closure methods for laparotomy incisions for preventing incisional hernias and other wound complications. Cochrane Database Syst Rev. 2017;11:CD005661

22. Henriksen NA, Deerenberg EB, Venclauskas L, Fortelny RH, Miserez M, Muysoms FE. Meta-analysis on Materials and Techniques for Laparotomy Closure: The MATCH Review. World J Surg. 2018;42(6): 1666-1678

23. Zollinger RM. The atlas of surgical operations: Elliott Carr Cutler and Robert Zollinger. Am J Surg. 2003;186(3):211-6. 


\section{Appendix 2.A}

\section{General questions}

Question 1:

Are you currently employed as a:

- Surgical trainee

- Gastro-intestinal and/or oncologic surgeon

- Trauma, vascular or pediatric surgeon

- General surgeon or other field (please specify)

\section{Question 2}

How many years have you been active in this role?

\section{Question 3}

Are you currently employed in $\mathrm{a}(\mathrm{n})$ :

- Academic hospital

- Non-academic teaching hospital

- Non-academic, non-teaching hospital

\section{Question 4}

How many midline laparotomies do you perform annually?

- Less than 10

- 10 to 30

- 30 to 60

- more than 60

\section{Closure material and technique}

\section{Question 5}

Do you close the peritoneum separately when closing a midline laparotomy?

- Yes

- No

\section{$\underline{\text { Question } 6}$}

How many layers do you close when closing a midline laparotomy?

- One mass suture (all layers together)

- Two layers

- Three layers

- $\quad$ Other (please specify) 


\section{Question 7}

When closing a midline laparotomy, do you close the abdominal fascia with:

- Running sutures

- $\quad$ Single sutures

\section{Question 8}

How many sutures do you normally use when closing the abdominal fascia?

- One suture

- Two sutures

- Other (please specify)

\section{$\underline{\text { Question } 9}$}

What type of suture material do you use when closing the abdominal fascia?

- $\quad$ Single suture-threads

- Loop suture-threads

\section{Question 10}

What type of suture material do you use when closing the abdominal fascia?

- Rapid absorbable sutures

- Slow absorbable sutures

- Non-absorbable sutures

\section{Question 11}

What type of suture material do you use when closing the abdominal fascia?

- Monofilament sutures

- Braided sutures

\section{$\underline{\text { Question } 12}$}

What size suture material do you use when closing the abdominal fascia?

- 2

- 1

- 0

- 2-0

- 3-0

- 4-0

- $\quad$ other (please specify) 


\section{$\underline{\text { Question } 13}$}

What type of needle do you use when closing the abdominal fascia?

- Straight needle

- Curved needle

\section{Question 14}

What type of needle-point do you use when closing the abdominal fascia?

- $\quad$ Sharp tip

- Blunt tip

\section{$\underline{\text { Question } 15}$}

When securing the sutures for closing the abdominal fascia, do you use a:

- Surgical knot

- Aberdeen knot

- Other self-locking knot

\section{Question 16}

What size fascia bites do you normally use when closing the abdominal fascia?

- $0-5 \mathrm{~mm}$

- 6-10 mm

- $\quad 11-20 \mathrm{~mm}$

- $>20 \mathrm{~mm}$

\section{Question 17}

What size fascia steps do you normally use between two bites when closing the abdominal fascia?

- $0-5 \mathrm{~mm}$

- 6-10 mm

- $10-20 \mathrm{~mm}$

- $>20 \mathrm{~mm}$

\section{Question 18}

Do you normally aim for a suture-length to wound-length ratio when closing the abdominal fascia?

- Yes

- No 


\section{Question 19}

What suture-length to wound-length-ratio do you normally aim for when closing the abdominal fascia?

- none

- $1: 1$

- $2: 1$

- $3: 1$

- $4: 1$

- $5: 1$

- $\quad$ other (please specify)

\section{Question 20}

Do you currently use the same technique you learned during your surgical training?

- Yes

- $\quad$ No (please specify)

Incisional hernia questions

\section{$\underline{\text { Question } 21}$}

Which of the following types of laparotomy incisions is most at risk for development of incisional hernia:

- Midline laparotomy

- Transverse laparotomy

- Oblique laparotomy

\section{Question 22}

Incisional hernia is most diagnosed:

- Within 6 weeks after surgery

- During the first postoperative year

- After 1-5 years

- After more than 5 years 


\section{Question 23}

The incidence of incisional hernia after midline laparotomy is closest to:

- $1-5 \%$

- $6-10 \%$

- $11-15 \%$

- $16-20 \%$

- $20-25 \%$

- $>25 \%$

\section{Question 24}

Select the five most important risk factors for developing an incisional hernia from the following list:

- COPD

- Cardiovascular disease

- Aneurysm of the abdominal aorta

- Connective tissue disease

- Obesity

- Smoking

- Alcohol abuse

- Surgical site infection

- Postoperative ileus

- Urinary retention

- Postoperative mechanical ventilation

- High age

- Gender

- Diabetes mellitus

- Renal failure

- Corticosteroid use

- Malnutrition

- Colorectal cancer

- Previous ventral hernia 


\section{Chapter 3}

Randomized clinical trial comparing polypropylene or polydioxanone for midline abdominal wall closure

Bloemen A Dooren van $P$

Huizinga BF

Hoofwijk AGM

British Journal of Surgery. 2011;98:633-639 


\section{Abstract}

\section{Background}

Incisional hernia is a frequent complication of abdominal surgery, often requiring surgical intervention. This prospective randomized trial compared suture materials for closure of the fascia after abdominal surgery.

\section{Methods}

In 456 patients the abdominal fascia was closed with either non-absorbable (polypropylene; Prolene ${ }^{\circledast}$ ) or absorbable (polydioxanone; PDS ${ }^{\circledR}$ ) suture material. Follow-up was by clinical examination and ultrasonography at 6-month intervals. Outcome measures were incisional hernia, surgical-site infection and suture sinus.

\section{Results}

Some 223 patients were analysed after closure with Prolene $^{\circledR}$ and 233 after PDS ${ }^{\circledR}$. Median follow-up was 32 and 31 months respectively. There was no significant difference in the incidence of incisional hernia between the groups: $20.2 \%$ (45 of 223) for Prolene ${ }^{\circledR}$ and $24.9 \%$ (58 of 233 ) with PDS ${ }^{\circledR}(P=0.229)$. Kaplan-Meier analysis showed a cumulative rate after 4 years of 23.7 and $30.2 \%$ for Prolene ${ }^{\circledR}$ and PDS ${ }^{\circledR}$ respectively $(P=0.222)$. Secondary outcome measures showed no significant differences.

\section{Conclusion}

The incidence of incisional hernia in both groups was higher than expected from previous literature. There were no significant differences between the two suture methods. 


\section{Introduction}

Incisional hernia is a complication of abdominal surgery that can cause pain, and may lead to complications such as incarceration or strangulation. ${ }^{1-5}$ It is often diagnosed clinically by inspection, or palpation of a mass protruding through the abdominal wall at the site of a surgical scar. Diagnostic tools such as ultrasonography or computed tomography may be helpful in diagnosing small or early hernias.

Abdominal fascia that has lost structural integrity after a surgical incision needs to recover resistance to traction through wound healing. ${ }^{6}$ Initially, only sutures provide support to the approximated fascial edges. With time and wound healing the musculotendinous layers of the abdominal wall recover structural integrity. If the abdominal wall cannot resist intra-abdominal pressure, a hernia may form. ${ }^{6,7}$ Failure of recovery of the abdominal fascia can be influenced by biological and surgical factors. ${ }^{6-9}$ Disrupted metabolic connective tissue turnover is believed to be a biological factor predisposing to the development of incisional hernia. ${ }^{10-13}$ Other patient factors related to incisional hernia formation are older age, obesity, metabolic syndrome, chronic obstructive pulmonary disease (COPD), malnutrition and abdominal aortic aneurysm..$^{6-9,14}$ Surgical factors influencing the formation of incisional hernia are the type and size of incision, the method of closure of the abdominal wall and different aspects of wound healing, including surgical-site infections. ${ }^{15-18}$

Several reviews have studied the optimal suture repair for closing the abdominal fascia ${ }^{1,19-23}$, but a consensus has not been reached. In the present study, two types of suture material were compared: Prolene ${ }^{\circledR}$ (Ethicon, Johnson \& Johnson, Somerville, New Jersey, USA), a nonabsorbable polypropylene monofilament suture material, and PDS $^{\circledR}$ (polydioxanone; Ethicon), a slowly absorbed monofilament suture material. PDS ${ }^{\circledR}$ offers tissue support for the first 60 days after implantation; thereafter, support gradually lessens until the material has been absorbed after 183-238 days (manufacturer data).

The study hypothesis was that a non-absorbable suture (Prolene ${ }^{\circledR}$ ) would result in fewer incisional hernias than a slowly absorbed suture (PDS $\left.{ }^{\circledR}\right)$, while not causing other complications such as suture sinus or surgical-site infection.

\section{Methods}

All patients who had an elective or emergency midline laparotomy at the Department of General Surgery of the Orbis Medical Centre in the Netherlands between October 2001 and January 2005 were included in this prospective randomized trial. Follow-up 
lasted until June 2009. Exclusion criteria were pregnancy, presence of an abdominal hernia, lack of informed consent, age younger than 18 years and a life expectancy of less than 1 year. Approval for this trial was obtained from the ethics committee of the parent hospital and registered in the Dutch national register for human research.

Treatment allocation was done by means of computerized random numbers; 700 numbered, sealed and opaque envelopes were prepared. After written informed consent had been obtained, patients were allocated randomly to one of the two treatment arms by opening an envelope just before the surgical procedure, after induction of general anaesthesia.

Closure of the fascia of the abdominal wall was performed after surgery had been completed using one of the two suture materials (Prolene ${ }^{\circledR}$ or PDS ${ }^{\circledR}$ ) as prescribed by randomization. For both suture materials a similar strength of material was used $(1 / 0)$ and the fascia was closed in a single layer with wide bites through the rectus sheath (minimum $1 \mathrm{~cm}$ from the incision edge). The suture length to laparotomy wound length ratio was at least $4: 1$. Continuous sutures and two complete suture lengths were used for all wounds. The procedures were mostly done by residents in various stages of training at the Orbis Medical Centre, under the close supervision of a trained surgeon. The surgeons could not be blinded to the allocated intervention.

Development of an incisional hernia was the primary outcome. Secondary outcomes included surgical-site infection and suture sinus. Patients were reviewed after 1 month, and then every 6 months in outpatients, or earlier if the patient experienced a complication. During these consultations, patients were interviewed by an observer who was blinded to the suture material used. All participants were examined by inspection and palpation of the abdomen during a Valsalva manoeuvre while the patient was lying flat. The abdominal wall was also examined by ultrasonography.

Incisional hernia could be diagnosed clinically, or by ultrasonography independently of any symptoms reported by the patient. Ultrasonography was added to physical examination in order to detect early incisional hernias, as small hernias may be difficult to palpate, especially in obese patients. Any treatment for incisional hernia was recorded.

Incisional hernia was defined as 'any abdominal wall gap with or without a bulge in the area of a postoperative scar, perceptible or palpable by clinical examination or imaging' ${ }^{24,25}$ Ultrasound diagnosis was based on a defect at least $1 \mathrm{~cm}$ in diameter, with a prolapse of (part of) an abdominal viscus or fat.

Early postoperative fascial dehiscence was distinguished from later incisional hernia, being defined by a clinically palpable gap in the abdominal fascia with, or without wound dehiscence during the first 30 days after surgery. The distinction was made because these patients required a reintervention, which precluded further long-term 
follow-up for incisional hernia. Surgical-site infection was defined according to the latest Centers for Disease Control and Prevention/National Healthcare Safety Network criteria. ${ }^{26}$ No distinction was made between superficial and deep surgical-site infection. A suture sinus was present if a microabscess or chronic granulomatous inflammation resulted in a track that could be cured only when the relevant suture or knot was removed.

\section{Statistical analysis}

Based on data on incisional hernia available at the start of this trial, the rate was expected to vary from 10.3 to $20.6 \%{ }^{5,27,28}$ A power calculation based on the expected incidence of incisional hernia of $10 \%$ for Prolene ${ }^{\circledR}$ and $20 \%$ for PDS ${ }^{\circledR}$, and a proposed power of $80 \%$ with $\alpha=0.05$, showed that the minimum size of each group should be 201 patients. Therefore, it was planned to include 300 patients in each treatment arm.

At the end of follow-up (June 2009), intervention allocation was revealed to the researchers. Initially, the group of patients who developed fascial dehiscence in the first 30 days after surgery was excluded from analysis of the incidence of incisional hernia. A second analysis in which these early failures were considered as early incisional hernias was also performed.

When heterogeneity was detected in baseline criteria, a subgroup analysis was performed for these participants to determine whether this influenced the overall results. The $\chi^{2}$ goodness-of-fit test and Student's $t$ test were used to test for homogeneity of the test population, and for significance of results. Kaplan-Meier analyses were performed. The maximum acceptable standard error was 0.05 . Where needed, a Mantel-Cox (log rank) analysis was used to test for significant differences in the incidence of incisional hernia. Statistical analysis was done using SPSS ${ }^{\circledR}$ version 17.0 (SPSS, Chicago, Illinois, USA).

\section{Results}

A total of 687 consecutive patients were eligible for participation in this trial, of whom 523 were enrolled and randomized. Of the 164 excluded patients, 86 did not meet the inclusion criteria, 11 refused to participate and 67 were not eligible for other reasons (a different suture material was used, or the surgeon forgot to include a patient, particularly in the acute setting). Some 256 patients were allocated to Prolene ${ }^{\circledR}$ repair and 267 to PDS $^{\circledR}$ (Figure 3.1). 


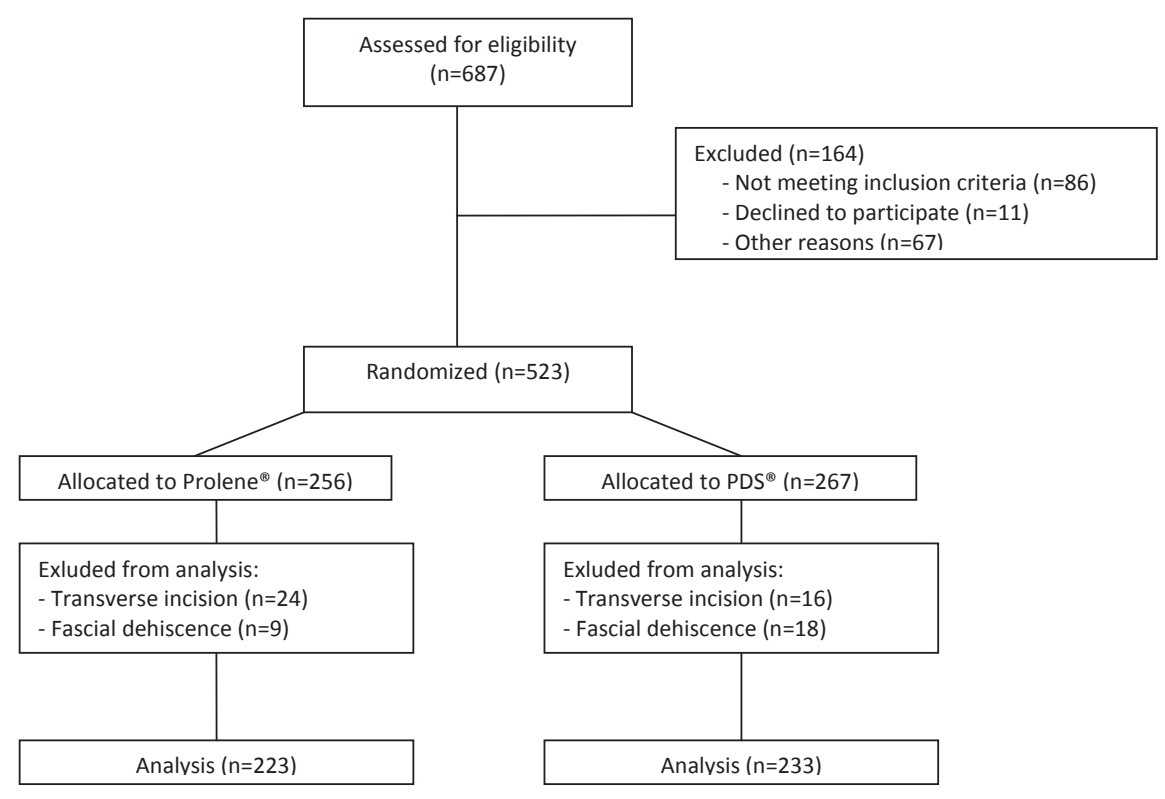

Figure 3.1 Randomization and inclusion flowchart.

Baseline characteristics of the patients in each treatment group were similar, except that more patients with COPD were randomized into the PDS ${ }^{\circledR}$ group $\left(\chi^{2}=7.66,1\right.$ d.f., $P=0.006)$. There was no significant heterogeneity in other characteristics between the two groups (Table 3.1).

Forty randomized patients were excluded from analysis because a transverse incision was used instead of a midline laparotomy, in violation of the study protocol. Twentyseven patients with fascial dehiscence were initially also excluded from the Kaplan-Meier analysis of incisional hernia because they underwent an early reintervention.

Mean follow-up was 34.5 (95\% confidence interval 31.6 to 37.3 ) months in the Prolene ${ }^{\circledR}$ arm and 33.3 (30.5 to 36.0 ) months in the PDS ${ }^{\circledR}$ arm. Median follow-up was 32 and 31 months respectively. 
Table 3.1 Baseline characteristics of randomized participants and procedures.

\begin{tabular}{|c|c|c|c|}
\hline & $\begin{array}{c}\text { Prolene }^{\circledR} \\
(n=256,48.9 \%)\end{array}$ & $\begin{array}{c}\text { PDS }^{\circledR} \\
(n=267,51.1 \%)\end{array}$ & $\begin{array}{c}\text { Total } \\
(n=523,100 \%)\end{array}$ \\
\hline Age (years) & 63.1 (SD 13.8) & 63.8 (SD 13.8) & 63.4 (SD 13.8) \\
\hline \multicolumn{4}{|l|}{ Sexe: } \\
\hline - Male & 152 (59.4\%) & 147 (55.1\%) & 299 (57.2\%) \\
\hline - Female & 104 (40.6\%) & 120 (44.9\%) & 224 (42.8\%) \\
\hline Body Mass Index & $25.6(S D 4.6)$ & $25.8(S D 4.4)$ & $25,7(13.1-50.6$ SD 4.5) \\
\hline - Unknown & 10 (3.9\%) & $5(1.9 \%)$ & 15 (2.9\%) \\
\hline \multicolumn{4}{|l|}{ Smoking: } \\
\hline - Yes & $62(24.2 \%)$ & $64(24.0 \%)$ & $126(24.1 \%)$ \\
\hline - No & $181(70.7 \%)$ & $197(73.8 \%)$ & $378(72.3 \%)$ \\
\hline - Unknown & $13(5.1 \%)$ & $6(2.2 \%)$ & $19(3.6 \%)$ \\
\hline \multicolumn{4}{|l|}{ COPD: } \\
\hline - Yes & $10(3.9 \%)$ & $\begin{array}{c}27(10.1 \%) \\
\left(\chi^{2}=7.66, p=0.006\right)\end{array}$ & $37(7.1 \%)$ \\
\hline - No & 246 (96.1\%) & 240 (89.9\%) & 486 (92.9\%) \\
\hline \multicolumn{4}{|l|}{ Steroids: } \\
\hline - Yes & $16(6.3 \%)$ & 21 (7.9\%) & 37 (7.1\%) \\
\hline - No & $236(92.2 \%)$ & 245 (91.8\%) & 481 (92.0\%) \\
\hline - Unknown & $4(1.6 \%)$ & $1(0.4 \%)$ & $5(1.0 \%)$ \\
\hline \multicolumn{4}{|l|}{ Diabetes Mellitus } \\
\hline - Yes & 25 (9.8\%) & $17(6.4 \%)$ & 42 (8.0\%) \\
\hline - No & 231 (90.2\%) & $250(93.6 \%)$ & 481 (92.0\%) \\
\hline \multicolumn{4}{|c|}{ Aneurysm of the Abdominal Aorta? } \\
\hline - Yes $(>4.5 \mathrm{~cm})$ & $25(9.8 \%)$ & $24(9.0 \%)$ & 49 (9.4\%) \\
\hline - No & $228(89.1 \%)$ & 239 (89.5\%) & 467 (89.3\%) \\
\hline - Unknown & $3(1.2 \%)$ & $4(1.5 \%)$ & $7(1.3 \%)$ \\
\hline \multicolumn{4}{|l|}{ Earlier laparotomy? } \\
\hline - Yes & $88(34.4 \%)$ & $98(36.7 \%)$ & $186(35.6 \%)$ \\
\hline - No & 167 (65.2\%) & $169(63.3 \%)$ & $336(64.2 \%)$ \\
\hline - Unknown & $1(0.4 \%)$ & 0 & $1(0.2 \%)$ \\
\hline \multicolumn{4}{|l|}{ Diagnosis: } \\
\hline - Rectal carcinoma & $44(17.2 \%)$ & $59(22.1 \%)$ & $103(19.7 \%)$ \\
\hline - Colon carcinoma & $42(16.4 \%)$ & $60(22.5 \%)$ & $102(19.5 \%)$ \\
\hline - Sigmoid carcinoma & $36(14.1 \%)$ & $23(8.6 \%)$ & $59(11.3 \%)$ \\
\hline - Aneurysm abdominal aorta & $29(11.3 \%)$ & $29(10.9 \%)$ & $58(11.1 \%)$ \\
\hline - Diverticulitis & $20(7.8 \%)$ & $18(6.7 \%)$ & $38(7.3 \%)$ \\
\hline - Inflammatory bowel disease & $14(5.5 \%)$ & $15(5.6 \%)$ & $29(5.5 \%)$ \\
\hline - Gastric carcinoma & $9(3.5 \%)$ & $13(4.9 \%)$ & $22(4.2 \%)$ \\
\hline - Cholecystitis/cholelithiasis & $14(5.5 \%)$ & $7(2.6 \%)$ & $21(4.0 \%)$ \\
\hline - Bowel perforation & $10(3.9 \%)$ & $9(3.4 \%)$ & $19(3.6 \%)$ \\
\hline - Hiatal hernia & $10(3.9 \%)$ & $7(2.6 \%)$ & $17(3.3 \%)$ \\
\hline - Appendicitis & $5(2.0 \%)$ & $8(3.0 \%)$ & $13(2.5 \%)$ \\
\hline - Other & $23(9.0 \%)$ & 19 (7.1\%) & $42(8.0 \%)$ \\
\hline \multicolumn{4}{|l|}{ Setting: } \\
\hline - Elective & $205(80.1 \%)$ & $228(85.4 \%)$ & $433(82.8 \%)$ \\
\hline - Emergency & $51(19.9 \%)$ & $39(14.6 \%)$ & $90(17.2 \%)$ \\
\hline \multicolumn{4}{|l|}{ Incision type: } \\
\hline - Total median & $173(67.6 \%)$ & $196(73.4 \%)$ & $369(70.6 \%)$ \\
\hline - Supra-umbilical median & $29(11.3 \%)$ & $27(10.1 \%)$ & $56(10.7 \%)$ \\
\hline - Infra-umbilical median & $30(11.7 \%)$ & $28(10.5 \%)$ & $58(11.1 \%)$ \\
\hline - Transverse & $24(9.4 \%)$ & $16(6.0 \%)$ & $40(7.6 \%)$ \\
\hline
\end{tabular}




\section{Incisional hernia}

Forty-five patients $(20.2 \%)$ developed an incisional hernia in the Prolene ${ }^{\circledast}$ group, compared with $58(24.9 \%)$ in the $\mathrm{PDS}^{\oplus}$ group $\left(\chi^{2}=1.45,1\right.$ d.f., $\left.P=0.229\right)$. The mean delay before the appearance of the incisional hernia was 25.7 (95\% confidence interval 21.1 to 30.3 ) months in the Prolene ${ }^{\circledR}$ group and 22.9 (18.5 to 26.5 ) months in the PDS ${ }^{\circledast}$ group $(P=0.297)$. The majority of incisional hernias were diagnosed by both physical examination and ultrasonography ( 82 hernias); 21 were diagnosed by ultrasonography alone.

New incisional hernias most commonly developed between 13 and 18 months after surgery in both treatment arms. After 4 years the cumulative estimated incidence of incisional hernia was $23.7 \%$ in the Prolene ${ }^{\circledR}$ group and $30.2 \%$ in the PDS $^{\circledR}$ group on Kaplan-Meier analysis ( $\chi^{2}=1.49,1$ d.f., $P=0.222$, log rank test).

In a second analysis, cases of fascial dehiscence were considered as early incisional hernias; there were nine in the Prolene ${ }^{\circledast}$ group and 18 in the PDS ${ }^{\circledR}$ group. Kaplan-Meier analysis similarly showed no significant difference between the methods $\left(\chi^{2}=3.37,1\right.$ d.f., $P=0.067$ ) (Figure 3.2).

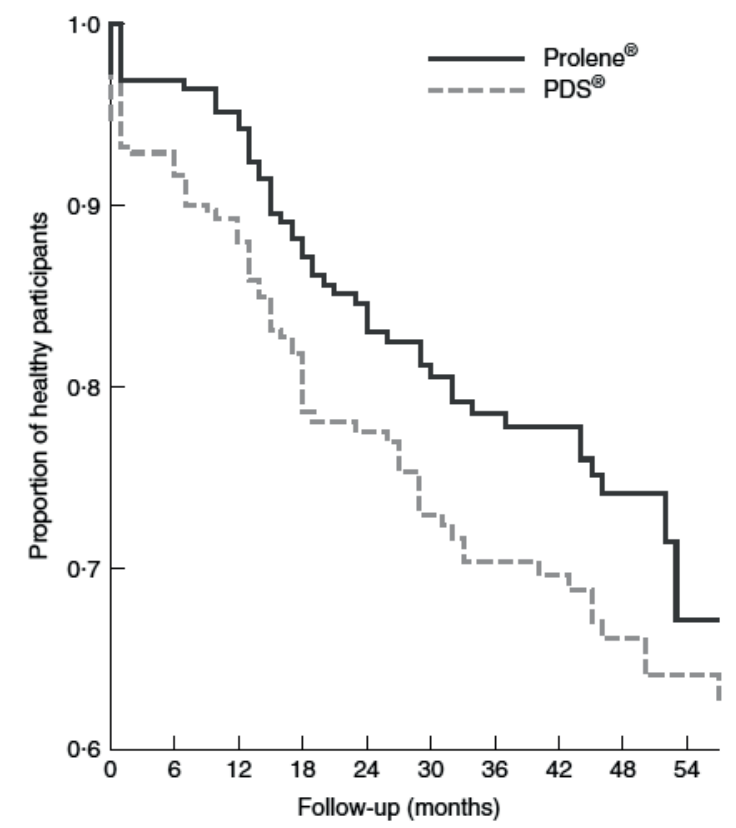

$\begin{array}{lllllllllll}\begin{array}{l}\text { No. at risk } \\ \text { Prolene }^{\circledR}\end{array} & 256 & 224 & 204 & 178 & 150 & 123 & 106 & 87 & 66 & 39 \\ \text { PDS }^{\circledR} & 267 & 227 & 205 & 163 & 145 & 121 & 97 & 85 & 69 & 49\end{array}$

Figure 3.2 Kaplan-Meier analysis for development of incisional hernia (including early fascial dehiscence). 
Most of the 103 patients who developed an incisional hernia received no treatment (82) or chose a hernia corset (7). Fourteen patients underwent surgical repair either using direct suture closure (2 Prolene ${ }^{\circledR}, 1$ PDS $^{\circledR}$ ) or insertion of a mesh (2 Prolene ${ }^{\circledR}$, 9 PDS $^{\circledR}$ ). Of the 21 patients whose incisional hernia was diagnosed solely by ultrasonography, only one requested surgical treatment by placement of a mesh to support the abdominal wall.

Because there was significant heterogeneity between the two groups with respect to COPD, these patients were also analysed separately. $\chi^{2}$ analysis showed no significant difference in the rate of incisional hernia $\left(\chi^{2}=0.01,1\right.$ d.f., $\left.P=0.914\right)$. The log rank (Mantel-Cox) test showed no significant difference between the two suture types in a Kaplan-Meier analysis $\left(\chi^{2}=0.24,1\right.$ d.f., $\left.P=0.623\right)$. The results were similar when patients with fascial dehiscence were included.

\section{Secondary outcome measures}

In the Prolene ${ }^{\circledR}$ group, 14 participants (6.3\%) developed surgical-site infection and three $(1.3 \%)$ a suture sinus. In the PDS ${ }^{\circledR}$ group, 18 patients $(7.7 \%)$ developed a surgicalsite infection and five $(2.1 \%)$ a suture sinus. There were no significant differences in rate of surgical-site infection $(P=0.366)$ or suture sinus $(P=0.602)$ between the two groups (Table 3.2).

Table 3.2 Incidence of main outcome measures.

\begin{tabular}{lccc}
\hline & $\begin{array}{c}\text { Prolene }^{\circledR} \\
(n=223,48.9 \%)\end{array}$ & $\begin{array}{c}\text { PDS }^{\circledR} \\
(n=233,51.1 \%)\end{array}$ & P-value \\
\hline Incisional Hernia (fascial dehiscence excluded) & $45(20.2 \%)$ & $58(24.9 \%)$ & 0.229 \\
Incisional Hernia (fascial dehiscence included) & $56(21.1 \%)$ & $76(26.7 \%)$ & 0.088 \\
Surgical site infection & $14(6.3 \%)$ & $18(7.7 \%)$ & 0.366 \\
Suture sinus & $3(1.3 \%)$ & $5(2.1 \%)$ & 0.602 \\
\hline
\end{tabular}

\section{Discussion}

Previous reports comparing different suture materials for abdominal closure have described varying rates of incisional hernia from 2 to $20 \% \cdot{ }^{1-5,27-30}$ The rate in the present study was comparable, but the cumulative rate on Kaplan-Meier analysis was higher, suggesting that incisional hernia may be more common than previously thought.

Several factors may have influenced this finding. First, Kaplan-Meier analysis estimates cumulative rates of incisional hernia during follow-up and compensates for unknown data in patients lost to follow-up. With increasing numbers lost to follow-up, the 
estimate of cumulative incidence becomes increasingly uncertain. In this study the loss to follow-up was considerable and the mean follow-up of 34 months was lower than the planned minimum follow-up of 54 months (4.5 years). A second reason for the high rate of incisional hernia was the study design, in which all patients underwent regular physical examination and ultrasonography, and there were strict diagnostic criteria. Inclusion of ultrasound-detected hernias was warranted as these small incisional hernias are most at risk of incarceration, making their detection relevant. ${ }^{31}$ Den Hartog and colleagues ${ }^{32}$ compared ultrasonography with computed tomography for diagnosing incisional hernia, reporting a sensitivity of $70.8 \%$ and a specificity of $100 \%$ for ultrasonography.

There is also a lack of a clear classification for incisional hernia. Several classifications have been proposed, but none has gained widespread acceptance. ${ }^{26,31,33,34}$ There is no consensus on how incisional hernia should be diagnosed. As a result, each study uses its own definitions and classifications, making it difficult to compare the results.

Patient-related factors, as well as surgical factors, play a role in the development of incisional hernia. The type of suture material used for closure of the abdominal fascia is controlled by the surgeon and is a factor that can easily be influenced. It has been stated that the ideal suture material after laparotomy should prevent occurrence of an incisional hernia or wound dehiscence, without increasing surgical-site infection, wound pain or formation of suture sinus. ${ }^{20}$ The slowly absorbed suture material PDS ${ }^{\circledR}$ would theoretically be best suited for this purpose.

In this study there was a trend in favour of Prolene ${ }^{\circledR}$, as the total incidence of incisional hernia at the end of follow-up was higher in the PDS ${ }^{\circledR}$ group; the cumulative incidence determined by Kaplan-Meier analysis was also higher in this group. These findings were not, however, statistically significant.

This trend in favour of Prolene ${ }^{\circledR}$ may have been caused by the significantly higher proportion of patients with COPD in the PDS ${ }^{\circledR}$ group. COPD is a known risk factor for incisional hernia. Yet the subgroup analysis in which only patients with COPD were analysed yielded no significant difference between the two groups.

Differences in the rate of incisional hernia between previous reports and the present study may also be explained by a limited follow-up in some studies, thereby missing late hernias. Studies with a longer follow-up had mixed conclusions. Lewis and Wiegand $^{35}$ compared the rate of incisional hernia 5 years after repair with nonabsorbable suture material (Prolene ${ }^{\circledR}$ ) versus absorbable suture material (Dexon ${ }^{\circledR}$; Syneture, Covidien, Mansfield, UK), and found more incisional hernias in the Dexon ${ }^{\circledR}$ group ( $P=0.01$ ). Brolin ${ }^{36}$ compared PDS $^{\circledR}$ with nonabsorbable Ethibond ${ }^{\circledR}$ (Ethicon, Johnson \& Johnson), and after a mean follow-up of 29 months found more incisional hernias in the Ethibond ${ }^{\circledR}$ group $(P=0.04)$. Carlson and Condon ${ }^{37}$ compared nylon sutures 
with Maxon ${ }^{\circledR}$ (Syneture, Covidien) absorbable sutures and found no significant difference between the two suture types.

In the past two decades, six meta-analyses have been published on the subject of abdominal closure after laparotomy. The meta-analyses of Rucinski and colleagues ${ }^{21}$ and Ceydeli and Wise ${ }^{19}$ agreed with the findings in the present study; they did not discover significant differences in development of incisional hernia between absorbable and non-absorbable sutures. Both Weiland et al. ${ }^{22}$ and Hodgson and co-workers1 concluded that non-absorbable sutures were associated with lower rates of incisional hernia. Weiland and colleagues ${ }^{22}$ found that non-absorbable, continuous sutures had significantly lower rates of incisional hernia, but were more often associated with infection and fascial dehiscence. Hodgson and co-workers ${ }^{1}$ also found a lower incisional hernia rate for non-absorbable continuous sutures. Van 't Riet et al. ${ }^{20}$ concluded in their meta-analysis that slowly absorbed sutures reduced the risk of incisional hernia without increasing wound pain or suture sinus frequency.

The overall conclusion of the most recently published meta-analysis by Diener and colleagues $^{23}$ was that, for elective midline laparotomy, continuous, slowly absorbed sutures cause significantly fewer incisional hernias than interrupted and rapidly absorbed or non-absorbable suture materials. They noted that this may also be true for emergency surgery, but there were insufficient data to support this. Subgroup analysis of the trials most comparable with the present study included pooled data comparing non-absorbable with absorbable suture materials in patients who underwent midline laparotomy in elective or emergency settings. In this analysis, six studies were pooled, containing a total of 3219 patients. ${ }^{5,35,37-40}$. No significant difference was found (odds ratio $1.11,95 \%$ confidence interval 0.71 to $1.75 ; P=0.16$ ), although the trend appeared to favour non-absorbable materials.

It has been suggested that most incisional hernias develop between the first postoperative month and the first year after surgery, yet many patients do not develop signs or symptoms until several years later. ${ }^{17,18,41-43}$ In the present randomized clinical trial where all patients were examined regularly, the peak incidence occurred 13-18 months after surgery for both Prolene ${ }^{\circledR}$ and PDS ${ }^{\circledR}$. The peak incidence was larger in group sutured with $\mathrm{PDS}^{\circledR}$, which may have been influenced by the fact that it loses $40 \%$ of breaking strength after 1 month. ${ }^{44}$ This may be too short a time for the abdominal wall to recover enough structural integrity, as the abdominal fascia regains only $51-59 \%$ of its original tensile strength after 42 days. ${ }^{45,46}$ Yet the rate of incisional hernia formation was higher in both groups than expected from previous studies. As no difference was identified between the two materials, no preference for either Prolene ${ }^{\circledR}$ or PDS ${ }^{\circledR}$ can be recommended from this study. 
Chapter 3

\section{Acknowledgements}

The authors declare no conflict of interest. 


\section{References}

1. Hodgson NC, Malthaner RA, Ostbye T. The search for an ideal method of abdominal fascial closure: a meta-analysis. Ann Surg 2000;231(3):436-42.

2. Hoer J, Lawong G, Klinge U, Schumpelick V. [Factors influencing the development of incisional hernia. A retrospective study of 2,983 laparotomy patients over a period of 10 years]. Chirurg 2002;73(5):474-80.

3. Kingsnorth A, LeBlanc K. Hernias: inguinal and incisional. Lancet 2003;362(9395):1561-71.

4. Santora TA, Roslyn JJ. Incisional hernia. Surg Clin North Am 1993;73(3):557-70.

5. Wissing J, van Vroonhoven TJ, Schattenkerk ME, Veen HF, Ponsen RJ, Jeekel J. Fascia closure after midline laparotomy: results of a randomized trial. Br J Surg 1987;74(8):738-41.

6. Franz MG. The biology of hernia formation. Surg Clin North Am 2008;88(1):1-15, vii.

7. Franz MG. The biology of hernias and the abdominal wall. Hernia 2006;10(6):462-71.

8. Lynen Jansen P, Rosch R, Rezvani M, Mertens PR, Junge K, Jansen M, et al. Hernia fibroblasts lack betaestradiol-induced alterations of collagen gene expression. BMC Cell Biol 2006;7:36.

9. Yahchouchy-Chouillard E, Aura T, Picone O, Etienne JC, Fingerhut A. Incisional hernias. I. Related risk factors. Dig Surg 2003;20(1):3-9.

10. Junge K, Klinge U, Rosch R, Mertens PR, Kirch J, Klosterhalfen B, et al. Decreased collagen type I/III ratio in patients with recurring hernia after implantation of alloplastic prostheses. Langenbecks Arch Surg 2004;389(1):17-22.

11. Klinge U, Si ZY, Zheng H, Schumpelick V, Bhardwaj RS, Klosterhalfen B. Abnormal collagen I to III distribution in the skin of patients with incisional hernia. Eur Surg Res 2000;32(1):43-8.

12. Rosch R, Binnebosel M, Junge $K$, Lynen-Jansen $P$, Mertens PR, Klinge $U$, et al. Analysis of c-myc, PAI-1 and $U$ PAR in patients with incisional hernias. Hernia 2008;12(3):285-8.

13. Rosch R, Junge K, Knops M, Lynen P, Klinge U, Schumpelick V. Analysis of collagen-interacting proteins in patients with incisional hernias. Langenbecks Arch Surg 2003;387(11-12):427-32.

14. Chevrel JP. [The treatment of large midline incisional hernias by "overcoat" plasty and prothesis (author's transI)]. Nouv Presse Med 1979;8(9):695-6.

15. Wantz GE, Chevrel JP, Flament JB, Kingsnorth A, Schumpelick V, Verhaeghe P. Incisional hernia: the problem and the cure. J Am Coll Surg 1999;188(4):429-47.

16. Ausobsky JR, Evans M, Pollock AV. Does mass closure of midline laparotomies stand the test of time? A random control clinical trial. Ann R Coll Surg Engl 1985;67(3):159-61.

17. Playforth MJ, Sauven PD, Evans M, Pollock AV. The prediction of incisional hernias by radio-opaque markers. Ann R Coll Surg Engl 1986;68(2):82-4.

18. Pollock AV, Evans M. Early prediction of late incisional hernias. Br J Surg 1989;76(9):953-4.

19. Ceydeli A, Wise L. Finding the best abdominal closure: an evidence-based review of the literature. Current Surgery 2005;62(2):220-5.

20. van 't Riet M, Steyerberg EW, Nellensteyn J, Bonjer HJ, Jeekel J. Meta-analysis of techniques for closure of midline abdominal incisions. Br J Surg 2002;89(11):1350-6.

21. Rucinski JMM PG, Wise L. Closure of the abdominal midline fascia: meta-analysis delineats the optimal technique. Am Surg 2001;67:421-6.

22. Weiland DE BR, Del Sordi S. Choosing the best abdominal closure by meta-analysis. Am J Surg 1998;176(6):666-70.

23. Diener MK, Voss S, Jensen K, Buchler MW, Seiler CM. Elective midline laparotomy closure: the INLINE systematic review and meta-analysis. Ann Surg 2010;251(5):843-56.

24. Israelsson LA, Jonsson T. Incisional hernia after midline laparotomy: a prospective study. Eur J Surg 1996;162(2):125-9.

25. Mudge M, Hughes LE. Incisional hernia: a 10 year prospective study of incidence and attitudes. Br J Surg 1985;72(1):70-1.

26. Korenkov M, Paul A, Sauerland S, Neugebauer E, Arndt M, Chevrel JP, et al. Classification and surgical treatment of incisional hernia. Results of an experts' meeting. Langenbecks Arch Surg 2001;386(1): 65-73. 
27. Muysoms FE, Miserez M, Berrevoet F, Campanelli G, Champault GG, Chelala E, et al. Classification of primary and incisional abdominal wall hernias. Hernia 2009;13(4):407-14.

28. Horan TC, Andrus M, Dudeck MA. CDC/NHSN surveillance definition of health care-associated infection and criteria for specific types of infections in the acute care setting. Am J Infect Control 2008;36(5): 309-32.

29. Eisner L, Harder F. [Incisional hernias]. Chirurg 1997;68(4):304-9.

30. Osther PJ, Gjode P, Mortensen BB, Mortensen PB, Bartholin J, Gottrup F. Randomized comparison of polyglycolic acid and polyglyconate sutures for abdominal fascial closure after laparotomy in patients with suspected impaired wound healing. Br J Surg 1995;82(8):1080-2.

31. Schumpelick V, editor. [Incisional Hernia]. Stuttgart: Thieme; 2000.

32. den Hartog D, Dur AH, Kamphuis AG, Tuinebreijer WE, Kreis RW. Comparison of ultrasonography with computed tomography in the diagnosis of incisional hernias. Hernia 2009;13(1):45-8.

33. Chevrel JP, Rath AM. Classification of incisional hernias of the abdominal wall. Hernia 2000;4:7-11.

34. Dietz UA, Hamelmann W, Winkler MS, Debus ES, Malafaia O, Czeczko NG, et al. An alternative classification of incisional hernias enlisting morphology, body type and risk factors in the assessment of prognosis and tailoring of surgical technique. J Plast Reconstr Aesthet Surg 2007;60(4):383-8.

35. Lewis RT WF. Natural history of vertical abdominal parietal closure: prolene versus dexon. CJS 1989;32(3):196-200.

36. Brolin RE. Prospective, randomized evaluation of midline fascial closure in gastric bariatric operations. Am J Surg 1996;172(4):328-31.

37. Carlson MA, Condon RE. Polyglyconate (Maxon) versus nylon suture in midline abdominal incision closure: a prospective randomized trial. Am Surg 1995;61(11):980-3.

38. Richards PC, Balch CM, Aldrete JS. Abdominal wound closure. A randomized prospective study of 571 patients comparing continuous vs. interrupted suture techniques. Ann Surg 1983;197(2):238-43.

39. Krukowski ZH, Matheson NA. 'Button hole' incisional hernia: a late complication of abdominal wound closure with continuous non-absorbable sutures. Br J Surg 1987;74(9):824-5.

40. Israelsson LA, Jonsson T. Closure of midline laparotomy incisions with polydioxanone and nylon: the importance of suture technique. Br J Surg 1994;81(11):1606-8.

41. Burger JW, Lange JF, Halm JA, Kleinrensink GJ, Jeekel H. Incisional hernia: early complication of abdominal surgery. World J Surg 2005;29(12):1608-13.

42. Korenkov M, Sauerland S, Arndt M, Bograd L, Neugebauer EA, Troidl H. Randomized clinical trial of suture repair, polypropylene mesh or autodermal hernioplasty for incisional hernia. Br J Surg 2002; 89(1):50-6.

43. Luijendijk RW, Hop WC, van den Tol MP, de Lange DC, Braaksma MM, JN IJ, et al. A comparison of suture repair with mesh repair for incisional hernia. N Engl J Med 2000;343(6):392-8.

44. Outlaw KK, Vela AR. Breaking strength and diameter of absorbable sutures after in vivo exposure in the rat. Am Surg 1998;64:348-54.

45. Douglas DM. The healing of aponeurotic incisions. Br J Surg 1952;40:79-84.

46. Rath AM. The healing of laparotomies: a review of the literature. Part I. Physiologic and pathologic aspects. Hernia 1998;2:145-9. 


\title{
Chapter 4
}

Evaluation of a new elastic ostomy appliance to decrease skin complications: results of a pilot study

\author{
Bloemen A \\ Aarts $F$ \\ Bouvy ND \\ Nijhuis PHA
}

Wound Management and Prevention. 2020;66:30-36 


\section{Abstract}

\section{Aim}

Peristomal skin complications due to appliance leakage frequently occur in all types of ostomies, resulting in great emotional, social, and financial impact for patients. This pilot study was conducted to evaluate the safety and use of a new, reusable, nonadherent, elastic device.

\section{Method}

A convenience sample of nonhospitalized patients with ileostomies and colostomies was recruited through the Dutch ostomy patient association. Participant inclusion criteria stipulated the presence of ileostomy or colostomy, a body mass index (BMI) between 18 and 30, and presence of an ostomy for at least 1 month. Patients with existing prolapse or necrosis of the ostomy, inability to give consent, or concurrent usage of other aids to prevent leakage or skin problems were excluded. Participants were fitted with and asked to wear the appliance continuously for 4 weeks and report experiences in a structured diary. Patient charts were reviewed for baseline demographic characteristics that included age, gender, American Society of Anaesthesiologists classification, and BMI. Study nurses performed structured weekly interviews and inspections of the ostomies and peristomal skin. The primary outcome measure was occurrence of serious adverse events such as ostomy necrosis or perforation. Secondary outcome measures were patient reported incidents of leakage and satisfaction during wear and changing of the appliance. Peristomal skin complications also were recorded. Descriptive statistics were used to analyze results. In addition, subgroup analysis of patients with a parastomal hernia was performed because of the potential benefits of the device design in these cases.

\section{Results}

Participants included 23 patients (16 with colostomies, 7 with ileostomies); 13 participants (57\%) were female. Mean age and BMI were 64 years and 28.3, respectively. Six (6) patients had a parastomal hernia. Due to shifting or discomfort while wearing the appliance, 16 participants discontinued use before the end of the study and were excluded from analysis from the point they left the study. Mean duration of participation was 12.8 days. No adverse events occurred. Mean number of incidents of leakage/week decreased from $3.5 \pm 4.9$ at start of the study to $1.8 \pm 1.3$ at week 4 . The mean number of pouches used/week decreased from $10.5 \pm 5.4$ to $8 \pm 2.6$. Peristomal skin reactions present in 15 patients at start of the study decreased to 1 patient at the end of the study. Patient satisfaction did not change over the course of the study. Patients with parastomal hernias had similar results.

\section{Conclusion}

No serious adverse events were reported and leakage and skin irritation were found to improve, but participant dropout rate was high and average usage time was only 12.8 days, which limited interpretation of the results. The data suggest that the appliance may offer an (intermittent) alternative to existing ostomy materials for patients experiencing troublesome leakages, peristomal skin problems, or parastomal hernias, but further research is needed to explore these outcomes. 


\section{Introduction}

In the Netherlands, approximately 38000 patients have a small or large bowel enterostomy and each year over 5500 new colostomies are created. ${ }^{1}$ Peristomal skin complications are disorders of the peristomal skin that range from mild erythema to erosions or ulcerations. Peristomal skin complications are known to present challenges related to their high incidence, negative impact on quality of life, and associated costs. According to a recent systematic review by Malik et al. ${ }^{2}$, peristomal skin complications are the most frequent complication associated with ostomies; they occur in 2.4 to $46.2 \%$ of ostomies. In a retrospective analysis by Shiraishi et al. $^{3}$ of 333 consecutive patients who had an intestinal ostomy created in a single Japanese centre, an incidence of up to $78.6 \%$ was reported.

Peristomal skin complications put a high emotional and social burden on patients. A recent Dutch survey ${ }^{4}$ among patients with ostomies found that even though quality of life with an ostomy is generally acceptable, peristomal complications and leakages are important limiting factors quality of life. The negative effects of peristomal skin complications on quality of life have also been described in several other international studies that include large cross-sectional surveys with more than 2000 included participants and a smaller prospective observational study of 37 patients. ${ }^{5-8}$

Peristomal skin complications also place a considerable financial burden on individual patients and society in general. In a retrospective study that included 168 patients with all types of ostomies, Taneja et al. ${ }^{9}$ found that in patients with peristomal skin complications within 120 days after surgery the mean health care costs were approximately $\$ 8000$ higher when compared to patients without skin complications.

The etiology of skin-related ostomy complications is multifactorial: contact dermatitis can develop because of bowel effluent leakage, injury can occur due to mechanical pressure or friction, bacterial of fungal local infections can cause peristomal skin complications and rare allergic reactions to ostomy adhesive can contribute to the development of skin lesions. ${ }^{10,11}$

The location of an ostomy determines the ease or difficulty of stoma care. In a review of surgical strategies to improve ostomy formation, Strong ${ }^{12}$ described the ideal location of an ostomy as the superior aspect of the infra umbilical fat mound, visible to the patient, positioned below the belt line, and surrounded by a relatively flat surface 5-7 centimetres in diameter. According to a retrospective study of 105 patients by Person et al. ${ }^{13}$, preoperatively marking the ostomy site with these considerations in mind leads to a significantly improved quality of life and decrease in complications. An improperly located ostomy at skinfolds or scars may contribute to leakage and lead to additional difficulties in positioning and application of ostomy materials. ${ }^{2}$ Bulging or 
folding of skin due to the presence of parastomal herniation further predisposes to skin complications.

The location and protrusion of ostomies cannot be changed after creation without surgical revision, but improved ostomy materials may decrease leakages and therefore patient comfort. A new type of ostomy appliance (TOMAS, TOMAS LTD) consists of a synthetic adapter with a convex oval shape that is placed over the ostomy. The adaptor functions as a flange on which enterostomy pouches can be connected in the same way as other 2-piece ostomy systems. An O-shaped cellulose-based absorbent gauze is placed between the skin surrounding the ostomy and the adapter. A polyester based elastic waistband is integrated in the adapter. No adhesive is used to affix the adapter or waistband. The convex shape, in combination with the tight fitting elastic waistband, keeps the material in place, while the gauze absorbs any fluids, which are not collected in the pouch (Figure 4.1).

A pilot study was performed to assess the safety and use of this device. The primary outcome measure was occurrence of serious adverse events such as ostomy necrosis or perforation. Secondary outcome measures were occurrence of leakage, presence and resolution of peristomal skin complications, and patient satisfaction with the device.

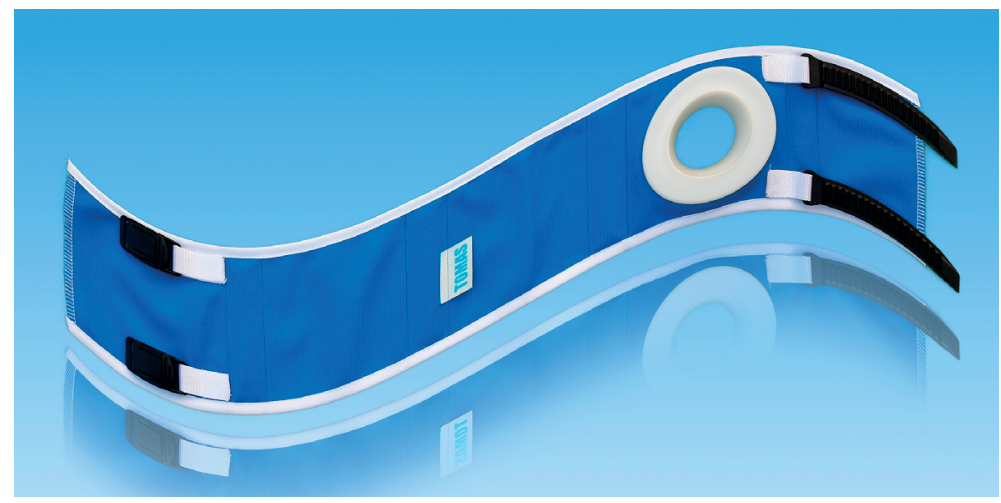

Figure 4.1 The elastic ostomy appliance used in the study.

\section{Methods}

The ethical review board of the Maastricht University Hospital and the Dutch Health Care Inspectorate approved this study. Assigning each participant a unique study number, which was referenced in all forms and the database, ensured patient 
confidentiality and anonymity. Thus, the anonymized study forms could not be traced back to participants.

A nationwide convenience sample of participants was recruited; invitations to participate were extended through newsletters and social media of the Dutch enterostomy patient association, as well as via outpatient consultations at the authors' clinic. Inclusion criteria were presence of ileostomy or a colostomy, a body mass index (BMI) between 18 and 30, and presence of an ostomy for at least one month. Presence of pre-existing peristomal skin complications was not required for inclusion in the study, because the main goal of the study was to evaluate safety of the product. Patients with major prolapse or necrosis of the ostomy, inability to consent to participation of the study or current usage of other aids to prevent leakage or skin problems, as well as hospitalized patients, were not eligible for inclusion in the study.

The study was conducted from April $1^{\text {st }} 2018$ till September $30^{\text {th }} 2018$. After written consent was obtained and baseline measurements were taken, a specialized ostomy nurse fit all participants with the ostomy waistband. The ostomy care nurse received training by the manufacturer of the appliance in the correct fitting and adjustment of the appliance, as well as training in patient counselling in correct use of the appliance.

If necessary, an ostomy nurse adjusted the belt during the study; reasons for adjustment of the appliance included loose fit with shifting or leakage or a tight fit that caused the participant pain or discomfort.

Participants were instructed to wear the appliance continuously for 4 weeks. The appliance was removed for bathing. The absorbing gauze was to be changed daily or earlier if fully saturated. Participants were allowed to continue their usual daily activities.

The following baseline characteristics were measured at the start of the study: gender, age, BMI, the American Society of Anaesthesiologists (ASA) classification of fitness and the presence of a parastomal hernia.

Participants were assigned a unique study number. During the study period, patients kept a written diary to record their experiences. Structured interviews and physical examination of the ostomy were performed by 2 ostomy nurses before start of the study and each consecutive week thereafter during outpatient clinic visits.

The primary outcome measure of this safety and feasibility pilot study was occurrence of serious adverse events such as ostomy necrosis or perforation, which would lead to immediate cessation of usage of the belt and optimum treatment as determined by the attending physician. If a patient discontinued participation before completion of the study, the time and reason were recorded. 
Occurrence and frequency of leakage, ostomy-related skin problems and frequency of change of ostomy pouches were secondary outcome measures. If present, skin problems were graded in the following categories: erythema, erosions, bleeding or other reactions.

Patients reported satisfaction with regard to comfort experienced during and changing of the materials and during daily use; other subjective experiences during usage also were scored. Satisfaction with the appliance and emotional and personal impact of these materials were recorded at the start of the study and at subsequent weekly clinic visits using a 10-point Likert scale where 1 was defined as very uncomfortable and 10 as very comfortable.

The structured interviews and physical examination of the ostomy were performed before start of the study and each consecutive week thereafter in the outpatient clinic. The patient diaries were reviewed and discussed, and the stoma and peristomal skin were inspected during these visits. Findings were reported in standardized study forms. During the study period, patients kept a written diary to record their experiences. In addition to a description of their experiences during use of the appliance, participants were queried specifically on several topics. Patients were asked to note in the study form each incident of leakage, the number of pouches and gauzes used, and the comfort during wear and during change of the appliance, the ostomy pouch, and the protective gauze. Patients were also asked to describe/categorize peristomal skin complications if present.

The data forms and written patient diaries were processed anonymously into an electronic dataset anonymously by the authors ( $A B$ en $P N)$ who were blinded regarding patient identity. The same authors performed the data-analysis. The responses to the questions were coded and entered into the SPSS software package (version 22 for Windows, IBM Corp). Narrative aspects of the diaries were analysed, and the number of common responses were noted. Patients who discontinued the study before the planned endpoint of 4 weeks were excluded from analysis from the date they left the study.

Student's T-test and Chi-squared test were used to test for differences in baseline characteristics in participants. The Wilcoxon signed rank test was performed to detect significance of differences in repeated measures as the study progressed. A $P$-value smaller than 0.05 was considered statistically significant.

Because the new appliance combines an ostomy appliance with the features of a hernia support truss, patients with a parastomal hernia potentially have larger benefits from the new materials. A subgroup analysis was therefore performed for participants with a parastomal hernia. 


\section{Results}

Of the 23 patients enrolled (13 female [57\%], mean age 64 [range 36-81 years]), 16 had a colostomy (70\%) and 7 had an ileostomy (all ostomies were permanent). Mean BMI was 28.3. Fourteen patients (61\%) had a ASA classification II. No significant differences in baseline characteristics were found. Among the 6 participants with a parastomal hernia, 1 had an ileostomy and 5 had a colostomy. The characteristics of the participants are listed in Table 4.1.

Sixteen participants left the study early. Of the 7 patients who wore the appliance for 4 weeks, 5 (31.3\% of colostomy participants) had a colostomy and $2(28.6 \%$ of ileostomy participants) had an ileostomy. The dropout rate did not differ significantly by stoma type.

Participants wore the appliance for a mean of 12.8 (range 1-28) days; persons with colostomies wore the appliance for 14 days, persons with ileostomies for 10 days and persons with parastomal hernias for 15.2 days.

Reasons for early cessation of participation in the study or for intermittent wear of the appliance varied: patients reported more smell or flatus (6 patients), discomfort due to tightness of the elastic waistband (4 patients), occurrence of night-time leakages due to movement of the bandage (9 patients), or a combination of the reasons above. In nearly all patients, the girdle had to be adjusted at least once to achieve comfort while maintaining acceptable fixation of the adapter around the ostomy.

Table $4.1 \quad$ Patient characteristics.

\begin{tabular}{lcccc}
\hline & Colostomy $(\mathrm{n}=16)$ & lleostomy $(\mathrm{n}=7)$ & Total $(\mathrm{n}=23)$ & $P$-value \\
\hline Mean age in years & $64[36-81]$ & $62[51-71]$ & $64[36-81]$ & NS \\
Mean days of participation & $14[1-28]$ & $10[1-28]$ & $12.8[1-28]$ & NS \\
Gender & & & & NS \\
- male & $7(42)$ & $3(43)$ & $10(43)$ & \\
- female & $9(58)$ & $4(57)$ & $13(57)$ & NS \\
Mean Body Mass Index $\left(\mathrm{kg} / \mathrm{m}^{2}\right)$ & $28.4[19-36.7]$ & 26.4 & $28.3[19-36.7]$ & \\
ASA classification & & & 0 & NS \\
-1 & 0 & 0 & $14(61)$ & \\
-2 & $10(63)$ & $4(56)$ & $3(13)$ & \\
-3 & $2(13)$ & $1(14)$ & 0 & NS \\
- 4 & 0 & 0 & $5(22)$ & \\
- unknown & $4(24)$ & $1(14)$ & $6(26)$ & \\
Parastomal hernia present & $5(31)$ & $1(14)$ & & \\
\hline
\end{tabular}

Percentages are reported in round parentheses. Range reported in brackets. ASA = American Society of Anesthesiologists. NS = not significant. 


\section{Primary outcome measure}

No serious adverse events such as necrosis or perforation were observed among the participants during the study. One patient with pre-existing prolapse of the ostomy was seen at the emergency department of a nearby hospital because of swelling and oedema and was advised to discontinue participation. After removal of the appliance, these complaints diminished quickly. No friction or pressure injuries leading to peristomal skin complications were detected.

\section{Secondary outcome measures}

\section{Leakages and skin reactions}

During the study the mean number of leakage incidents decreased from $3.5 \pm 4.9$ per week (baseline) while using their old materials to $1.8 \pm 1.3$ per week among the participants at the end of the study (Table 4.2). The Wilcoxon signed rank test found a significant decrease between baseline number of incidents of leakages and number of leakages at 2 weeks of participation (mean duration of participation) in this interval ( $Z=53 P<0.001)$.

Skin reactions also decreased as the patients wore the appliance longer (Table 4.2). At baseline, 15 patients (65\%) reported skin reactions, ranging from erythema to erosions and bleeding. At conclusion of the study only 1 out of the 7 patients reported skin erythema (14.3\%). Four of these 7 patients started the study with peristomal skin complication ( 2 patients had erythema, 1 patient had skin erosions and 1 patient had peristomal skin bleeding).

Most participants showed a decrease in use of collection pouches during the study when compared to baseline measurements: mean number of pouches used weekly decreased from $10.5 \pm 5.4$ at baseline to $8.0 \pm 2.6$ at the end of the study without reaching statistical significance. (Table 4.2)

\section{Patient reported satisfaction}

Baseline data on comfort at the start of the study and during use remained constant (7.1 \pm 1.7 and $7.8 \pm 1.0$, respectively). Final mean satisfaction among the 7 patients regarding changing the device were similar to baseline measurement at the start of the study (7.3 \pm 1.7 and $6.7 \pm 2.1$, respectively).

Among the 12 patients (52\%) who reported oedema and increase in size of the stoma compared to the start of the study, 5 stopped wearing the appliance or started to wear it intermittently. 
Participants reported the following aspects of the appliance in their diaries: ease of use (5 patients $(21.7 \%)$, the possibility to omit adhesive materials to allow application of topical ointment on skin lesions (3 patients, 13\%) and a comfortable tight fit of the waistband (5 patients, $21.7 \%$ ).

Reported disadvantages included the tight fit around the waist, which was reported to be corset-like (13 patients, $56.5 \%$ ), the possibility of girdle shift if the appliance was not adjusted correctly (7 patients, 30.4\%) and an increase in noticeable flatus and smells (2 patients, $8.7 \%)$.

Table 4.2 Outcome measures.

\begin{tabular}{|c|c|c|c|c|c|}
\hline & $\begin{array}{l}\text { Before start } \\
\quad(n=23)\end{array}$ & $\begin{array}{l}\text { Week } 1 \\
(n=16)\end{array}$ & $\begin{array}{c}\text { Week } 2 \\
(n=9)\end{array}$ & $\begin{array}{c}\text { Week } 3 \\
(n=8)\end{array}$ & $\begin{array}{c}\text { Week } 4 \\
(n=7)\end{array}$ \\
\hline \multicolumn{6}{|c|}{ Mean number of leakages (SD) } \\
\hline - ileostomy & $5.4(6.5)$ & $4.5(3.4)$ & $4(4.2)$ & $4(4.2)$ & $4(0)$ \\
\hline - colostomy & $2.7(4.0)$ & $1.1(2.0)$ & $1.2(2.1)$ & $0.5(0.8)$ & $1.4(0.9)$ \\
\hline - total & $3.5(4.9)$ & $2.0(2.9)$ & $1.6(2.5)$ & $1.4(2.4)$ & $1.8(1.3)$ \\
\hline \multicolumn{6}{|c|}{ Mean number of ostomy pouches (SD) } \\
\hline - ileostomy & $6.8(0.4)$ & $10.5(5.0)$ & $7(0)$ & $7(0)$ & $7(0)$ \\
\hline - colostomy & $11.9(5.8)$ & $10.3(3.6)$ & $8.6(3.9)$ & $8.7(2.9)$ & $8.4(3.1)$ \\
\hline - total & $10.5(5.4)$ & $10.3(3.6)$ & $8.3(3.4)$ & $8.3(2.5)$ & $8(2.6)$ \\
\hline \multicolumn{6}{|c|}{ Presence of skin reactions ${ }^{\circ}$} \\
\hline - erythema & 7 & 2 & 4 & 4 & 1 \\
\hline - erosion & 4 & 2 & 2 & 0 & 0 \\
\hline - bleeding & 2 & 0 & 1 & 0 & 0 \\
\hline - other & 2 & 2 & 1 & 0 & 0 \\
\hline \multicolumn{6}{|c|}{ Mean patient satisfaction (SD)* } \\
\hline - ease of wear & $7.1(1.6)$ & $6.5(1.4)$ & $6.1(1.7)$ & 6.9 (1.9) & $7.3(1.0)$ \\
\hline - ease of care & $7.8(1.7)$ & $6.4(1.8)$ & 7.4 (1.9) & $7.4(1.5)$ & $6.7(2.1)$ \\
\hline
\end{tabular}

$\mathrm{n}=$ sample size of measurement at time point. $\mathrm{SD}=$ standard deviation ${ }^{\circ}$ number of patients with skin reactions. * patient satisfaction on a 0 to 10 point scale.

\section{Parastomal hernia}

Of the 6 participants with a parastomal hernia, 2 (both with a colostomy) completed the study. Participants with a parastomal hernia showed a decrease in frequency of leakages: at baseline, mean number of leakages per week was $1.7 \pm 1.6$, which decreased to $0.2 \pm 0.7$ at the end of the study. At the start of the study, 4 patients with parastomal hernia had skin erythema and 2 patients had erosions surrounding the ostomy. Although 1 of the patients with erythema had progression of erythema to erosions in the first week of usage, by the fourth week, skin irritations had resolved in the participants with parastomal hernia.

The quantity of collection pouches used decreased during the study. Baseline number of appliances used was $15 \pm 6.7$ per week, decreasing to $7 \pm 0$ in the final week. 
The mean patient reported satisfaction during use of the appliance showed an increase from baseline to the final week $(5.8 \pm 1.3$ to $8 \pm 0)$ in patients with parastomal herniations. Mean satisfaction with change of materials increased from $6.75 \pm 1.5$ at baseline to 8 in the third week; the final satisfaction was 5.5 \pm 3.5 .

Participants with parastomal hernia reported an increase of smells and flatus. While other participants reported the belt's was a disadvantage, patients with a parastomal herniation described this to be a major advantage of the device.

\section{Discussion}

This was the first pilot study to evaluate the safety and use of this new ostomy appliance. No adverse events occurred, and in patients who completed the study, incidents of leakage and skin lesions decreased, as well as quantity of used pouches, including among patients with parastomal hernias.

These results suggest that the appliance may be suited for temporary or intermittent use in patients with parastomal hernia or frequent leakage incidents and peristomal skin complications, possibly because the omission of applications and adhesives allows the peristomal skin to heal. However, more than half of all participants did not complete the 4 week study.

Participants were generally satisfied with their current appliances and participated in this study to help develop new solutions for fellow ostomy patients who suffer from frequent leakages and peristomal skin erosions. Almost all participants experienced considerable early discomfort during use of the device as well as early leakage. These factors improved with adjustment of the appliance and familiarisation with the use and feeling of the tight elastic bandage around the waist. Despite participant motivations for engaging in the study, this early setback induced early cessation of participation for some patients. As seen in the results, participants who continued after this initial adjustment or 'learning curve' reported an improvement in comfort and satisfaction. Noticeably, patients with parastomal hernia considered the tight fit of the appliance an advantage of the system. Possibly this is because the appliance combines ostomy materials with the function of a hernia bandage.

A potential target population for use of the appliance may be patients with allergic peristomal contact dermatitis. A recent retrospective review by Cressey et al. ${ }^{14}$ posits that allergy to stoma products may be more prevalent than previously thought. In a selected population of 54 patients who were treated by a dermatologist for peristomal dermatitis, 12 out of 18 patients (66.7\%) with active dermatitis had positive allergy testing to stoma care products. Further study in a general ostomy population is needed 
to verify these findings. If allergic peristomal skin complications due to adhesives are more common than previously thought, the new appliance may offer an alternative for these patients.

Until now, most attention in research for prevention and management of peristomal skin problems has been focussed on the material of the flanges and on different barrier creams, lotions or sprays that prevent the skin from coming into contact with the irritating ostomy effluent. ${ }^{15,16}$ One disadvantage of these products is that they have to be affixed to the skin and subsequently removed. This risks damaging the peristomal skin due to mechanical friction or chemical injury. To the author's knowledge, the study appliance is the first ostomy system in recent history that negates this risk by omitting the need for application of adhesives and therefore the risk of skin injury.

The appliance may also decrease the economic burden of ostomy materials and ostomy-related skin complications for both patients and health care systems by utilizing a reusable adaptor and elastic bandage. The slight decrease ostomy pouch usage may offer some reduction in costs. However, the foremost economic benefit may be from preventing peristomal skin problems.

Taneja et al. ${ }^{9}$ found an approximate extra cost of $\$ 8000$ for readmissions, extra outpatient visits, and material costs in patients with peristomal skin complications. In their retrospective assessment of data, Meisner et al. ${ }^{17}$ also noted an increased cost; a seven-week treatment period (including appliances and accessories) was €263 for a patient with peristomal skin complications compared with €215 for persons without skin complications. Their cost analysis was based on a treatment algorithm that used the dataset of the Dialogue Study ${ }^{18}$; an open-label, noncomparative, multinational study, that documented real-life experiences of stoma care in 3017 participants.

More prospective observational research is needed on this new appliance to verify the findings of this pilot study, preferably in comparison to existing ostomy systems. Future studies may help ascertain optimal target groups, usage criteria, and indications. Such studies will also need to focus on patient selection and counselling of the system before inclusion in a study to prevent high dropout rates. Adapting the system, such as changing the width of the elastic waistband or inserting rigid parts in the waistband akin to bones in a corset may increase comfort. 


\section{Limitations}

The most important limitation of the study that should be considered when interpreting the results is the small sample size and high dropout rate of participants. Another limitation of the study is the wide range of participant BMI (19 to 36.7). Obesity is a known risk factor for increased postoperative complications in general. ${ }^{19}$ As found in both prospective and retrospective observational cohort studies, ${ }^{20-22}$ complications such as ostomy-retraction and development of parastomal hernia is also higher in obese patients. A recent German observational study by Braumann et al. ${ }^{23}$ also found a higher rate of peristomal skin complications in obese patients, compared to non-obese patients. Although obese patients potentially benefit more from the appliance, their obesity decrease comfort and tolerance of the device; presence of skinfolds and curves may induce leakages and shifting, which requires tighter fitting of the elastic waistband.

\section{Conclusion}

This 4-week pilot study involving 23 ileostomy and colostomy patients evaluated the safety and use of a new ostomy appliance that employs an elastic waistband connected to a synthetic adapter around the ostomy. No adverse events were reported in the study. Among the 7 participants who completed the study, leakage and peristomal skin problems appeared to improve with use. The study experienced a high participant dropout rate, which limited the interpretation of results. However, results suggest that the appliance has the potential to offer an alternative to existing ostomy materials for patients experiencing troublesome leakages, peristomal skin problems, or parastomal hernias. Future studies should focus on these patient groups. 


\section{References}

1. Stomavereniging [Internet]. [cited 2019 Apr 8]. Available from: https://www.stomavereniging.nl/ufaqs/ hoeveel-stomadragers-er-nederland-en-hoeveel-er-lid-stomavereniging/.

2. Malik TAM, Lee MJ, Harikrishnan AB. The incidence of stoma related morbidity - A systematic review of randomised controlled trials. Ann R Coll Surg Engl. 2018;100:501-508.

3. Shiraishi T, Nishizawa Y, Nakajima M, Kado R, Ikeda K, Tsukada Y, et al. Risk factors for the incidence and severity of peristomal skin disorders defined using two scoring systems. Surg Today. 2020;50: 284-291.

4. Goldstine J, Van Hees R, Van De Vorst D, Skountrianos G, Nichols T. Factors influencing health-related quality of life of those in the Netherlands living with an ostomy. Br J Nurs. 2019;28:S10-S17.

5. Nichols T, Goldstine J, Inglese G. A multinational evaluation assessing the relationship between peristomal skin health and health utility. Br J Nurs. 2019;28:S14-S19.

6. Nichols T. Health Utility, Social Interactivity, and Peristomal Skin Status: A Cross-Sectional Study. J wound, ostomy, Cont Nurs Off Publ Wound, Ostomy Cont Nurses Soc. 2018;45:438-443.

7. Maydick-Youngberg D. A Descriptive study to explore the effect of peristomal skin complications on quality of life of adults with a permanent ostomy. Ostomy Wound Manag. 2017;63:10-23.

8. Gooszen AW, Geelkerken RH, Hermans J, Lagaay MB, Gooszen HG. Quality of life with a temporary stoma: Ileostomy vs. colostomy. Dis Colon Rectum. 2000;43:650-655.

9. Taneja C, Netsch D, Rolstad BS, Inglese G, Eaves D, Oster G. Risk and Economic Burden of Peristomal Skin Complications Following Ostomy Surgery. J wound, ostomy, Cont Nurs Off Publ Wound, Ostomy Cont Nurses Soc. 2019;46(2):143-149.

10. Almutairi D, LeBlanc K, Alavi A. Peristomal skin complications: what dermatologists need to know. International Journal of Dermatology. 2018;57:257-264.

11. Martin JA, Hughes TM, Stone NM. Peristomal allergic contact dermatitis - Case report and review of the literature. Contact Dermatitis. 2005; 52:273-275.

12. Strong SA. The Difficult Stoma: Challenges and Strategies. Clin Colon Rectal Surg. 2016;29:152-159.

13. Person B, Ifargan R, Lachter J, Duek SD, Kluger $Y$, Assalia A. The impact of preoperative stoma site marking on the incidence of complications, quality of life, and patient's independence. Dis Colon Rectum. 2012;55:783-787.

14. Cressey BD, Belum VR, Scheinman P, Silvestri D, McEntee N, Livingston V, et al. Stoma care products represent a common and previously underreported source of peristomal contact dermatitis. Contact Dermatitis. 2017;76:27-33.

15. Black P. Peristomal skin care: an overview of available products. Br J Nurs. 2014; 16:1048, 1050, 1052-4 passim.

16. Tam K-W, Lai J-H, Chen H-C, Hou W-H, Ko W-S, Chen S-L, et al. A systematic review and meta-analysis of randomized controlled trials comparing interventions for peristomal skin care. Ostomy Wound Manage. 2014; 60:26-33.

17. Meisner S, Lehur PA, Moran B, Martins L, Jemec GBE. Peristomal skin complications are common, expensive, and difficult to manage: A population based cost modeling study. PLoS One. 2012;7:e37813.

18. Andersen BD, Keizerswaard P Van, Castro MM, English E, Carter D. Introduction to the Dialogue Study: Methods and baseline demographic findings. Gastrointestinal Nursing. 2011;9:4-8.

19. Tjeertes EEKM, Hoeks SSE, Beks SSBJC, Valentijn TTM, Hoofwijk AGM, Stolker RJRJ. Obesity - a risk factor for postoperative complications in general surgery? BMC Anesthesiol. 2015;15:112.

20. Arumugam PJ, Bevan L, Macdonald L, Watkins AJ, Morgan AR, Beynon J, et al. A prospective audit of stomas-analysis of risk factors and complications and their management. Color Dis. 2003;5:49-52.

21. Duchesne JC, Wang YZ, Weintraub SL, Boyle M, Hunt JP. Stoma complications: a multivariate analysis. Am Surg. 2002;68(:961-966.

22. De Raet J, Delvaux G, Haentjens $P$, Van Nieuwenhove $Y$. Waist circumference is an independent risk factor for the development of parastomal hernia after permanent colostomy. Dis Colon Rectum. 2008; 51:1806-1809. 
23. Braumann C, Müller V, Knies M, Aufmesser B, Schwenk W, Koplin G. Quality of life and need for care in patients with an ostomy: a survey of 2647 patients of the Berlin OStomy-Study (BOSS). Langenbeck's Arch Surg. 2016;401:1191-1201. 


\section{Part B}

Diagnosis and treatment of abdominal wall hernias 



\section{Chapter 5}

Comparison of ultrasonography and physical examination in the diagnosis of incisional hernia in a prospective study

Bloemen A

Dooren van $\mathrm{P}$ Huizinga BF

Hoofwijk AGM

Hernia. 2012;16:53-57 


\section{Abstract}

\section{Purpose}

Incisional hernia is a frequently occurring complication after abdominal surgery with different reported incidences (2-20\%). The incidence of incisional hernia is defined by the diagnostic tools and diagnostic criteria used. Diagnosis by physical examination is sometimes difficult, especially in small incisional hernias or in obese patients. The additional diagnostic value of standardized ultrasonography was evaluated in this prospective study.

\section{Methods}

A total of 456 patients participating in a randomized trial comparing two suture materials for closure of the abdominal fascia underwent physical examination and ultrasonography at six-month intervals. Wound complaints and treatment of incisional hernia were also noted. Statistical analysis was performed using Chi-squared and Fisher's exact test (SPSS). Intertest variability analysis was performed.

\section{Results}

During a median follow up of 31 months, 103 incisional hernias were found. A total of 82 incisional hernias were found by physical examination and an additional 21 with ultrasonography. Six of these additional hernias were symptomatic and only one of the additional hernias received operative treatment. Intertest variability was low with a Kappa of $0.697(P<0.001)$.

\section{Conclusions}

When strict diagnostic criteria are applied and combined diagnostic methods are used, the incidence of incisional hernia is even higher than previously estimated. Because of the standardized follow-up, most hernias were found in an early stage of development and were not symptomatic. Standardized ultrasonography during follow-up yields a significant number of, mostly asymptomatic, hernias which would not be found using physical examination alone. This is especially relevant in research settings. 


\section{Introduction}

Incisional hernia is a frequent complication after abdominal surgery. The reported incidences in available literature range from 2 to $20 \% .^{1-9}$ This large difference is not only caused by variations in study designs, but also because diverse definitions and diagnostic methods are used in finding incisional hernias.

The currently most widely used definition for incisional hernia by Korenkov et al. and acknowledged by an experts meeting of the European Hernia Society in 2008 is: 'Any abdominal wall gap with or without a bulge in the area of a postoperative scar, palpable or perceptible by clinical examination or imaging ${ }^{\prime 10,11}$

The clinical diagnosis of incisional hernia is usually made by inspection and palpation of a hernial orifice with a mass protruding through the abdominal wall at the location of a surgical scar at rest and during Valsalva's maneuver. In small incisional hernias and in obese patients, diagnosis of incisional hernia can be difficult using only physical examination. It has been suggested that these small cicatrical hernias have a higher risk of incarceration, but we found no evidence supporting this. ${ }^{12}$

Diagnostic tools such as ultrasonography or computed tomography scan (CT-scan) may be helpful in diagnosing incisional hernia, though they are not routinely performed $A$ recent comparison between ultrasonography and CT-scanning in a small series (40 patients) showed a sensitivity of $70.8 \%$ and a specificity of $100 \%$. The authors concluded that ultrasonography has a very good specificity and positive predictive value when compared to CT-scanning. ${ }^{13}$

We found no literature, which studied the possible role of standardized ultrasonography in diagnosing cicatrical hernia, especially in research settings.

Therefore, we examined the diagnostic value of standardized ultrasonography, a cheap and safe diagnostic tool, in addition to physical examination for diagnosing incisional hernia. Part of the present study, which concentrates on the incidence of incisional hernia when using different suture materials (Prolene versus Polydioxanone (PDS ${ }^{\circ}$ ), Ethicon, Johnson \& Johnson, Somerville, New Jersey, USA) for closure of the abdominal fascia after midline laparotomy, was designed to investigate this. ${ }^{14}$ All patients received physical examinations and ultrasonography regularly during follow-up with strictly defined diagnostic criteria. 


\section{Patients and methods}

\section{Participants}

All patients undergoing elective or emergency median laparotomy at the General Surgery Department of the Orbis Medical Centre, a general hospital in the Netherlands, between October 2001 and January 2005 were eligible for inclusion in the trial and randomized according to the main goal of this study. The abdominal fascia was closed with either Prolene ${ }^{\oplus}$ or PDS ${ }^{\oplus}$, as prescribed by randomisation. This trial was registered (ISRCTN65599814 at http://www.clinical-trials.com and the study design and our results have been described elsewhere. ${ }^{14}$ Exclusion criteria for this trial were pregnancy, presence of an abdominal hernia, no informed consent, age younger than 18 years, life expectancy of less than one year, patients with organ transplants and patients with known wound healing problems. Patients with blunt abdominal trauma were not excluded from the trial.

\section{Follow-up}

Included patients were followed-up after one month and every six months during visits to our outpatient clinic or earlier if patients experienced complaints. Patients who had a evisceration or fascial dehiscence in the direct postoperative period were excluded from analysis. Follow-up lasted until June 2009. Criteria for end of follow up were detection of an incisional hernia or a minimum follow-up of 24 to 36 months in all patients.

During these consultations, patients were examined by an observer who was blinded for the suture material used. In the supine patient, the abdomen was inspected and palpated during Valsalva's manoeuvre and while the patient was relaxed. The abdominal wall was also examined in rest and during Valsalva's manoeuvre using ultrasound imaging by the same observer. The observer was trained in ultrasonography, but was not a practicing radiologist. The main outcome measure was incisional hernia.

Any wound complaints were also noted and classified into the following categories: aesthetic complaints, discomfort and pain, incarceration of the hernia or no complaints. If an incisional hernia was detected, the treatment was registered (conservative, with of without a hernial bandage, primary closure or placement of mesh material).

We used Korenkov's description of incisional hernia: Any abdominal wall gap with or without a bulge in the area of a postoperative scar, palpable or perceptible by clinical examination or imaging.

On ultrasound an incisional hernia was defined as any defect of the fascia or as a hernial orifice with a minimum size of 1 centimetre, or as a visible hernial sac either with or without abdominal contents. 


\section{Analysis}

Statistical analysis was performed using the SPSS 17.0 software package ${ }^{\circledR}$ Intertest reliability analysis was performed to determine consistency between the tests. The chisquared goodness-of-fit test, Fishers exact test and Student's T-test were used to detect significance of results.

\section{Results}

A total of 687 consecutive patients were eligible for participation in the trial, of which 523 patients were enrolled. Of the 164 excluded patients, 86 did not meet the inclusion criteria, 11 refused to participate and 67 patients were not included for other reasons (a different suture material was used or forgotten to include by surgeons, especially in acute settings). Figure 5.1 shows the flowchart of inclusion and analysis in this study. We excluded 40 randomized patients from the final analysis, because these patients underwent a transverse incision instead of a median laparotomy. Patients with a fascial dehiscence were also excluded from the analysis for incisional hernia due to reinterventions. This resulted in a further exclusion of 27 patients. In total, 456 patients were analyzed. Table 5.1 shows the baseline characteristics of the analyzed patients.

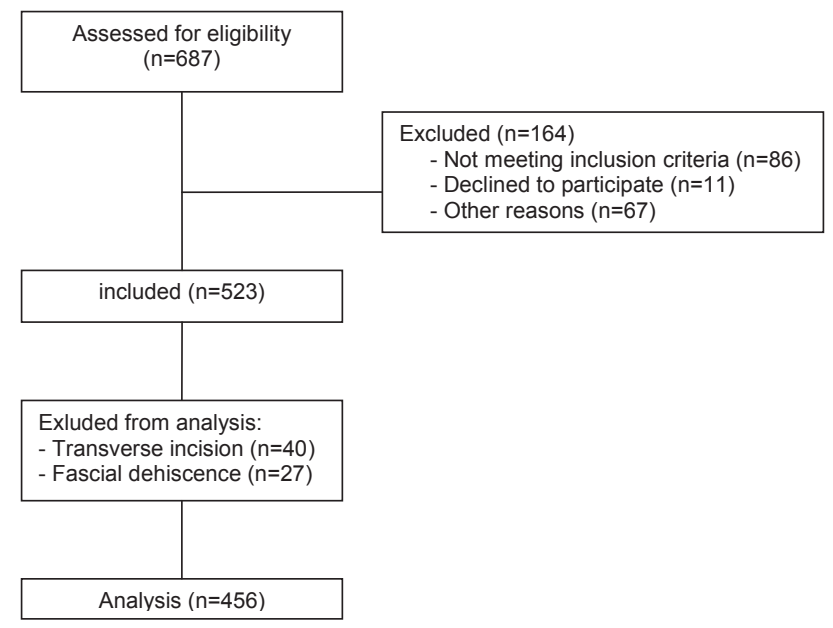

Figure 5.1 Inclusion and analysis flowchart. 
Table 5.1 Baseline characteristics of analyzed participants. Percentages in parentheses. * Standard deviation.

\begin{tabular}{|c|c|}
\hline & Participants $(n=456)$ \\
\hline Age: (years) & $63.3(13.9)^{*}$ \\
\hline \multicolumn{2}{|l|}{ Sexe: } \\
\hline - Male & $264(57.8)$ \\
\hline - Female & $193(42.2)$ \\
\hline Body Mass Index: & $25.5(4.4) *$ \\
\hline - Unknown & 13 \\
\hline \multicolumn{2}{|l|}{ Smoking: } \\
\hline - Yes & $108(23.6)$ \\
\hline- No & $335(73.3)$ \\
\hline - Unknown & $14(3.1)$ \\
\hline \multicolumn{2}{|l|}{ COPD: } \\
\hline - Yes & $34(7.4)$ \\
\hline - No & $423(92.6)$ \\
\hline \multicolumn{2}{|l|}{ Steroids: } \\
\hline - Yes & $32(7.0)$ \\
\hline$-\mathrm{No}$ & $421(92.1)$ \\
\hline - Unknown & $4(0.9)$ \\
\hline \multicolumn{2}{|l|}{ Diabetes Mellitus: } \\
\hline - Yes & $41(9.0)$ \\
\hline - No & $416(91.0)$ \\
\hline \multicolumn{2}{|c|}{ Aneurysm of the Abdominal Aorta? } \\
\hline - Yes $(>4.5 \mathrm{~cm})$ & $46(10.1)$ \\
\hline - No & $405(88.5)$ \\
\hline - Unknown & $6(1.4)$ \\
\hline \multicolumn{2}{|l|}{ Earlier laparotomy? } \\
\hline - Yes & $151(33.0)$ \\
\hline - No & $306(77.0)$ \\
\hline \multicolumn{2}{|l|}{ Suture material in fascia closure: } \\
\hline - Prolene & 223 (48.9) \\
\hline$-\mathrm{PDS}^{\circ}$ & $233(51.1)$ \\
\hline \multicolumn{2}{|l|}{ Diagnosis: } \\
\hline - Rectal carcinoma & $97(21.3)$ \\
\hline - Colon carcinoma & $88(19.3)$ \\
\hline - Sigmoid carcinoma & $53(11.6)$ \\
\hline - Aneurysm abdominal aorta & $53(11.6)$ \\
\hline - Diverticulitis & $32(7.0)$ \\
\hline - Inflammatory bowel disease & $28(6.1)$ \\
\hline - Gastric carcinoma & $24(5.3)$ \\
\hline - Bowel perforation & $17(3.7)$ \\
\hline - Hiatal hernia & $17(3.7)$ \\
\hline - Appendicitis & $6(1.3)$ \\
\hline - Other & $41(9.0)$ \\
\hline \multicolumn{2}{|l|}{ Setting: } \\
\hline - Elective & $393(86.2)$ \\
\hline - Emergency & $63(13.8)$ \\
\hline \multicolumn{2}{|l|}{ Incision type: } \\
\hline - Total median & 346 (75.9) \\
\hline - Supra-umbilical median & $55(12.1)$ \\
\hline - Infra-umbilical median & $55(12.1)$ \\
\hline
\end{tabular}


Mean follow-up during the study was 33.8 months (95\% Confidence Interval 31.8-35.8) and median follow-up was 31 months. Unfortunately, with increasing follow-up time, a considerable loss to follow-up occurred, due to diminished patient willingness to participate in the regular hospital visits.

In 103 (22.6\%) patients an incisional hernia was found with physical examination, ultrasonography, or both. In the patients with incisional hernia, the abdominal fascia was closed with Prolene in 45 patients and with PDS in 58 patients, a non-significant difference $(P=0.229)$.

The intertest reliability between ultrasonography and physical examination was Kappa $=0.697(P<0.001), 95 \% \mathrm{Cl} 0.653-0.741$. This indicates a substantial agreement between the two diagnostic methods.

However, of the 103 patients with an incisional hernia, 82 (79.6\%) were diagnosed with physical examination. An additional 21 (20.4\%) hernias were found with ultrasonography, which were not identified at physical examination. Table 5.2 shows the results of physical examination and ultrasound in the diagnosis of incisional hernia. When compared with each other, physical examination had a false negative rate of $25.3 \%$ and the false negative rate of ultrasonography was $24.4 \%$.

Table 5.2 Diagnosis of incisional hernia. Percentages are in parentheses.

\begin{tabular}{lccr}
\hline & $\begin{array}{c}\text { Physical examination } \\
\text { positive for hernia }\end{array}$ & $\begin{array}{c}\text { Physical examination } \\
\text { negative for hernia }\end{array}$ & Total \\
\hline Ultrasonography positive for hernia & $62(13.6)$ & $21(4.6)$ & $83(18.2)$ \\
Ultrasonography negative for hernia & $20(4.4)$ & $353(77.4)$ & $373(81.8)$ \\
Total & $82(18.0)$ & $374(82)$ & $456(100)$ \\
\hline
\end{tabular}

Because obesity may influence the findings of both physical examination and ultrasonography, a subgroup analysis was performed only those patients with a Body Mass Index above 25 (Table 5.3). In this subgroup, 64 hernias were identified; 50 (78.1\%) by physical examination and 14 (21.9\%) more by ultrasonography alone. The false negative rate for physical examination in this group was comparable with the overall group at $25.5 \%$ but for ultrasonography it was lower: $18 \%$. This could indicate that ultrasonography is more sensitive in obese patients.

Table 5.3 Diagnosis of incisional hernia in patients with a $\mathrm{BMI}>25$. Percentages are in parentheses.

\begin{tabular}{lccc}
\hline & $\begin{array}{c}\text { Physical examination } \\
\text { positive for hernia }\end{array}$ & $\begin{array}{c}\text { Physical examination } \\
\text { negative for hernia }\end{array}$ & Total \\
\hline Ultrasonography positive for hernia & $41(18.0)$ & $14(6.1)$ & $55(24.1)$ \\
Ultrasonography negative for hernia & $9(3.9)$ & $164(71.9)$ & $173(75.9)$ \\
Total & $50(21.9)$ & $178(78.1)$ & $228(100)$ \\
\hline
\end{tabular}


Most incisional hernias were asymptomatic (70 patients, 68.0\%). The relationship between symptoms and the results of investigation are summarized in Table 5.4. Out of the 33 patients with symptomatic incisional hernias, 6 hernias (18.2\%) were identified by ultrasonography only.

Table $5.4 \quad$ Symptoms and diagnosis. Percentages are in parentheses.

\begin{tabular}{lccccc}
\hline & None & Aesthetic & Discomfort & Incarceration & Total \\
\hline Physical exam positive & $55(53.4)$ & $5(4.6)$ & $19(18.4)$ & $3(2.9)$ & $82(79.6)$ \\
$\begin{array}{l}\text { Physical exam negative and } \\
\text { ultrasonography positive }\end{array}$ & $15(14.6)$ & $2(1.9)$ & $4(3,9)$ & $0(0)$ & $21(20.4)$ \\
Total & $70(68.0)$ & $7(6,8)$ & $23(22.3)$ & $3(2.9)$ & $103(100)$ \\
\hline
\end{tabular}

Of the 103 incisional hernias, 82 were managed without treatment, 7 patients received a hernial bandage, 3 hernias were managed surgically with primary closure and 11 patients received placement of mesh material (Table 5.5). Treatment was initiated in one patient with incisional hernia only identified by ultrasound examination. This patient was treated surgically with placement of mesh material.

Table 5.5 Diagnosis and treatment of incisional hernia. Percentages are in parentheses.

\begin{tabular}{lccccc}
\hline & Conservative & Hernial bandage & Primary closure & Mesh & Total \\
\hline Physical exam positive & $62(60.2)$ & $7(6.8)$ & $3(2.9)$ & $10(9.7)$ & $82(79.6)$ \\
$\begin{array}{l}\text { Physical exam negative and } \\
\text { ultrasonography positive }\end{array}$ & $20(19.4)$ & $0(0)$ & $0(0)$ & $1(1.0)$ & $21(20.4)$ \\
Total & $82(79.6)$ & $7(6.8)$ & $3(2.9)$ & $11(10.7)$ & $103(100)$ \\
\hline
\end{tabular}

In total, there were 70 initially asymptomatic hernias, of which 68 were managed conservatively and 2 were later on treated surgically. Of the 33 symptomatic incisional hernias, 21 did not require operative treatment and 12 patients received surgery. One of these treated symptomatic hernias was identified by ultrasonography only at the request of the patient.

\section{Discussion}

The available literature provides no clear radiological diagnostic criteria for incisional hernia. Therefore, we chose to define an incisional hernia in this study as any abdominal wall defect with a minimum diameter of one centimetre, with or without a hernial sac. This strict definition includes those hernias, which are most difficult to 
diagnose using physical examination alone. Also these hernias have the highest risk of incarceration, due to their small orifice and are therefore the most important to find. ${ }^{12}$ When these strict diagnostic criteria are applied and combined diagnostic methods are used, a high incidence of incisional hernia is found. The incidence of incisional hernia in our test population was slightly higher than the reported high-end incidences of incisional hernia in the literature. ${ }^{1-9}$ However, it should be noted that, because neither physical examination nor ultrasonography has a sensitivity and specitivity of $100 \%$, the true incisional hernia rate is unknown, though this may be close, due to the combined use of both modalities.

The intertest variability in our study showed a substantial agreement between physical examination and ultrasonography. This is in contrast to the false negative rates of both modalities, which were both approximately $25 \%$. This may be due to a possible bias, which occurred because both ultrasonography and physical examination were performed by the same observer. This researcher may be more likely to miss an incisional hernia with ultrasonography when it was not found during physical examination. Also, although the observers were trained in performing ultrasonography of the abdominal wall, they were no radiologists.

Therefore, although the intertest comparison showed comparable results, it may be that both physical examination and ultrasonography are limited diagnostic tools, with a limited sensitivity for detecting incisional hernia. Combining the two methods lead to a substantial increase in detection of incisional hernias. This can also be seen in Table 5.2. Some 353 patients clearly did not have an incisional hernia as ultrasonography and physical examination were both negative and some 62 patients had a definite incisional hernia with a positive physical exam and positive ultrasonography. In 41 patients there is a gray area in which one diagnostic modality was negative and the other positive. In these cases, the combination of the two methods led to the diagnosis of incisional hernia.

The high false negative rate of both diagnostic methods may be caused by two factors: first, the accuracy of both methods suffers from patient characteristics such as obesity. Second, due to the design of this study, patients were examined at regular intervals, regardless of complaints. This may mean that incisional hernias were detected very early in development, when their size was small and before patients experienced complaints, making detection more difficult.

Because examination with ultrasonography yielded 21 (20.4\%) additional incisional hernias which were not found at physical examination the optimal diagnostic method for detecting incisional hernia may be the combination of the two methods, without 
using more expensive modalities which use electromagnetic radiation, such as CTscanning.

Sixty-eight percent of the patients in our study did not report any complaints when an incisional hernia was diagnosed and in those with complaints, few opted for treatment after diagnosis. This may be due to the standardized follow-up: hernias were detected early in their development, before they became symptomatic and required treatment.

\section{Conclusion}

There are no clear diagnostic criteria for incisional hernia available in the literature. Standardized ultrasonography during follow-up yields a significant number of, mostly asymptomatic, hernias which would not be found using physical examination alone. This is especially relevant in research settings.

The authors declare no conflict of interest, no funding was received for this study. 


\section{References}

1. Eisner L, Harder F. [Incisional hernias]. Chirurg 1997;68 (4):304-309

2. Hodgson NC, Malthaner RA, Ostbye T. The search for an ideal method of abdominal fascial closure: a meta-analysis. Ann Surg 2000;231 (3):436-442

3. Hoer J, Lawong G, Klinge U, Schumpelick V. [Factors influencing the development of incisional hernia. A retrospective study of 2,983 laparotomy patients over a period of 10 years]. Chirurg 2002;73(5): 474-480.

4. Israelsson LA, Jonsson T. Incisional hernia after midline laparotomy: a prospective study. Eur J Surg 1996;162 (2):125-129

5. Kingsnorth A, LeBlanc K. Hernias: inguinal and incisional. Lancet 2003;362 (9395):1561-1571.

6. Mudge M, Hughes LE. Incisional hernia: a 10 year prospective study of incidence and attitudes. Br J Surg $1985 ; 72(1): 70-71$

7. Osther PJ, Gjode P, Mortensen BB, Mortensen PB, Bartholin J, Gottrup F. Randomized comparison of polyglycolic acid and polyglyconate sutures for abdominal fascial closure after laparotomy in patients with suspected impaired wound healing. Br J Surg 1995;82(8):1080-1082

8. Santora TA, Roslyn JJ. Incisional hernia. Surg Clin North Am 1993;73(3):557-570

9. Wissing J, van Vroonhoven TJ, Schattenkerk ME, Veen HF, Ponsen RJ, Jeekel J. Fascia closure after midline laparotomy: results of a randomized trial. Br J Surg 1987;74(8):738-741

10. Korenkov M, Paul A, Sauerland S, Neugebauer E, Arndt M, Chevrel JP, Corcione F, Fingerhut A, Flament JB, Kux M, Matzinger A, Myrvold HE, Rath AM, Simmermacher RK. Classification and surgical treatment of incisional hernia. Results of an experts' meeting. Langenbecks Arch Surg 2001;386(1):65-73

11. Muysoms FE, Miserez M, Berrevoet F, Campanelli G, Champault GG, Chelala E, Dietz UA, Eker HH, EI Nakadi I, Hauters P, Hidalgo Pascual M, Hoeferlin A, Klinge U, Montgomery A, Simmermacher RK, Simons MP, Smietanski M, Sommeling C, Tollens T, Vierendeels T, Kingsnorth A. Classification of primary and incisional abdominal wall hernias. Hernia 2009;13(4):407-414.

12. Schumpelick V (ed). [Incisional Hernia]. Thieme, Stuttgart 2000.

13. den Hartog D, Dur AH, Kamphuis AG, Tuinebreijer WE, Kreis RW. Comparison of ultrasonography with computed tomography in the diagnosis of incisional hernias. Hernia 2009;13(1):45-48.

14. Bloemen A, van Dooren P, Huizinga BF, Hoofwijk AG. Randomized clinical trial comparing polypropylene or polydioxanone for midline abdominal wall closure. Br J Surg 2011;98(5):633-639.] 



\section{Chapter 6}

Pitfalls and clinical recommendations for the primary lumbar hernia based on a systematic review of the literature

van Steensel S

Bloemen A van den $\mathrm{Hil} \mathrm{LCL}$

van den Bos J

Kleinrensink GJ

Bouvy ND

Hernia. 2019;23:107-117 


\section{Abstract}

\section{Purpose}

The lumbar abdominal wall hernia is a rare hernia in which abdominal contents protrude through a defect in the dorsal abdominal wall, which can be of iatrogenic, congenital, or traumatic origin. Two anatomical locations are known: the superior and the inferior lumbar triangle. The aim of this systematic review is to provide a clear overview of the existing literature and make practical clinical recommendations for proper diagnosis and treatment of the primary lumbar hernia.

\section{Methods}

The systematic review was conducted according to the PRISMA guidelines. A systematic search in PubMed, MEDLINE, and EMBASE was performed, and all studies reporting on primary lumbar hernias were included. No exclusion based on study design was performed. Data regarding incarceration, recurrence, complications, and surgical management were extracted.

\section{Results}

Out of 670 eligible articles, 14 were included and additional single case reports were analysed separately. The average quality of the included articles was 4.7 on the MINORS index (0-16). Risk factors are related to increased intra-abdominal pressure. CT scanning should be performed during pre-operative workup. Available evidence favours laparoscopic mesh reinforcement, saving open repair for larger defects. Incarceration was observed in $30.8 \%$ of the cases and $2.0 \%$ had a recurrence after surgical repair. Hematomas and seromas are common complications, but surgical site infections are relatively rare.

\section{Conclusion}

The high risks of incarceration in lumbar hernias demand a relatively fast elective repair. The use of a mesh is recommended, but the surgical approach should be tailored to individual patient characteristics and risk factors. 


\section{Introduction}

Even in times of advanced medicine, it is possible that the rarity of a condition complicates diagnosis and treatment; such a challenge is found in the lumbar hernia. The lumbar hernia was first suggested by Barbette in the late seventeenth century and Garangeot published the first case in 1731. A lumbar hernia is a protrusion of intraperitoneal or extraperitoneal contents through a defect of the posterolateral abdominal wall. ${ }^{1}$

Anatomically, three types of lumbar hernia are identified; the superior lumbar hernia, the inferior lumbar hernia, and the diffuse lumbar hernia. The superior lumbar triangle, also known as the Grynfeltt-Lesshaft triangle, is bordered by the 12th rib and posterior inferior serratus muscle superiorly, laterally by the posterior border of the internal oblique muscle, and medially by the anterior border of the erector spinae muscle. ${ }^{2}$ The anatomic boundaries of the inferior lumbar triangle, generally known as Petit's triangle, are the iliac crest inferiorly, the medial border of the external oblique muscle on the lateral side, and medially the lateral border of the latissimus dorsi muscle ${ }^{3}$ (see Figure 6.1). The third anatomical type of lumbar hernia is not limited by the previously discussed anatomical structures, is of considerable size, and, therefore, designated as a diffuse lumbar hernia. This is usually seen following a traumatic event or secondary to surgery. These secondary hernias are aetiologically distinguished from primary or spontaneous lumbar hernias and, therefore, fall outside the scope of this systematic review, which will only focus on primary lumbar hernias. ${ }^{4}$

Predisposing factors for primary acquired hernias are similar to those of other hernias and related to an elevated intra-abdominal pressure such as pregnancy, obesity, ascites, or chronic bronchitis ${ }^{4,5}$, and weakness of the posterior abdominal wall caused by aging, muscle atrophy, and chronic debilitating disease. Extreme thinness and intense slimming may also predispose for the development of hernias. ${ }^{4,5}$ Another major determinant for hernia formation is the size of the area at risk, which is determined by the size and form of the triangle, the length and angulation of the 12th rib, the size of the musculus quadratus lumborum, and the musculus serratus posterior. All these factors combined result in a higher prevalence in short, obese people with wide hips and more horizontal ribs resulting in larger triangles. ${ }^{4,5}$

Just like other abdominal wall hernias, the most common clinical presentation is a palpable, usually reducible mass, which increases in size when abdominal pressure rises. The mass may disappear when the patient assumes a supine position. Symptoms may be back pain or lumbago along the area of the distribution of the sciatic nerve, possibly accompanied by unspecific abdominal discomfort and fatigue. One in ten patients with lumbar hernia present with acute complications, such as bowel 
obstruction or urinary obstruction, requiring emergency intervention. ${ }^{4}$ It is important to consider a broad differential diagnosis including tumours, such as lipomas, sarcomas or kidney mass, and infectious disorders, like abscesses and panniculitis. Furthermore, a pannicular lumbosacroiliac hernia or a hematoma should be kept in mind.

The rarity of primary lumbar hernia and the high risk of acute presentation prompted us to perform a systematic review of the literature on treatment options and management. Due to the differences in aetiology of the lumbar hernia, this systematic review focuses on the primary lumbar hernia. The aim is to provide a clear overview of the existing literature and make practical clinical recommendations for the proper diagnosis and treatment.

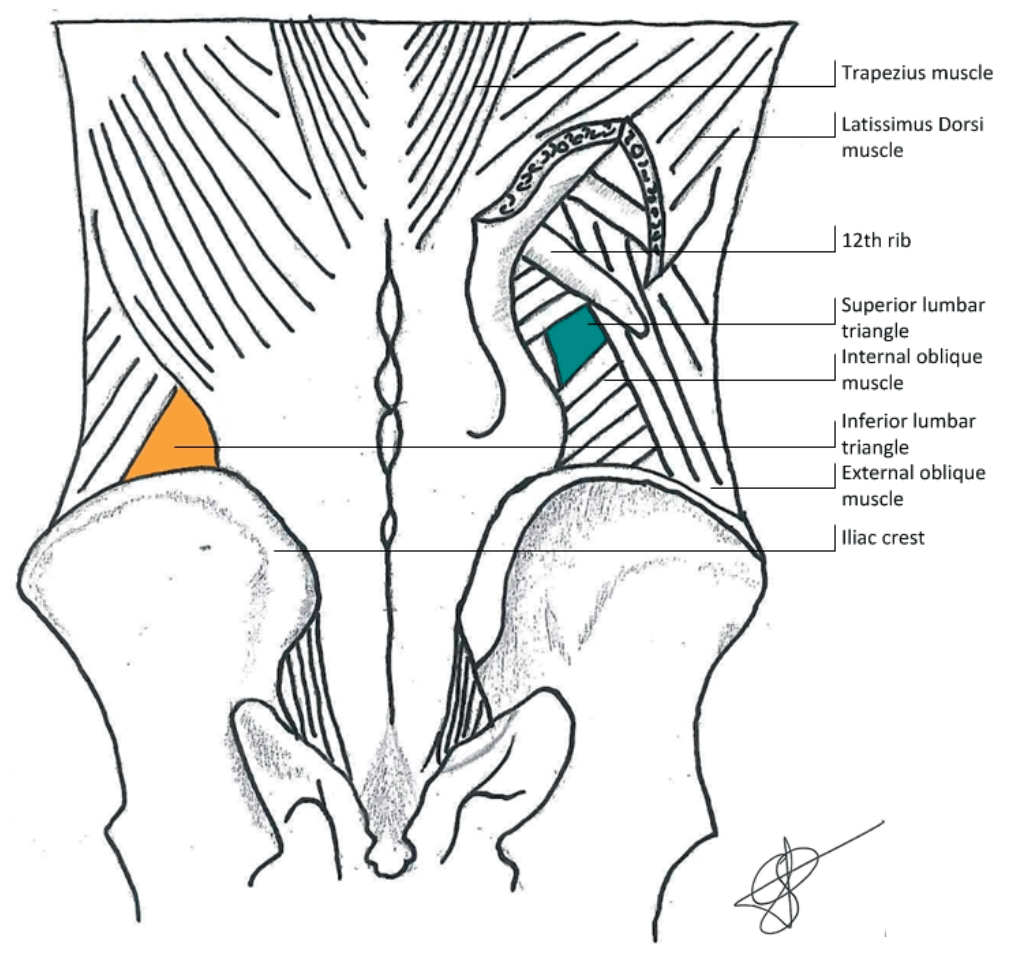

Figure 6.1 Anatomy of the dorsal abdominal wall, boundaries of the inferior and superior lumbar space. 


\section{Methods}

\section{Systematic search and study selection}

This systematic review was performed according to the PRISMA guidelines ${ }^{6}$ and its protocol was registered online on Prospero [CRD42018085537]. PubMed, MEDLINE, and EMBASE were searched on the 8th of august 2017 using all search terms and synonyms for lumbar hernia, which are presented in Table 6.1 and all references were checked for possible eligible articles. All articles were screened based on title and abstract by two independent reviewers (SvS and JvdB). If eligible, the full text was screened by the same independent reviewers. Disagreement was settled by discussion between the reviewers and arbitrated by a third independent reviewer (AB) if necessary. All articles of added value reporting on primary or spontaneous lumbar hernia written in English, Dutch, or German were included and articles reporting on incisional, congenital, or traumatic lumbar hernias were excluded. Articles reporting on a single case were analysed separately. If, after rigorous search, no abstract or full text was retrievable, the article was ruled out. Because of the low number of publications expected to be found, a broad search was performed and restrictions were limited to a minimum to review all the available literature and provide the most extensive foundation for clinical recommendations as possible.

Table 6.1 Search terms used in literature search.

\begin{tabular}{ll}
\hline Search terms & \\
\hline Abdominal Hernia (MesH) & Lumbar hernia \\
Abdominal Hernia & Lumbar triangle \\
& Inferior lumbar triangle \\
& Superior lumbar triangle \\
& Dorsal hernia \\
& Petit \\
& Petit triangle \\
& Petit's triangle \\
& Petit hernia \\
& Grynfeltt-Lesshaft \\
& Grynfeltt-Lesshaft triangle \\
& Grynfeltt-Lesshaft hernia \\
\hline
\end{tabular}

\section{Quality assessment}

In case of a case series reporting on lumbar hernias, the quality assessment was done using the methodological index for non-randomised studies (MINORS), which consist of eight criteria and four additional criteria in case of a comparative study. The items are 
scored 0 for not reported, 1 for reported but inadequate, and 2 for reported and adequate with a maximum score of 16 for non-comparative and 24 for comparative studies. ${ }^{7}$ The quality assessment was performed by two independent reviewers (SvS and JvdB). Disagreement was settled by discussion and, if necessary, a third reviewer $(A B)$ was contacted for arbitration.

\section{Data extraction}

In case of diversity in study design, outcomes, and reporting, the high heterogeneity would impair useful conclusions from a meta-analysis, and thus, a structured narrative synthesis of the extracted data will be performed. Data on diagnosis and treatment of primary lumbar hernia were extracted. If available, recurrence rates, patient characteristics, and complication rates were extracted from the articles using a standardised form. Case reports were analysed separately, because of unavoidable differences in design, manner of reporting results, and potential risk of bias.

\section{Results}

\section{Systematic search}

After the removal of duplicates, a total of 670 articles were identified for title and abstract screening (see Figure 6.2). 547 articles were excluded leaving 28 articles for full-text screening, resulting in the inclusion of $14^{4,8-20}$ articles in this systematic review, of which 5 had a prospective design ${ }^{9,10,12,13,17}, 3$ a retrospective design ${ }^{8,18,19}$ and in 5 articles, the design was unclear. ${ }^{4,11,14-16}$ In most cases, multiple types of lumbar hernia were included in the study, and in four studies, the aetiology of the lumbar hernia was not specified beyond lumbar or acquired..$^{8,9,11,16}$ Five studies ${ }^{9,10,13,16,19}$ used the open approach for the repair of the lumbar hernia, one study ${ }^{8}$ only included patients with a laparoscopic repair, and three studies ${ }^{4,12,17}$ included both. Of the total population of 420 patients described, 85 patients were diagnosed with a spontaneous or primary lumbar hernia and 33 patients with a primary or acquired lumbar hernia not specified, leaving 118 patients in total. The follow-up ranged from 1 month to 170 months (see Table 6.2 for the patient and study characteristics). 


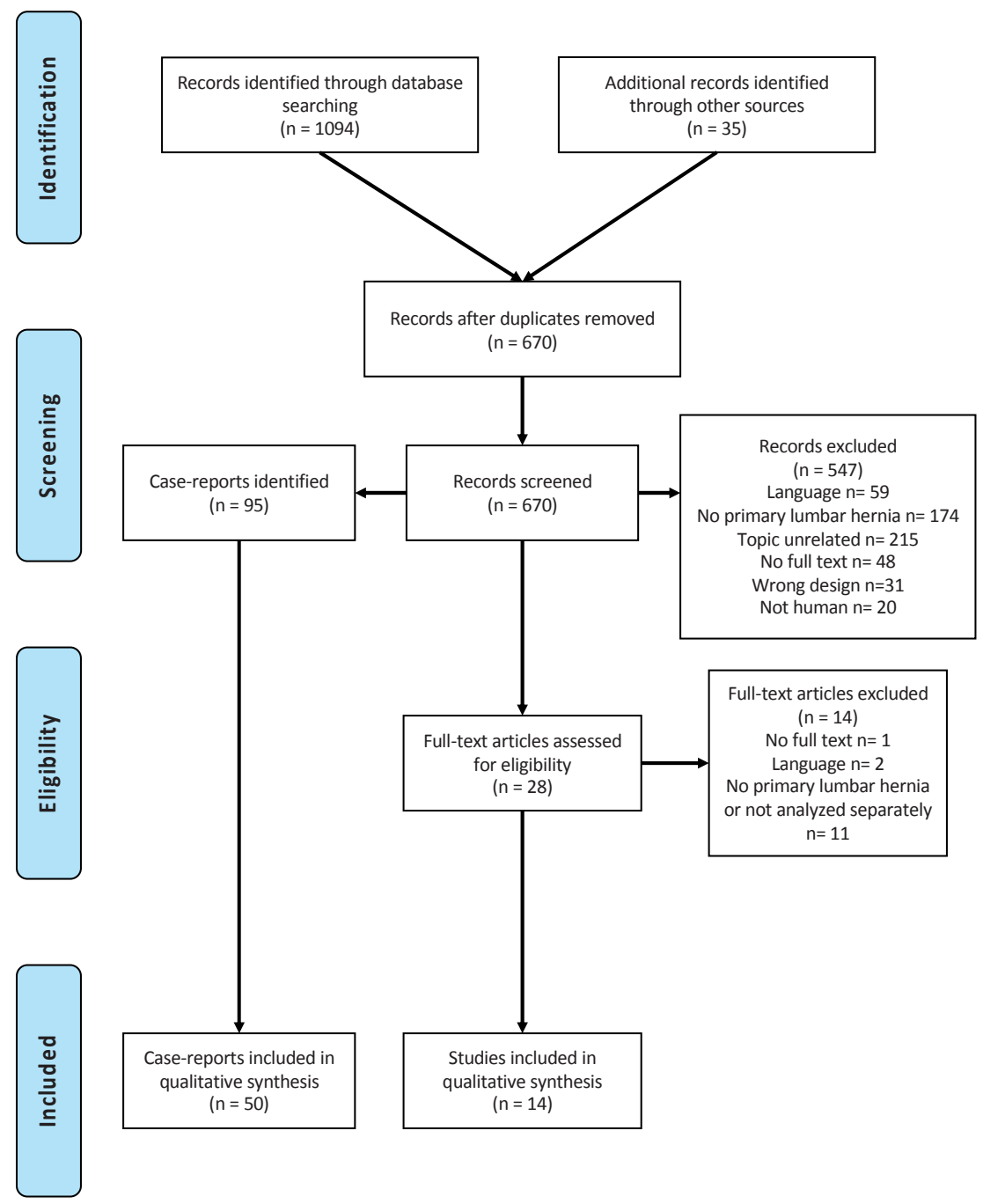

Figure 6.2 PRISMA 2009 flow diagram.

\section{Quality assessment}

One comparative study scored 19 out of a possible 24 points on the MINOR index. ${ }^{17}$ Regarding the non-comparative studies, the median MINOR score was 4 ranging from 1 to 9 . All studies scored poorly on reporting loss to follow-up and unbiased endpoints. The duration of follow-up and the relevant endpoints were described adequately in most included studies (See Table 5.3). 


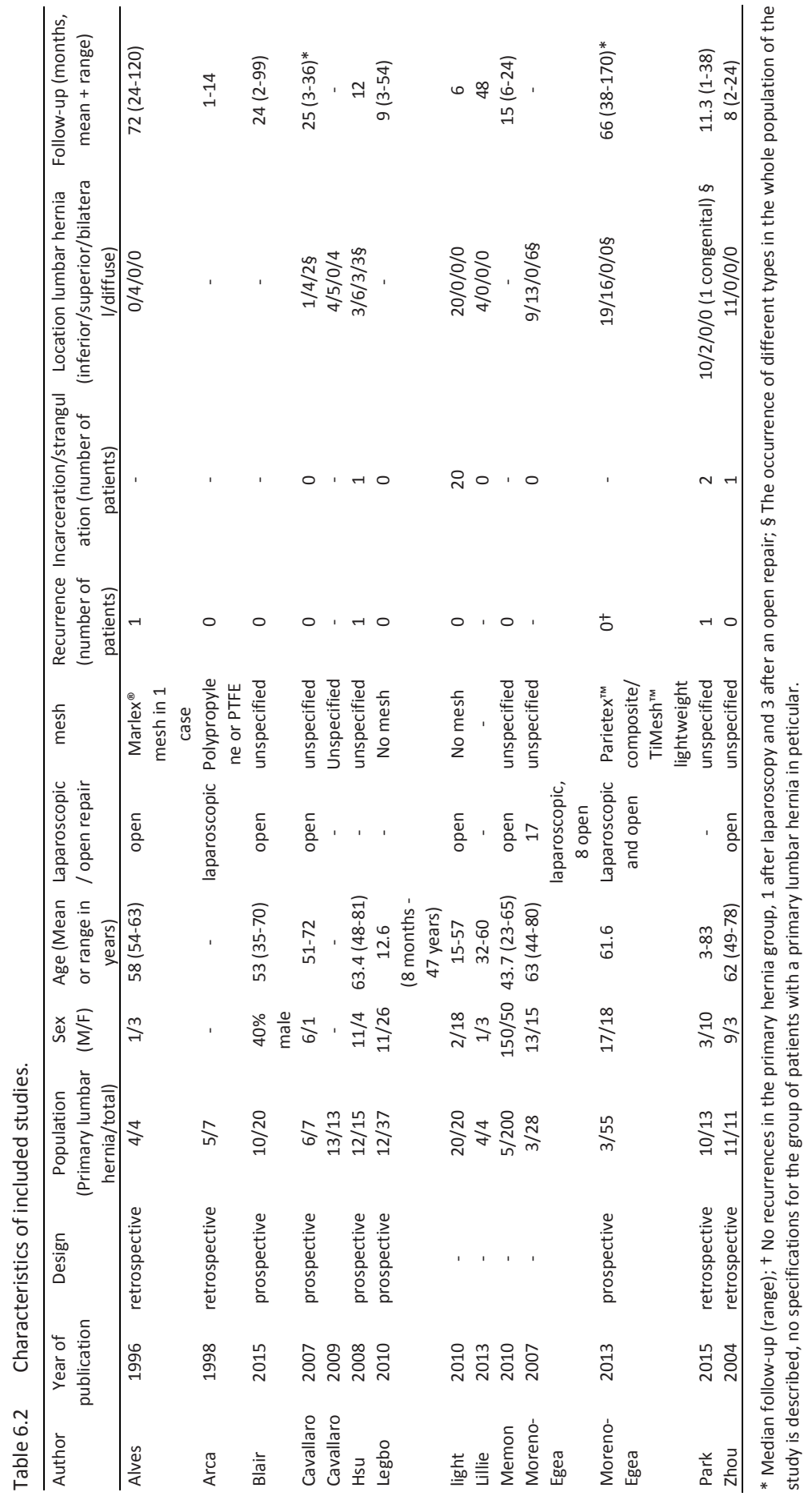




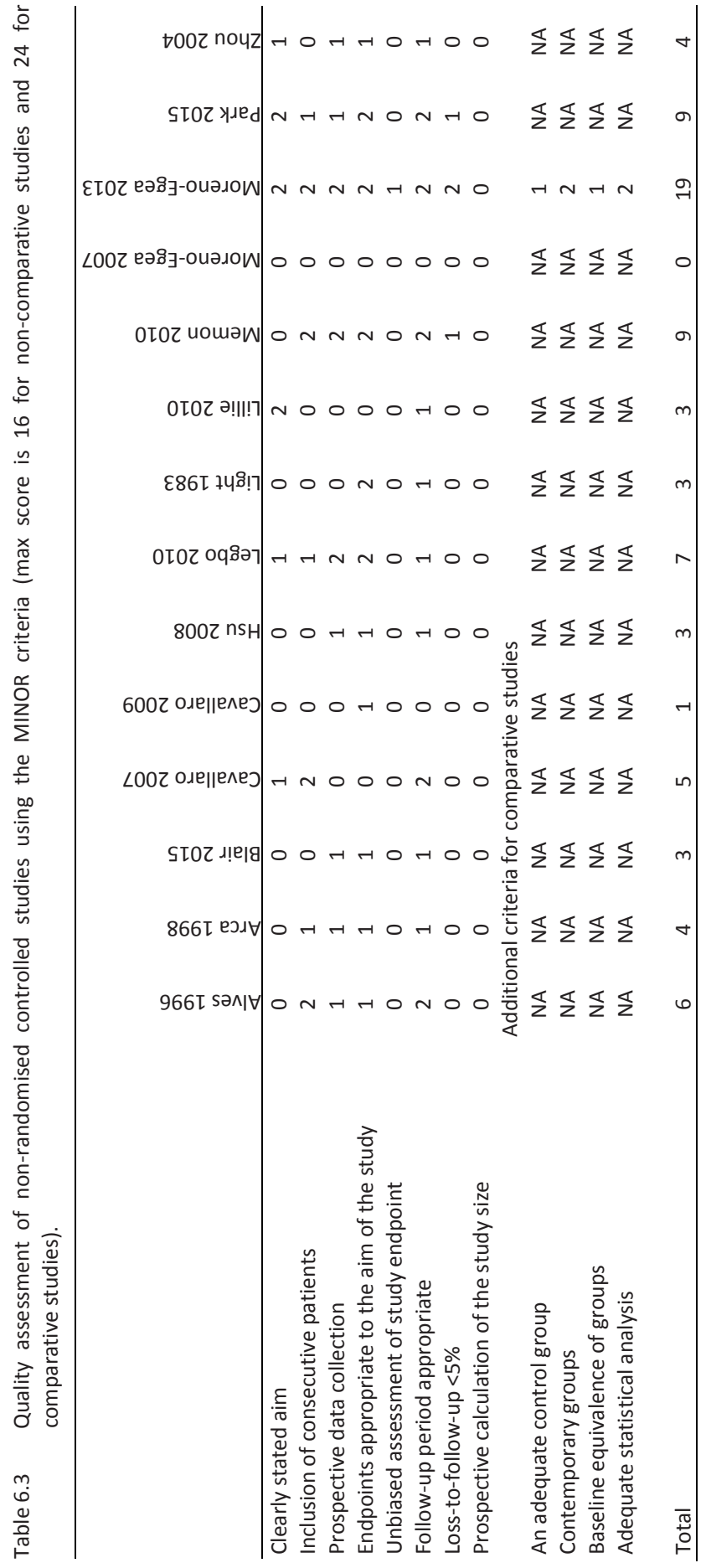




\section{Diagnosis}

The gold standard for the diagnosis of a lumbar hernia is performing a CT scan, with a sensitivity of $98 \%$ based on its possibility (1) to distinguish between fascial and muscular layers, (2) to detect a defect in one of these layers, and (3) to assess the nature of the potential herniated content. ${ }^{5,21-25}$ Furthermore, CT scans are useful for diagnosing the asymptomatic non-palpable lumbar hernia. ${ }^{22}$ This can influence the operative approach, because primary repair of lumbar hernias can be performed via the retroperitoneum. ${ }^{23}$ The differentiation between a lumbar hernia and muscle atrophy should be made using CT scans. It is advisable to evaluate the patient with a lumbar hernia routinely and plan the surgery proper using CT imaging. ${ }^{5}$ Studies that focus on the use of MRI specifically in the case of lumbar hernias have not been carried out. ${ }^{15}$ Ultrasonography does not seem useful when a direct clinical suspicion is absent or in obese patients. $^{5}$

\section{Treatment}

Similar to all abdominal wall hernias, the lumbar hernia has a progressive character with an increase in size, back pain ${ }^{17}$ and, sometimes, bowel obstruction. ${ }^{26,27}$ Predictors associated with an increased likelihood for recurrence are obesity and a defect size larger than $15 \mathrm{~cm}^{28}$

Operative repair with the elimination of the defect and reconstruction and reinforcement of the resilient abdominal wall, capable of resisting stress in the future, is probably the most effective treatment. ${ }^{5}$ Surgical approach is presented with technical difficulties in defining the external edges of the fascial defect. The location, the lack of adequate fascia, and the weakness of the surrounding tissue result in problematic visualisation of the defect. Furthermore, the bony boundaries, in close proximity of the defect, are a limiting factor in repair. ${ }^{1,8,17}$

Primary closure and mesh augmentation of the defect are the most important techniques. Primary closure of the defect has the potential to be effective in small hernias, but not in large lumbar hernias because of the high tension created over the defect in combination with the limited strength of the tissues surrounding the defect. $^{8,10,29}$ The literature does not elaborate much regarding the choice of mesh for lumbar hernia repair. Like the repair of other types of hernias, a coated mesh for intraabdominal use or, otherwise, a lightweight mesh is recommended. ${ }^{17}$ It was once suggested to use two meshes, one placed in a sublay and the other in an onlay technique, in a tension-free repair of the lumbar hernia. ${ }^{30}$ Garg et al. investigated the use of a tension-free sutureless repair for lumbar hernias in a dorsal approach in three infants and one adult, and concluded that this method was easy, safe, and effective. ${ }^{31} \mathrm{~A}$ 
trans-abdominal partial extra-peritoneal technique (TAPE) for repairing lumbar hernias has been reported. It is concluded that this technique was feasible and might be preferable to the open technique in complicated cases. ${ }^{32,33}$ Other surgical techniques for lumbar hernia repair are use of a rotational flap or onlay flap. These techniques require extensive dissection and are accompanied by the risk of ischemia and muscle atrophy due to compromised vascularisation of the flap, which can result in a failed repair and a potentially larger defect than the original. ${ }^{8,10,29}$

Similar to other abdominal hernias, the use of synthetic meshes in a tension-free repair is widely accepted because of the experience in the other fields of abdominal wall surgery. Other advantages are its effectiveness and in expensiveness. ${ }^{8,10}$ The decision regarding the location of the mesh placement and the approach depends on the aetiology of the lumbar hernia, divided in acquired and primary lumbar hernias. ${ }^{10,17}$ Small primary lumbar hernias $(<5 \mathrm{~cm})^{4}$ with well-defined borders, a normal lumbar anatomy, and without visceral content are good candidates for the pre-peritoneal approach. The pre-peritoneal laparoscopic approach seems feasible and safe, and, in contrast to the trans-abdominal retroperitoneal laparoscopy, does not require excessive mobilization of intra-abdominal structures, and avoids intra-peritoneal adhesions. $^{34,35}$ Moreno-Egea et al. confirmed in a prospective study that the general advantages of laparoscopic surgery apply to the repair of the lumbar hernia. The laparoscopic approach showed a significantly shorter hospital stay; earlier return to normal activity, less analgesic consumption and less pain both 1 and 6 months postoperatively. ${ }^{17}$ In addition, Moreno-Egea et al. showed, in a series of 16 consecutive patients, that the mean final costs of a laparoscopic operation are significantly less when compared to the open approach. ${ }^{36}$ The open approach can be reserved for large defects, in case of incarceration and when the laparoscopic approach has failed. ${ }^{4}$ When placement of the mesh is difficult due to bordering bone structures and if the defect leaves no sufficient fascia for suture fixation, bone anchor fixation is a feasible and safe method. $^{37}$

\section{Obstruction/incarceration}

Eight studies reported on the incarceration or strangulation of a lumbar hernia, describing 78 patients in total $\left.\right|^{4,10,12-15,18,19}$, of which 24 patients were classified as having an incarcerated hernia (30.8\%). One case of bowel incarceration and a case of a strangulated hernia with bowel obstruction were mentioned. Light et al. $^{38}$ reported on 20 cases of lumbar hernia in which incarcerated fat was observed. 


\section{Recurrence}

In 11 studies $^{8-10,12-14,16-20}$ the recurrence rate was reported, of which seven studies $^{8-10,13,14,16,19}$ reported zero recurrences after surgery. Therefore, the mean recurrence rate was 2 out of 98 patients with a primary hernia (2.0\%). In the series of four patients of Alves et al. ${ }^{20}$, one recurrence occurred after 10 days following a primary repair. Park et al. ${ }^{18}$ reported one recurrence 6 months postoperatively, after repair with a mesh plug, but neglected to mention what type of lumbar hernia was repaired.

\section{Single case reports}


describing 55 cases (see Table 6.4 for patient and study characteristics). In 49 patients, the location of the lumbar hernia was reported, and 34 (69.4\%) occurred in the superior lumbar triangle, $12(24.5 \%)$ in the inferior lumbar triangle, and $3(6.1 \%)$ in both locations. In 44 patients, the operation technique was described and 34 (77.3\%) were repaired using a mesh and 10 (22.7\%) lumbar defects were primary closed. In five case reports $44,47,59,61,82$, the patient was not operated for the lumbar hernia. 10 patients were operated laparoscopically, and in 22 patients, an open repair was performed. The recurrence rate was $5.9 \%$. In one case ${ }^{5}$, a recurrence occurred after 2 years following a primary open repair. The other case ${ }^{60}$ describes a bilateral recurrence 1 month postoperatively, which occurred after an open repair with a polypropylene mesh. Two case reports ${ }^{34,73}$ described a seroma after mesh repair which was treated by needle aspiration. An incarceration occurred in 12 out of the 40 patients (29.3\%) of which occurrences of these symptoms were recorded.

Table 6.4 Characteristics of the included case-reports.

\begin{tabular}{lc}
\hline Number of cases & 55 \\
Sex (M/F) & $23 / 28$ \\
Age (mean) & 63 \\
Location (superior/inferior/both) & $34 / 12 / 3$ \\
Location (left/right/bilateral) & $29 / 18 / 5$ \\
Mesh repair (occurrence/total reported) & $34 / 44$ \\
Operation (laparoscopic/open repair) & $10 / 22$ \\
Follow-up (range) & 7 days - 24 months \\
Recurrence (occurrence /total reported) & $2 / 34$ \\
Incarceration and strangulation (occurrence/total reported) & $12 / 40$ \\
\hline
\end{tabular}




\section{Discussion}

This is the first systematic review on primary lumbar hernias and offers the largest data set on this subject by including all studies concerning primary lumbar hernia regardless of design. The aim is to provide a clear overview of the available literature and make evidence based practical and clinical recommendations and to identify pitfalls regarding diagnosis and treatment.

Overall quality of the included studies assessed using the MINOR criteria was relatively low. This is a result of the design of the included studies, mostly case series, nonrandomised designs, or retrospective studies. A prospective calculation was lacking in all the included studies. Furthermore, an unbiased evaluation of the endpoints using adequate blinding often was not performed and the loss to follow-up was not mentioned in most studies.

The surgical approach should be tailored to the individual hernia characteristics. A laparoscopic pre-peritoneal approach is preferable in small, simple primary lumbar hernias leaving the open approach for the complex cases. In the repair of a lumbar hernia, the general advantages of a laparoscopic approach, regarding a faster postoperative recovery and pain reduction, apply. A possible alternative is suggested by

Beffa et al. $^{86}$; the robotic trans-abdominal pre-peritoneal approach, which has potential advantages regarding lumbar hernia repair.

Regarding mesh repair versus primary closure, no recommendations can be made based on the data presented in this review, but following the overwhelming evidence in hernia research, it seems clear that patients would benefit from a repair with a mesh. And above all should the choice of mesh be dictated by the surgical approach. For example, the extra-peritoneal repair of a lumbar hernia is suitable for repair with a noncoated mesh, which is probably more cost-effective than coated meshes for intraperitoneal placement. The recurrence rate is relatively high and with publication bias playing a major role, the true recurrence rate might even be higher. Most recurrences occurred after an open repair, but definitive conclusions cannot be drawn.

The percentage of incarceration in this type of hernia is considerably high. Although the design of the included studies increases the risk of publication bias, the incarceration rate found in the included studies and in the single case reports was similar. Macchi et al. found, in a recent anatomic-radiologic study, evidence for a "lumbar canal" after analysing a randomly selected series of CT scans of the abdomen. This lumbar canal is described as being a real musculoaponeurotic tunnel with a postero-anterior direction. It is suggested that the superior and inferior lumbar triangle are connected with the deep peritoneal opening or deep lumbar ring located at the superior lumbar triangle and the subcutaneous opening or superficial lumbar ring at the inferior lumbar 
triangle. ${ }^{87}$ This "lumbar canal" and as well as a complex anatomic composition of multiple layers of the abdominal wall might increase the risk of incarceration. It is recommended that surgical correction is performed electively as early as possible and preferably by a surgeon with experience in the field of hernia surgery. This timeframe allows for adequate diagnostic imaging but minimizes the risk of incarceration. Although a clinical diagnosis suffices, a CT scan is regarded the gold standard to assess the extent of the lumbar hernia, the involved anatomical structures, the level of atrophy, and the possible content of the hernia.

The diagnosis and treatment of lumbar hernias are complicated by its low incidence, resulting in scarce experience and lack of consensus in the literature. Heterogeneity in the population, based on the subdivision in aetiology, increases this problem. Publication bias, due to the design of the included studies, might result in an overestimation of the complaints and complications of the patient at presentation, like incarceration. On the other hand, it can cause an underestimation of the recurrence rates. More high-quality research is needed, in which, unfortunately, is the incidence of a lumbar hernia a severely limiting factor. Centralising care for this rare entity would increase specialisation and produce the volumes needed for adequate research. Furthermore, cooperation between specialised abdominal wall centres would increase the awareness of this type of dorsal lumbar abdominal wall hernia.

\section{Conclusions}

The risks for incarceration in lumbar hernias are increased compared to the other hernias which requires relatively fast elective repair by a surgeon with experience in the field of hernia surgery. A laparoscopic pre-peritoneal repair with a mesh is recommended in lumbar hernia $<5 \mathrm{~cm}$, but the surgical approach in hernia $>5 \mathrm{~cm}$ should be tailored to individual patient characteristics and risk factors. 


\section{References}

1. Burt BM, Afifi HY, Wantz GE, Barie PS. Traumatic lumbar hernia: report of cases and comprehensive review of the literature. J Trauma Inj Infect Crit Care 2004;57(6):1361-1370.

2. Loukas M, El-Zammar D, Shoja MM, Tubbs RS, Zhan L, Protyniak B, et al. The clinical anatomy of the triangle of Grynfeltt. Hernia 2008;12(3):227-231.

3. Loukas M, Tubbs RS, El-Sedfy A, Jester A, Polepalli S, Kinsela C, et al. The clinical anatomy of the triangle of Petit. Hernia 2007;11(5):441-444.

4. Moreno-Egea A, Baena EG, Calle MC, Martinez JA, Albasini JL. Controversies in the current management of lumbar hernias. Arch Surgery 2007;142(1):82-88.

5. Suarez S, Hernandez JD. Laparoscopic repair of a lumbar hernia: report of a case and extensive review of the literature. Surg Endosc 2013;27(9):3421-3429.

6. Moher D, Liberati A, Tetzlaff J, Altman DG, Group P. Preferred reporting items for systematic reviews and meta-analyses: the PRISMA statement. BMJ 2009;339:b2535.

7. Slim K, Nini E, Forestier D, Kwiatkowski F, Panis Y, Chipponi J. Methodological index for non-randomized studies (MINORS): development and validation of a new instrument. ANZ J Surg 2003;73(9):712-716.

8. Arca MJ, Heniford BT, Pokorny R, Wilson MA, Mayes J, Gagner M. Laparoscopic repair of lumbar hernias. J Am Coll Surg 1998;187(2):147-152.

9. Blair LJ, Cox TC, Huntington CR, Ross SW, Kneisl JS, Augenstein VA et al. Bone anchor fixation in abdominal wall reconstruction: a useful adjunct in suprapubic and para-iliac Hernia repair. Am Surg 2015;81(7):693-697.

10. Cavallaro G, Sadighi A, Miceli M, Burza A, Carbone G, Cavallaro A. Primary lumbar hernia repair: the open approach. Eur Surg Res 2007;39(2):88-92.

11. Cavallaro G, Sadighi A, Paparelli C, Miceli M, D’Ermo G, Polistena A et al. Anatomical and surgical considerations on lumbar hernias. Am Surg 2009;75(12):1238-1241.

12. Hsu SD, Shen KL, Liu HD, Chen TW, Yu JC. Lumbar hernia: clinical analysis of cases and review of the literature. Chir Gastroenterol 2008;24(3):221-224.

13. Legbo JN, Legbo JF. Abdominal wall reconstruction using de-epithelialized dermal flap: a new technique. J Surg Techn Case Rep 2010;2(1):3-7.

14. Light HG. Hernia of the inferior lumbar space. A cause of back pain. Arch Surg 1983;118(9):1077-1080.

15. Lillie GR, Deppert E. Inferior lumbar triangle hernia as a rarely reported cause of low back pain: a report of 4 cases. J Chiropr Med 2010;9(2):73-76.

16. Memon MR, Shaikh AA, Memon SR, Jamro B. Results of stoppa's sublay mesh repair in incisional and ventral hernias. JPMA J Pak Med Assoc 2010;60(10):798-801.

17. Moreno-Egea A, Alcaraz AC, Cuervo MC. Surgical options in lumbar hernia: laparoscopic versus open repair. A long-term prospective study. Surg Innov 2013;20(4):331-344.

18. Park SH, Chung HS, Song SH. Lumbar hernia in South Korea: different from that in foreign literature? Hernia 2015;19(5):835-839.

19. Zhou X, Nve JO, Chen G. Lumbar hernia: clinical analysis of 11 cases. Hernia 2004;8(3):260-263.

20. Alves A Jr, Maximiano L, Fujimura I, Pires PW, Birolini D. Grynfelt hernia. Arq Gastroenterol 1996; 33(1):32-35

21. Baker ME, Weinerth JL, Andriani RT, Cohan RH, Dunnick NR. Lumbar hernia: diagnosis by CT. AJR Am J Roentgenol 1987;148(3):565-567.

22. Faro SH, Racette CD, Lally JF, Wills JS, Mansoory A. Traumatic lumbar hernia: CT diagnosis. AJR Am J Roentgenol 1990;154(4):757-759.

23. Killeen KL, Girard S, DeMeo JH, Shanmuganathan K, Mirvis SE. Using CT to diagnose traumatic lumbar hernia. AJR Am J Roentgenol 2000;174(5):1413-1415.

24. Salameh JR, Salloum EJ. Lumbar incisional hernias: diagnostic and management dilemma. JSLS 2004;8(4):391-394.

25. Martin J, Mellado JM, Solanas S, Yanguas N, Salceda J, Cozcolluela MR. MDCT of abdominal wall lumbar hernias: anatomical review, pathologic findings and differential diagnosis. Surg Radiol Anat SRA 2012;34(5):455-463. 
26. Steerman SN, Steerman PH. Scoliotic lumbar hernia as a cause of colonic obstruction. J Am Coll Surg 2004;199(1):162.

27. Teo KA, Burns E, Garcea G, Abela JE, McKay CJ. Incarcerated small bowel within a spontaneous lumbar hernia. Hernia 2010;14(5):539-541.

28. Moreno-Egea A, Carrillo-Alcaraz A. Management of non-midline incisional hernia by the laparoscopic approach: results of a long-term follow-up prospective study. Surg Endosc 2012;26(4):1069-1078.

29. Dowd CN. Congenital Lumbar Hernia, at the triangle of Petit. Ann Surg 1907;45(2):245-248.

30. Bigolin AV, Rodrigues AP, Trevisan CG, Geist AB, Coral RV, Rinaldi N et al. Petit Lumbar Hernia-a doublelayer technique for tension-free repair. Int Surg 2014;99(5):556-559.

31. Garg CP, Sharma P, Patel G, Malik P. Sutureless meshplasty in lumbar hernia. Surg Innov 2011;18(3):285-288.

32. Sun J, Chen X, Li J, Zhang Y, Dong F, Zheng M. Implementation of the trans-abdominal partial extraperitoneal (TAPE) technique in laparoscopic lumbar hernia repair. BMC Surg 2015;15:118.

33. Shekarriz B, Graziottin TM, Gholami S, Lu HF, Yamada H, Duh QY et al. Transperitoneal preperitoneal laparoscopic lumbar incisional herniorrhaphy. J Urol 2001;166(4):1267-1269.

34. Habib E. Retroperitoneoscopic tension-free repair of lumbar hernia. Hernia 2003;7(3):150-152.

35. Meinke AK. Totally extraperitoneal laparoendoscopic repair of lumbar hernia. Surg Endosc 2003;17(5):734-737.

36. Moreno-Egea A, Torralba-Martinez JA, Morales G, Fernandez T, Girela E, Aguayo-Albasini JL. Open vs laparoscopic repair of secondary lumbar hernias: a prospective nonrandomized study. Surg Endosc 2005;19(2):184-187.

37. Carbonell AM, Kercher KW, Sigmon L, Matthews BD, Sing RF, Kneisl JS et al. A novel technique of lumbar hernia repair using bone anchor fixation. Hernia 2005;9(1):22-25.

38. Light D, Gopinath B, Banerjee A, Ratnasingham K. Incarcerated lumbar hernia: a rare presentation. Ann R Coll Surg Engl 2010;92(3):W13-W14.

39. Ahmed ST, Ranjan R, Saha SB, Singh B. Lumbar hernia: a diagnostic dilemma. BMJ Case reports 20142014:15.

40. Alcoforado C, Lira N, Kreimer F, Martins-Filho ED, Ferraz AA. Grynfelt hernia. Arq Bras Cir Dig 2013;26(3):241-243.

41. Astarcioglu H, Sokmen S, Atila K, Karademir S. Incarcerated inferior lumbar (Petit's) hernia. Hernia 2003;7(3):158-160.

42. Belekar DM, Dewoolkar VV, Desai AA, Butala UK. Primary Grynfeltt's Hernia. Indian J Surg 2014;76(2):145-147.

43. Bickel A, Haj M, Eitan A. Laparoscopic management of lumbar hernia. Surg Endosc 1997;11(11): 1129-1130.

44. Cabello R, Cancho MJ, Monzo JI, Lopez I, Tabares J, Hernandez C. Herniation of renal pelvis and ureteropelvic junction resulting from superior lumbar triangle hernia. Scand J Urol Nephrol 2008;42(1):81-82.

45. Cesar D, Valadao M, Murrahe RJ. Grynfelt hernia: case report and literature review. Hernia 2012;16(1):107-111.

46. Chenoweth J, Vas W. Computed tomography demonstration of inferior lumbar (Petit's) hernia. Clin Imaging 1989;13(2):164-166.

47. Coulier B. Grynfelt hernia. JBR-BTR 2011;94(2):99.

48. Di Francesco F, Gourgiotis S, Solaini L. A very simple technique to repair Grynfeltt-Lesshaft hernia. Hernia 2010;14(4):439-441.

49. Fogarty JD, Hafron JM, Melman A. Renal obstruction caused by herniation of renal pelvis and ureteropelvic junction through superior lumbar triangle hernia (Grynfeltt hernia). Urology 2006;67(3):620-621.

50. Guillem P, Czarnecki E, Duval G, Bounoua F, Fontaine C. Lumbar hernia: anatomical route assessed by computed tomography. Surg Radiol Anat SRA 2002;24(1):53-56.

51. Hafner CD, Wylie JH Jr, Brush BE. Petit's lumbar hernia: repair with Marlex mesh. Arch Surg 1963; 86:180-186. 
52. Heniford BT, lannitti DA, Gagner M. Laparoscopic inferior and superior lumbar hernia repair. Arch Surg 1997;132(10):1141-1144.

53. Hide IG, Pike EE, Uberoi R. Lumbar hernia: a rare cause of large bowel obstruction. Postgrad Med J 1999;75(882):231-232/

54. Horovitz IL, Schwarz HA, Dehan A. A lumbar hernia presenting as an obstructing lesion of the colon. Dis Colon Rectum 1986;29(11):742-744.

55. Ipek T, Eyuboglu E, Aydingoz O. Laparoscopic management of inferior lumbar hernia (Petit triangle hernia). Hernia 2005;9(2):184-187.

56. Kim DJ, Park JW. A rare nonincisional lateral abdominal wall hernia. Ann Surg Treat Res 2015;88(2): 111-113.

57. Lai SW, Chen KY. Lumbar hernia of Grynfeltt's triangle. Indian J Med Res 2015;141(6):844.

58. Lau H, Lee F. Mesh plug hernioplasty of superior lumbar hernia. Ann Coll Surg Hong Kong 2002;6(1): 25-27.

59. Lawdahl RB, Moss CN, Van Dyke JA. Inferior lumbar (Petit's) hernia. AJR Am J Roentgenol $1986 ; 147(4): 744-745$.

60. Lichtenstein IL. Repair of large diffuse lumbar hernias by an extraperitoneal binder technique. Am J Surg 1986;151(4):501-504.

61. Luo $\mathrm{P}, \mathrm{He} X \mathrm{XW}$, Chen QY, Hong H, Yang L. Femoral intertrochanteric fracture with spontaneous lumbar hernia: a case report. Trauma Mon 2016;21(5):e25132.

62. Mingolla GP, Amelio G. Lumbar hernia misdiagnosed as a subcutaneous lipoma: a case report. J Med Case Rep 2009;3:9322.

63. Mismar A, Al-Ardah M, Albsoul N, Younes N. Underlay mesh repair for spontaneous lumbar hernia. Int J Surg Case Rep 2013;4(6):534-536.

64. Naidoo M, Singh B, Ramsaroop L, Satyapal KS. Inferior lumbar triangle hernia: case report. East Afr Med J 2003;80(5):277-280.

65. Nam SY, Kee SK, Kim JO. Laparoscopic transabdominal extraperitoneal mesh repair of lumbar hernia. J Korean Surg Soc 2011;81(Suppl 1):S74-S77.

66. Ng SS, Ng NC, Liu SY, Lee JF. Radiology for the surgeon. Soft-tissue case 58: incarcerated Grynfeltt hernia. Can J Surg 2006;49(2):129-130.

67. Pachani $A B$, Reza A, Jadhav RV, Mathews S. A primary idiopathic superior lumbar triangle hernia with congenital right scoliosis: a rare clinical presentation and management. Int J Appl Basic Med Res 2011;1(1):60-62.

68. Pitale A, Laughlin V. Superior lumbar hernia of Grynfellt. Postgrad Med J 2002;78(922):472.

69. Ploneda-Valencia CF, Cordero-Estrada E, Castaneda-Gonzalez LG, Sainz-Escarrega VH, Varela-Munoz O, De la Cerda-Trujillo LF et al. Grynfelt-Lesshaft hernia a case report and review of the literature. Ann Med Surg (Lond) 2016;7:104-106.

70. Rehman S, Rooh-ul-Muqim RH, Hassan R, Zarin M, Wazir MA, Aurangzeb M. Inferior lumbar hernia of Petit in a patient with neurofibromatosis type-1. Pak J Med Sci 2009;25(6):1015-1017.

71. Sharma P. Lumbar hernia. Med J Armed Forces India 2009;65(2):178-179.

72. Shiiki S, Kuwata Y, Kashihara E, Ueda U, Fuchimoto S, Orita K. A case of superior lumbar hernia. Jpn J Surg 1991;21(6):696-699.

73. Skrekas G, Stafyla VK, Papalois VE. A Grynfeltt hernia: report of a case. Hernia 2005;9(2):188-191.

74. Sofiene A, Amin M, Baraket O, Houcine M, Daghfous A, Rebai $W$ et al. Computed tomography demonstration of an incarcerated lumbur hernia. La Tunisie Med 2013;91(10):614.

75. Solaini L, di Francesco F, Gourgiotis S, Solaini L. A very simple technique to repair Grynfeltt-Lesshaft hernia. Hernia 2010;14(4):439-441.

76. Sundaramurthy S, Suresh HB, Anirudh AV, Rozario AP (2016) Primary lumbar hernia: a rarely encountered hernia. Int J Surg Case Rep 20:53-56

77. Tsujino T, Inamoto T, Matsunaga T, Uchimoto T, Saito K, Takai T et al. Idiopathic lumbar hernia: a case report. [Japanese]. Hinyokika kiyo. Acta Urol Jpn 2015;61(11):449-453.

78. Uei T, Suzuki K, Nakano K, Kurokawa K, Fukabori Y, Yamanaka H. Usefulness of magnetic resonance imaging for the diagnosis of superior lumbar hernia: a case report. [Japanese]. Hinyokika kiyo. Acta Urol Jpn 1999;45(12):839-842. 
79. Walgamage TB, Ramesh BS, Alsawafi Y. Case report and review of lumbar hernia. Int J Surg Case Rep 2015;6C(1):230-232.

80. Wei CT, Chen YS, Sun CK, Hsieh KC. Single-incision laparoscopic total extraperitoneal repair for a Grynfeltt hernia: a case report. J Med Case Rep 2014;8(16):16.

81. Witherspoon J, Chakravartty S, Parry CR, Williams GL, Stephenson BM. Open sutureless lumbar hernia repair using a 'memory ring' patch. Hernia 2012;16(2):227-228.

82. $\mathrm{Xu} \mathrm{T}$, Zhang $\mathrm{S}$, Wang $\mathrm{H}, \mathrm{Yu}$ W. Lumbar hernia associated with chronic obstructive pulmonary disease (COPD). Pak J Med Sci 2013;29(3):874-876.

83. Yamaguchi S, Tsutsumi N, Kusumoto E, Endo K, Ikejiri K, Yamashita Y et al. Lumbar hernia treated with lightweight partially absorbable mesh: report of a case. Fukuoka Igaku Zasshi 2013;104(12):575-579.

84. Zadeh JR, Buicko JL, Patel C, Kozol R, Lopez-Viego MA. Grynfeltt Hernia: a deceptive lumbar mass with a lipoma-like presentation. Case Rep Surg 2015;2015:954804.

85. Claus CMP, Nassif LT, Aguilera YS, Ramos EB, Coelho JCU. Laparoscopic repair of lumbar hernia (Grynfelt): technical description. Arq Bras Cir Dig 2017;30(1):56-59.

86. Beffa LR, Margiotta AL, Carbonell AM. Flank and Lumbar hernia repair. Surg Clin N Am 2018;98(3): 593-605.

87. Macchi V, Porzionato A, Morra A, Picardi EE, Stecco C, Loukas M et al. The triangles of Grynfeltt and Petit and the Lumbar tunnel: an anatomo-radiologic study. Hernia 2016;21:369-376. 


\title{
Chapter 7
}

Internal herniation of the abdominal wall

\author{
Bloemen A \\ Keijzers MJ \\ Konsten JLM \\ Aarts $\mathrm{F}$ \\ Vogelaar FJ
}

Clinical Case Reports. 2019;7:575-576 



\section{Question}

A 79 year old male undergoes exploratory laparoscopy because of an obstructive ileus with suspected incarcerated ventral hernia on CT-scan of the abdomen (Figure 7.1). Intra-operative findings are shown in Figure 7.2.

Which type of anatomical variation was found?

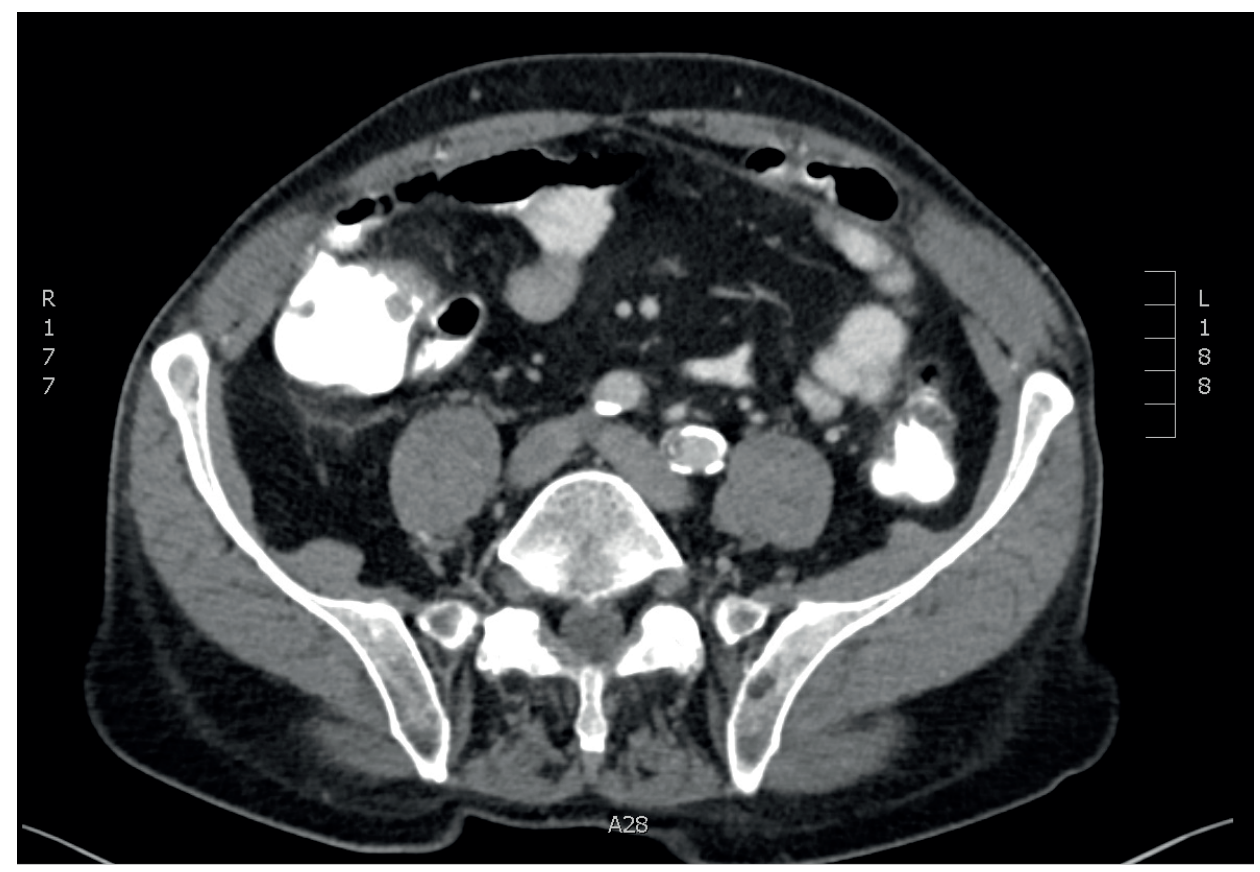

Figure 7.1 Transversal image of CT-scan of the abdomen. 


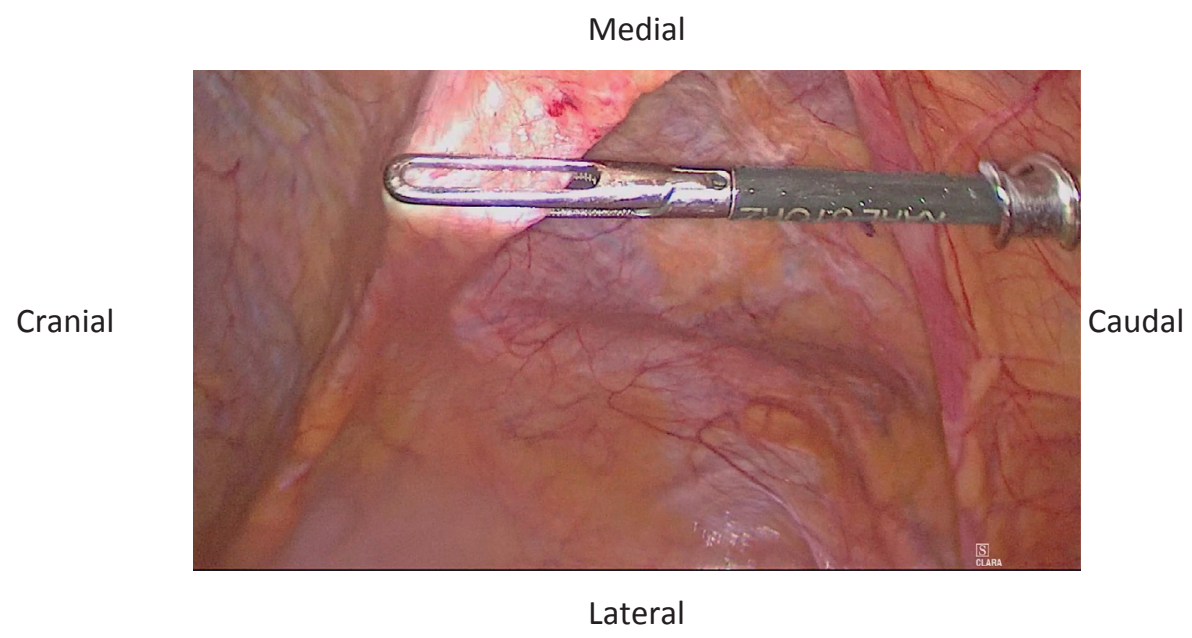

Figure 7.2 Intra-operative findings during laparoscopy.

\section{Answer}

An arcuate line hernia was found. Arcuate line hernias are rare internal herniations caused by a sharp end of the posterior aponeurotic sheath of the rectus muscle, rather than the more common gradual delineation of the sheath. A peritoneal fold with duplication behind this aponeurotic rim may form, creating an internal herniation. 


\section{References}

1. Coulier B. Multidetector computed tomography features of linea arcuate (arcuate-line of Douglas) and linea arcuate hernias. Surg Radiol Anat. 2007;29(5):397-403.

2. Montgomery A, Petersson U, Austrums E. The arcuate line hernia: operative treatment and a review of the literature. Hernia. 2013;17:391-396. 



\section{Chapter 8}

Incidence of arcuate line hernia in patients with abdominal complaints: radiological and

clinical features

Bloemen A

Kranendonk J

Sassen $\mathrm{S}$

Bouvy N

Aarts $\mathrm{F}$

Hernia. 2019;23:1199-1203 


\section{Abstract}

\section{Introduction}

Acute abdominal complaints are a frequent cause for consultation in the emergency department, with a large differential diagnosis. One cause is arcuate line herniation, but this entity is little known and rarely considered during initial analysis. The incidence of arcuate line herniation in this population is unknown.

\section{Methods}

A retrospective cohort study was performed. All patients who presented to the emergency department for surgical consultation during an 18-month period with abdominal complaints in who no diagnosis was found after analysis, and who had computed tomography imaging of the abdomen were included. CT-scans were reviewed with focus on abdominal wall pathology and correlated with clinical features.

\section{Results}

810 patients presented with abdominal complaints, 415 of these had CT-scans available for review and were included in the study. In 47 patients (11.3\%) an arcuate line anomaly was found and in 14 patients (3.4\%) a frank arcuate line herniation (grade 2 or 3) was found. Retrospective correlation with clinical complaints was found in $50 \%$ of these patients. Patients with arcuate line hernia had a significantly higher BMI and diabetes mellitus and aortic aneurysm were more prevalent in these patients.

\section{Conclusion}

Arcuate line herniation has a higher incidence than previously thought in patients with acute abdominal complaints and should be considered when evaluating these patients. 


\section{Introduction}

One of the most frequent reasons for visiting an emergency department in the Netherlands is the acute onset of abdominal complaints. According to the Dutch Central Statistics Agency, each year approximately 110000 patients visit an emergency department in the Netherlands for this reason. ${ }^{1}$

The differential diagnosis of acute abdominal complaints is multiple and a definite diagnosis is not always found during analysis in the emergency department or during outpatient follow-up. With reason, most attention goes to intra-abdominal diagnoses that may need urgent intervention such as acute appendicitis, diverticulitis or cholecystitis. More rare clinical entities that cause abdominal pain may be overlooked during initial and subsequent analysis. One such diagnosis is the arcuate line hernia, which can cause strangulation or incarceration of abdominal contents, with potentially life-threatening consequences. The arcuate line hernia is an internal herniation of abdominal contents in the lower abdominal wall due to a sharp ending of the posterior aponeurotic sheath of the rectus muscle (the semi-circular or arcuate line, also known as Douglas' line), rather than the more common gradual delineation of the posterior aponeurotic sheath (Figure 8.1).

Literature about arcuate line hernia is sparse and consists mostly of case reports. ${ }^{2-8}$ Based on these case-reports, arcuate line hernia appears to have a very low incidence. In patients presenting to the emergency department with acute abdominal complaints, this incidence may be higher. To the authors' best knowledge, this has not been previously investigated or reported. Therefore, a retrospective non-randomised cohort study was performed to investigate the incidence of arcuate line hernias in patients presenting with abdominal complaints in which no definite diagnosis was found after analysis.

\section{Methods}

All patients with acute abdominal complaints who were referred during an 18-month period (July 2017- December 2018) to the surgical department of the VieCuri Medical Centre, a teaching hospital in the Netherlands, were selected for inclusion in the study. If a definite diagnosis was found during initial analysis at the emergency department or subsequent outpatient follow-up, the patient was excluded from the study. The relevant patients were extracted from the electronic patient database using the billingcode 'other abdominal complaints'. Patients who had received a computed tomography scan (CT-scan) of the abdomen during work-up of the current complaints or during the 
last five years were included in the final analysis. CT-colonographies, -intravenous pyelography's and -angiography's were also included in the analysis. All patients were scanned with a 128-row multidetector CT (Somaton definition AS, Siemens, Germany). The collimation was $128 \times 0.5 \mathrm{~mm}$ with a pitch comprised between 0.35 and 1.5. Transversal and coronal reconstructions were created using Syngo.via software (Siemens, Germany)

A

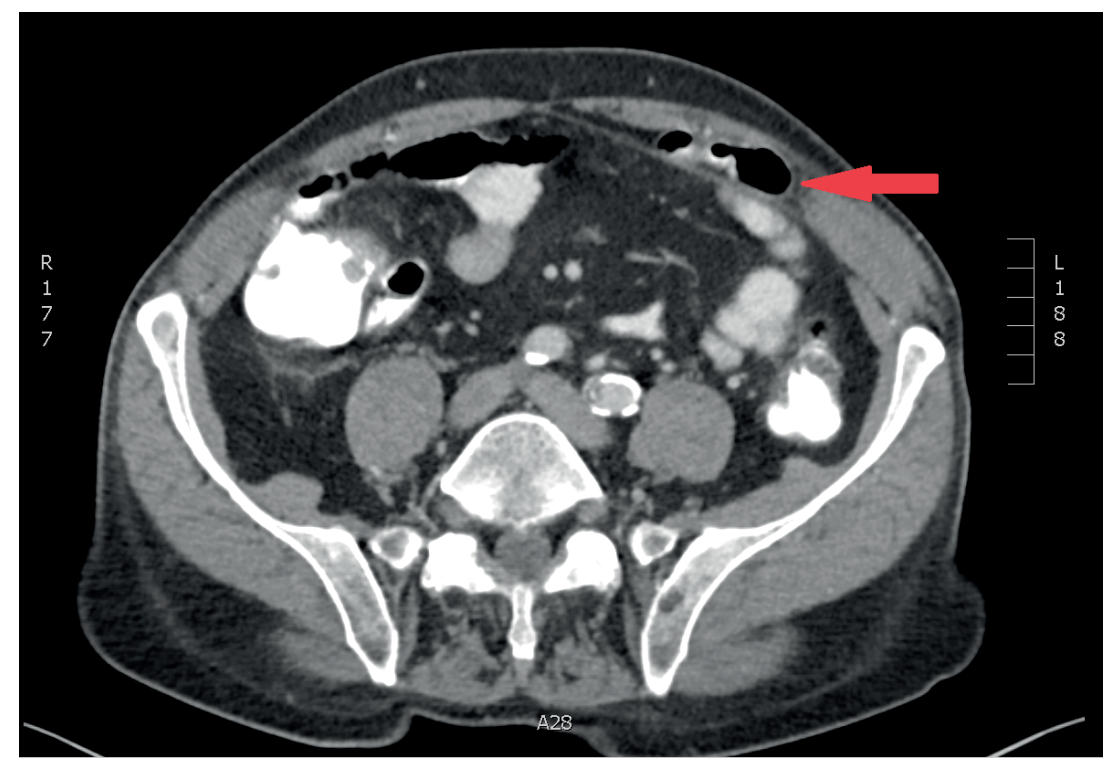

B

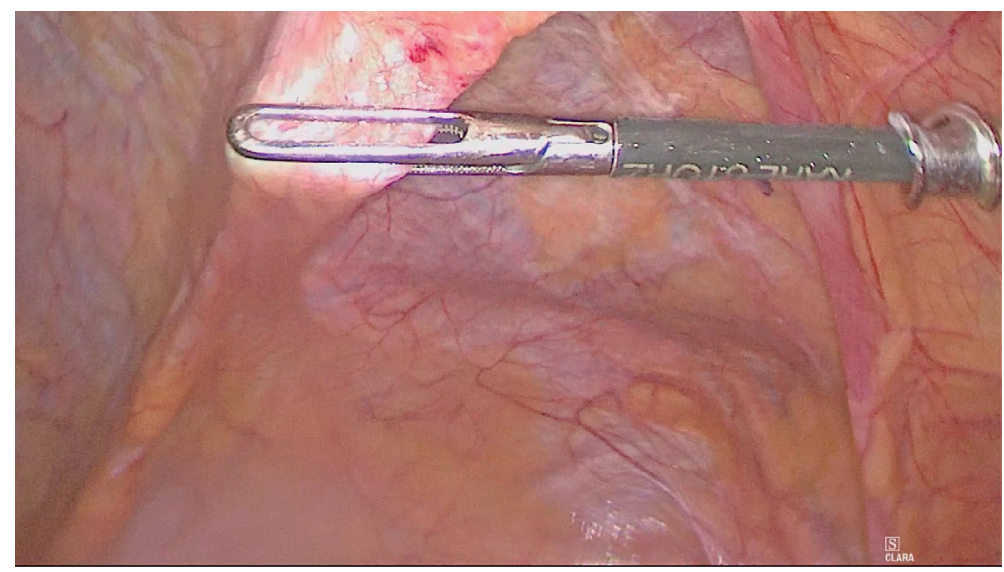

Figure 8.1 
The images were reviewed on a high-resolution 20.1 inch LCD monitor (MDRC-2120, Barco, Belgium).

The abdominal CT-scans were retrospectively reviewed and analysed for abdominal wall pathology with emphasis on arcuate line abnormalities. Arcuate line herniation was classified as previously described by Coulier: a delineation of the arcuate line with minimal bulging of intraperitoneal fat was classified as grade 1 (G1). Grade 2 (G2) herniation was defined as a minimal but substantial real herniation of fat and/or intestinal loops under the linea arcuata. Grade 3 (G3) was defined as a clear prominent herniation of abdominal structures (omental fat and/or bowel). ${ }^{9}$ Grade 2 and grade 3 were considered proper arcuate line hernias and grouped together. CT-scans were reviewed by the first author and any detected abdominal wall herniation was verified by a radiologist and surgeon, all of whom have special interest in abdominal wall pathology.

A retrospective correlation with the presented complaints was performed in patients with a detected arcuate line herniation. Charts were reviewed for known risk factors for development of abdominal wall hernias such as BMI, smoking, chronic obstructive pulmonary disease, aneurysm of the abdominal aorta, steroid usage, diabetes mellitus or presence of connective tissue diseases. Comparative statistical analysis using Student's T-test and chi-square test was performed of these factors to detect differences in these factors between patients with and without arcuate line herniation. A $P$-value of $<0.05$ was considered statistically significant.

Statistical analysis was performed using the SPSS software package ${ }^{\circledR}$, version 22 for Windows (SPSS Inc., Chicago, IL, USA).

In accordance with the Dutch Medical Research Act (Wet Medisch-wetenschappelijk Onderzoek), no approval of the ethics committee was needed, as this was a observational retrospective study.

\section{Results}

810 patients presented with abdominal complaints during the period from July $1^{\text {st }} 2017$ till December 31st 2018. No definite diagnosis was found at initial and subsequent analysis and these patients were billed as 'other abdominal complaints'. Of these patients, 415 had had a CT-scan in the last five years. The patient characteristics are listed in Table 8.1. 261 patients (63\%) were female and the other 154 (37\%) were male. Median age was 55 years (range 18-93 years). 
Table 8.1 Characteristics of included patients. Percentages are rounded at the fist decimal, ranges are reported in brackets.

\begin{tabular}{|c|c|c|c|}
\hline & $\begin{array}{c}\text { No arcuate line } \\
\text { abnormality found } \\
(n=368)\end{array}$ & $\begin{array}{c}\text { Arcuate line hernia } \\
\text { found } \\
(n=47)\end{array}$ & $P$-value \\
\hline Mean age in years & $54.1[18-93]$ & $60.9[20-88]$ & NS \\
\hline Mean Body Mass Index (kg/m^2) & $26.8[14.1-55.4]$ & $29.0[16.8-51.1]$ & 0.049 \\
\hline \multicolumn{4}{|l|}{ Gender } \\
\hline - male & $131(35.6)$ & $22(46.8)$ & NS \\
\hline - female & $237(64.4)$ & $25(53.2)$ & \\
\hline (past) Smoking & & & NS \\
\hline - yes & $138(37,5)$ & $21(44.7)$ & \\
\hline- no & $155(42.1)$ & $23(48.9)$ & \\
\hline - unknown & $75(20.4)$ & $3(6.4)$ & \\
\hline \multicolumn{4}{|l|}{ Diabetes Mellitus } \\
\hline - yes & $38(10.3)$ & $10(21.3)$ & 0.01 \\
\hline- no & $33(89.7)$ & $37(78.7)$ & \\
\hline \multicolumn{4}{|l|}{ Corticosteroid use } \\
\hline - yes & $14(3.8)$ & $6(12.8)$ & NS \\
\hline- no & $354(96.2)$ & $41(81.7)$ & \\
\hline \multicolumn{4}{|c|}{ Chronic obstructive pulmonary disease } \\
\hline - yes & $22(6.0)$ & $5(10.6)$ & NS \\
\hline- no & $346(94.0)$ & $42(89.4)$ & \\
\hline \multicolumn{4}{|l|}{ Aneurysm of abdominal aorta } \\
\hline - yes & $7(1.9)$ & $5(10.6)$ & 0.003 \\
\hline- no & $361(98.1)$ & $42(89.4)$ & \\
\hline \multicolumn{4}{|l|}{ Connective tissue disease } \\
\hline - yes & $3(0.8)$ & $1(2.1)$ & NS \\
\hline- no & $365(99.2)$ & $46(97.9)$ & \\
\hline
\end{tabular}

NS=not significant.

After analysis of the CT-scans, an arcuate line abnormality was found in 47 patients (11.3\%). The characteristics of these patients and hernias are described in Table 8.1 and 8.2. Grade 2 or 3 arcuate line hernia was found in 14 patients (3.4\%). No incarcerated arcuate line hernias were found. Patients with arcuate line herniation were found to have a significantly higher BMI, when compared to patients without arcuate line herniation. Diabetes mellitus and the presence of an aneurysm of the abdominal aorta were also seen more often in patients with arcuate line hernias. Arcuate line abnormality was equally divided among men and women and both the left and the right side were affected in the same frequency.

A bilateral arcuate line abnormality was found in 13 patients $(27.7 \%$ of patients with arcuate line abnormality) and in 4 patients (8.5\%) the bilateral abnormality was grade 2 or 3. 
Table 8.2 Characteristics of arcuate line herniations found. Percentages are rounded at the first decimal place.

\begin{tabular}{lrrr}
\hline & Grade 1 $(\mathrm{n}=33)$ & Grade 2 and 3 $(\mathrm{n}=14)$ & Total $(\mathrm{n}=47)$ \\
\hline Affected side & & & \\
- left & $13(39.4)$ & $5(35.7)$ & $18(38,3)$ \\
- right & $11(33.3)$ & $5(35.7)$ & $16(34.0)$ \\
- both & $9(27.3)$ & $4(28.6)$ & $13(27.7)$ \\
Complaints at arcuate line present & $12(36.4)$ & $7(50.0)$ & $19(40.4)$ \\
\hline
\end{tabular}

In addition to the detected arcuate line abnormalities, 12 (2.9\%) other abdominal wall herniations were found. These herniations varied from inguinal and femoral hernias to parastomal, incisional and lumbar hernias. No Spigelian or posterior rectus sheath hernias were found in this study.

Neither the treating physicians nor the involved radiologists considered arcuate line herniation in their differential diagnosis nor described any abnormal arcuate line anatomy in their reports at the time of presentation in the emergency department.

19 patients (4.6\%) had both an abnormal arcuate line anatomy and clinical complaints, such as pain or bulging at review of the charts in the context of the present study, which is $40.4 \%$ of all patients in who an arcuate line abnormality was detected. When looking specifically at grade 2 or 3 arcuate line hernias, 7 of these were found to correlate with clinical complaints (1.7\%), which is half of the 14 patients in who a grade 2 or 3 arcuate line hernia was detected.

\section{Discussion}

This is the largest retrospective cohort study on the incidence of arcuate line hernia to date. We found that in a population presenting with abdominal complaints the incidence of arcuate line abnormality (G1, G2 or G3) is $11.3 \%$. The percentage of detected arcuate line hernias (G2 or G3; 3.4\%) is almost double that of an earlier retrospective review of 315 random CT-scans of the abdomen by Coulier. In his series, arcuate line delineation was found in $8.57 \%$ and actual arcuate line herniation in $1.62 \%$ of the patients analysed. ${ }^{9}$

This higher incidence may be explained by improvements in imaging or changes in patient characteristics since publication of the previous manuscript in 2007.

Coulier analysed random patients, using a 64 row multidetector CT with a slice width of $0.65 \mathrm{~mm}$, whereas in the current study patients with abdominal complaints were included and a 128 row multidetector CT was used with a slice width of $0.5 \mathrm{~mm}$. This 
improved imaging in a selected patient population may increase diagnostic accuracy for detection of abdominal wall abnormalities.

Notable is that in this cohort, several patient characteristics were significantly different between patients with and without arcuate line hernias. A significantly higher BMI was found in patients with arcuate line hernias, as well as more diabetes mellitus and more abdominal aortic aneurysms. This implies that an impaired connective tissue turnover and obesity could have a role in the development of arcuate line herniation, as has previously been reported in other types of abdominal wall hernias, such as by Pans et al. in inguinal hernias. ${ }^{10}$

A comparison with the earlier series by Coulier is not possible, since these patient characteristics are unknown in that cohort. An intentional selection bias occurred in this study: we sought to identify clinically relevant arcuate line hernias and therefore only included patients presenting to the emergency department with abdominal complaints with available CT-scans and without alternative diagnosis.

In this series, the incidence of symptomatic arcuate line hernias was $4.6 \%$. This low incidence may explain unfamiliarity of physicians with the arcuate line hernia. The relative obscurity of arcuate line hernias is illustrated by the fact that neither the treating physicians nor the radiologists considered or recognized arcuate line anomalies in this study at initial presentation. It should be noted that no incarcerated arcuate line hernias were found in the study: detection of a significant arcuate line hernia with incarcerated bowel loop would be harder to miss by radiologists or surgeons reviewing a CT scan of a patient presenting with an acute abdomen due to secondary signs of ileus.

The arcuate line hernia may be difficult to diagnose during clinical examination, since no visible bulges may be present. Assessments of abdominal CT-scans with focus on the abdominal wall decreases likelihood of overlooking relevant abnormalities and should therefore be encouraged.

The low percentage of symptomatic arcuate line herniations can be explained by anatomical considerations:

Contrary to other types of abdominal wall hernias, the hernia orifice of arcuate line hernia is very wide. The orifice of arcuate line hernia was described by Montgomery et al. as "the top of a mitten", rather than the orifice of other hernias like incisional or umbilical hernias, which can be described as the stem of a mushroom. ${ }^{2}$ This wide orifice makes incarceration of contents more unlikely, as abdominal organs easily move in and out of the hernia.

The anatomy of the arcuate line illustrates the wide orifice: in the supra-umbilical and part of the infra-umbilical abdominal wall the rectus abdominis muscle is covered on 
the dorsal side by a plate of aponeurotic tissue which is formed by the fascia transversalis and posterior lamina of the internal oblique muscle. Somewhere between the umbilicus and pubic bone the posterior lamina of the internal oblique muscle joins the anterior lamina on the ventral side of the rectus muscle, leaving only the transversus fascia on the dorsal side with minimal strength. This level is called the arcuate or semicircular line. This level is variable. Some cadaveric studies found the arcuate line in $75 \%$ of cases below the umbilicus. ${ }^{11,12}$ Others found the arcuate line below the umbilicus in all cases. ${ }^{13,14}$ Likewise, the delineation in cadaveric studies was variable with the cessation of posterior fascia being gradual in $65-85 \%$ of cases and in $5-10 \%$ a pronounced fascial thickening or rim was seen at the end. Behind this rim a peritoneal fold may develop, which gives rise to the arcuate line hernia. Because the arcuate line includes the whole ventral abdominal wall, the hernia orifice of an arcuate line hernia may be just as wide.

The unfamiliarity of arcuate line hernia may also lead to confusion with other types of abdominal wall herniations such as Spigelian hernia or a posterior rectus sheath hernia. Both can present as an internal herniation that can arise at the same location as the arcuate line hernia. In the Spigelian hernia, abdominal contents protrude through a weakness between the lateral aponeurosis of the rectusfascia medially and the semilunar line laterally. The posterior rectus sheath hernia is an internal herniation through a congenital or acquired defect in the posterior rectus fascia and can arise at the semicircular line, but also other locations of the rectus fascia. ${ }^{15}$ In this study, neither of these hernia types were encountered, despite careful scrutiny of the CT-scans by three investigators. One explanation for this absence could be that these hernias were previously recognized by the treating surgeon and evaluating radiologist and were consequently not billed as 'other abdominal complaints' and therefore not included in this cohort.

Earlier literature on treatment of arcuate line hernia is limited. According to the surgeon's experience and preference, an open or endoscopic reduction of the hernia may be performed with mesh augmentation of the abdominal wall to prevent recurrence. Based on review of reported case reports, Montgomery et al. suggest a transabdominal laparoscopic approach in which the mesh is placed in the preperitoneal space after dissecting the peritoneum off the hernia sac. Afterwards, the peritoneum is closed over the mesh and defect and fixated with either tackers or sutures. ${ }^{2}$ Mesh augmentation of the defect is recommended to prevent early recurrence. The laparoscopic approach with preperitoneal mesh placement offers the surgeon the opportunity to inspect the viability of hernia contents while minimising risk of future 
adhesion formation by covering the mesh with peritoneum. If the peritoneum is insufficient to cover the mesh, an intraperitoneal onlay composite mesh (IPOM) can be considered as an alternative, although at the moment no intraabdominally placed mesh, coated or otherwise, has been proven to be free of risk of adhesion formation or bowel injury and erosions. All patients described in the review by Montgomery had no signs or recurrence or complaints at follow-up, which varied from 3.5 to 19 months after surgery.

While the absolute incidence of arcuate line anomalies in this study remains relatively low, the results illustrate the importance of clinical awareness of this entity when considering the patient presenting with abdominal pain. As stated by Scheltinga in a recent review on the Abdominal Cuteneous Nerve Entrapment Syndrome (ACNES): a 'visceral' focus during analysis of a patient with abdominal complaints may overlook an abdominal wall cause of the complaints, such as ACNES or abdominal myofascial pain syndrome. ${ }^{16}$ Arcuate line hernias may well be added to this list.

In this study $40.4 \%$ of patients with arcuate line abnormality had a clinical correlation with their complaints. In grade 2 or 3 herniations this correlation was found in $50 \%$ of patients. This poor correlation underlines the importance of careful patient selection for operative repair of arcuate line hernia.

\section{Conclusion}

Arcuate line delineation is found in $11.4 \%$ presenting with acute abdominal complaints. In $3.4 \%$ of these patients, an arcuate line herniation is found and a clinical correlation was found in half of these patients. In these patients, hernia reduction with (preperitoneal) mesh augmentation can be considered. 


\section{References}

1. Centraal Bureau voor Statistiek. SEH contacten gebaseerd op het DIS, 2012. Centraal Bureau voor Statistiek 2016. https://www.cbs.nl/nl-nl/maatwerk/2016/26/seh-contacten-gebaseerd-op-het-dis2012-. Accessed 13 March 2019.

2. Montgomery A, Petersson U, Austrums E. The arcuate line hernia: Operative treatment and a review of the literature. Hernia 2013;17:391-396.

3. Cappeliez O, Duez V, Alle JL, Leclercq F. Bilateral arcuate-line hernia. Am J Roentgenol 2003;180: 864-865.

4. Von Meyenfeldt EM, Van Keulen EM, Eerenberg JP, Hendriks ER. The linea arcuata hernia: A report of two cases. Hernia 2010;14:207-209.

5. Abasbassi M, Hendrickx T, Caluwé G, Cheyns P. Symptomatic linea arcuata hernia. Hernia 2011;15: 229-231.

6. Coulier B. Bilateral arcuate line hernia featuring the "ladybug's elytra" sign. Diagn Interv Imaging 2019; 100:387-388.

7. Messaoudi N, Amajoud Z, Mahieu G, Bestman R, Pauli S, Cleemput M Van. Laparoscopic arcuate line hernia repair. Surg Laparosc Endosc Percutan Tech 2014;24:e110-e112.

8. Siddique K, Slaven K, Samad A. Anterior abdominal wall "peritoneal recess": Cause for pseudoherniation of small bowel resulting in chronic abdominal pain. Ann R Coll Surg Engl 2013;95: e47-e49.

9. Coulier B. Multidetector computed tomography features of linea arcuata (arcuate-line of Douglas) and linea arcuata hernias. Surg Radiol Anat 2007;29:397-403.

10. Pans A, Pierard GE, Albert A. Immunohistochemical study of the rectus sheath and transversalis fascia in adult groin hernias. Hernia 1999;3:45-51.

11. Monkhouse WS, Khalique A. Variations in the composition of the human rectus sheath: a study of the anterior abdominal wall. J Anat 1986;145:61-66.

12. Rizk NN. The arcuate line of the rectus sheath--does it exist? J Anat 1991;175:1-6.

13. Cunningham SC, Rosson GD, Lee RH, Williams JZ, Lustman CA, Slezak S, et al. Localization of the arcuate line from surface anatomic landmarks: A cadaveric study. Ann Plast Surg 2004;53:129-131.

14. Loukas M, Myers C, Shah R, Tubbs RS, Wartmann C, Apaydin N, et al. Arcuate line of the rectus sheath: Clinical approach. Anat Sci Int 2008;83:140-144.

15. Mwachaka PM, Saidi HS, Odula PO, Awori KO, Kaisha WO. Locating the arcuate line of Douglas: Is it of surgical relevance? Clin Anat 2010;23:84-86.

16. Scheltinga MR, Roumen RM. Anterior cutaneous nerve entrapment syndrome (ACNES). Hernia 2018;22:507-516. 



\section{Chapter 9}

Discussion and future perspectives 

Abdominal wall hernias are a frequently occurring condition, which impair health and wellbeing of individual patients and the treatment of these hernias burdens available health care resources. This thesis discusses different types of abdominal wall hernias (incisional, parastomal, lumbar and arcuate line hernia) and different aspects of their prevention, diagnosis and treatment.

\section{Part A Prevention and treatment of iatrogenic abdominal wall hernias}

The first part of this thesis focuses on two frequently occurring types of acquired abdominal wall hernias: the incisional and parastomal hernia.

One of the most important risk factors for development of incisional hernia is the surgical technique used for closure after laparotomy. Unlike patient related factors, it is one of the few factors that can be influenced by the surgeon in order to decrease the incidence of incisional hernia. The body of current evidence for preventive strategies for incisional hernia is summarized in a guideline on abdominal wall closure by the European Hernia Society. A continuous, single layer suturing technique with a suture length to wound length (SL/WL) ratio at least $4: 1$, using a slowly absorbable monofilament suture with small fascial steps and bites and a self-locking knot appears to minimize the risk of incisional hernia development. ${ }^{1-5}$

Previously, little was known on the acceptance and implementation of this evidence. Chapter 2 discusses a survey among Dutch surgeons on this subject. The main findings were that surgeons do not universally adopt the recommendations of the guideline. Gastro-intestinal surgeons and surgeons employed in a university hospital are most likely to use the current best techniques. Risk factors for incisional hernia development are generally identified correctly but the correct incidence of incisional hernia was known by only $32 \%$ of participants. Earlier studies on implementation evidence on incisional hernia prevention found similar results. ${ }^{6-8}$

Since the latest guideline additional research has been published that further supports the small bites technique using a smaller suture size (2-0) and suggests using prophylactic mesh reinforcement in high risk patients. ${ }^{3,9,10}$ The technique was also found to be effective in emergency laparotomies by Tolstrup et al. ${ }^{11,12}$

These findings raise the question why such diversity in closure techniques persists in the face of increasing evidence in favor of these techniques. Several explanations can be considered: 
First, surgeons may be unaware of current best evidence. If this is the cause of lagging implementation, additional efforts to improve knowledge of the techniques should be made.

Second, a perception bias may also deter surgeons from using the techniques in two ways: if a surgeon has personal negative experience with a technique (i.e. a complication occurs when using the guideline), he or she may be dissuaded regardless of general evidence. On the other hand, a surgeon may not consider any change in technique necessary if no problems were encountered using the current technique. This may be the case with surgeons who perform laparotomies but do not treat abdominal wall hernias, such as vascular surgeons.

Third, the survey is by definition a snapshot of current practice; a shift in practice may have occurred since publication of the survey and a repeat of the survey would be of interest to investigate this.

Regardless of the reasons for not implementing current guidelines, the survey underscores that in order to improve surgical outcomes, performing and publishing scientific research is only the first step. 'Quality control'-studies that investigate implementation of this evidence are a necessary second step. If implementation lags behind the current evidence, measures should be taken to improve this.

In Chapter 3 the results of a randomized controlled trial are reported. The trial investigated one aspect of surgical technique in abdominal wall closure: the type of suture material used. The study found a trend in favour of Prolene as the total incidence of incisional hernia at the end of follow-up was higher in the PDS ${ }^{\circledR}$ group. This was also found in the Kaplan-Meier analysis performed. However, these findings were not statistically significant and no recommendation in favour of Prolene could be made. When fascial dehiscences are considered to be early incisional hernias, the trend in favour of Prolene became stronger but still did not reach significance.

Several meta-analyses on this subject with conflicting results had been published before the trial was conducted and, since publication, the Cochrane collaboration published a meta-analysis by Patel et al. ${ }^{13}$ The meta-analysis concluded that, although the methodological quality of the trial described in chapter 3 was found to be good, overall the body of evidence on the subject was of moderate quality, mainly due to heterogeneity in selected patient populations and examined techniques. No significant difference in incidence of incisional hernia was found between absorbable and nonabsorbable sutures.

It has been stated that the ideal suture material after laparotomy should prevent occurrence of an incisional hernia or wound dehiscence. ${ }^{14}$ This means that the ideal suture material should retain tensile strength during the postoperative period in which 
healing of the abdominal wall occurs. After this time, the suture material should dissolve or become inert in order to prevent problems such as suture sinus formation, adhesions or pain. The abdominal wall needs considerable time to recover strength after laparotomy: after 42 days, only $51-59 \%$ of it's original tensile strength is recovered. ${ }^{15,16}$

Since publication of the randomized trial two new suture materials have been introduced which may reduce incisional hernia rates: an ultra long term absorbable suture with high elasticity (Monomax) and a polypropylene mesh suture material (Duramesh ${ }^{\oplus}$ ). Albertsmeier et al. have prospectively evaluated the ultra long term absorbable material in a historical comparison with a slow absorbable suture material; no significant difference in incisional hernia was found. ${ }^{17} \mathrm{~A}$ second prospective study evaluating the Monomax suture is currently being performed by Fortelny et al. ${ }^{18}$

The mesh suture was found to have a greater wound breaking strength in an experimental setting. Dumanian et al. performed a clinical trial in patients with contaminated incisional hernia and found the mesh suture to be effective. ${ }^{19-21} \mathrm{~A}$ possible role for this material may be as an alternative for prophylactic mesh reinforcement in patients with increased risk of incisional hernia development.

Further research into improved suture materials for laparotomy closure is ongoing. New approaches, such as flax based materials and additional elastic sutures are being considered in animal experiments. ${ }^{22,23}$ Such research is very important to further decrease incidence of incisional hernia.

Chapter 4 evaluated a novel stoma appliance, designed for patients with parastomal hernias and peristomal skin complications. The appliance is a novel approach to improve quality of life for these patients and to decrease the financial burden that these complications place on the health care system. ${ }^{24}$

Until now, most attention in research for prevention and management of peristomal skin problems has been focused on the material of the flanges and on different barrier creams, lotions or sprays, which prevent the skin from coming into contact with the irritating stoma produce. ${ }^{25,26}$ One disadvantage of these products is that they invariably have to be fixated on the skin and subsequently removed. This risks damaging the peristomal skin due to mechanical friction or chemical injury. The TOMAS appliance is the first stoma system that negates this risk by omitting the need for application of adhesives and therefore the risk of skin injury.

A feasibility study on this new appliance was performed and found this appliance to be safe. The appliance was however uncomfortable for patients in its present form. In contrast, patients with parastomal hernias experienced high comfort and peristomal skin lesions improved during the study. These results suggest that the TOMAS appliance 
is well suited for (intermittent) use in patients with frequent leakage and peristomal skin complications, as the omission of applications and adhesives allows the peristomal skin to heal. Further research should focus on making the appliance more comfortable for patients.

\section{Part B Diagnosis and treatment of abdominal wall hernias}

Chapter 5 compares physical examination and ultrasonography for incisional hernia detection. We found that standardized ultrasonography in addition to physical examination during follow-up detects a significant number of additional incisional hernias. This is especially relevant in research settings.

This approach is less suited to the clinical setting where a step up diagnostic approach is more logical. Patients with a potential incisional hernia will usually be evaluated by physical examination first and will only need additional imaging if uncertainty persists or if pre-operative planning warrants this.

The incidence of incisional hernia in the literature is very variable and ranges from $3 \%$ to upwards of $20 \% .^{27-32}$ A lack of clear diagnostic criteria in the literature may contribute to this variety in reported incidences. In chapter 5 (and chapter 3), an incisional hernia was defined as any abdominal wall defect with a minimum diameter of one centimetre, with or without a hernial sac. This strict definition may have led to a high incidence of detected incisional hernia when compared to the abovementioned literature.

This lack of clear diagnostic criteria for diagnosis of incisional hernia was also noted by Kroese et al. in a recent systematic review on this subject. ${ }^{33}$ Uniform criteria for diagnosing incisional hernia in research settings would help in comparison and review of future studies. As shown in the present study, the combination of physical examination and ultrasonography would yield acceptable detection of incisional hernias in a research setting. In the clinical setting, this may obviate the need for CT scans, which use potentially harmful ionizing radiation. Beck et al. have described a standardized, surgeon performed, ultrasonography approach called DASH (Dynamic Abdominal Sonography for Hernia) which yielded high sensitivity (98\%) and specificity (88\%) for ventral hernia detection. ${ }^{34}$

CT scans will still play an important role in hernia surgery, because they offer additional information to the surgeon in the context of preoperative planning; CT scans allow evaluation of the contents of the hernia sac and an estimation of the percentage of the abdominal contents that have lost domain. This information is vital when determining the approach and technique for surgical repair of the incisional hernia and may help 
preoperative risk-assessment of complications. In a retrospective review of 65 complex ventral hernia repairs, Winters et al. found that increased visceral fat volume on preoperative CT scan was associated with a significantly higher risk of recurrence of the hernia and that increased subcutaneous fat and hernia sac volume was associated with a higher risk of surgical site infection. ${ }^{35}$

Primary lumbar hernias are rare and individual surgeons will have scarce experience with these hernias. Chapter 6 describes the first systematic review on primary lumbar hernias and makes evidence based practical and clinical recommendations and to identify pitfalls regarding diagnosis and treatment. Primary lumbar hernias are found to have a high risk of incarceration (30.8\%) and should therefore be surgically treated electively as early as possible and preferably by a surgeon with experience in the field of hernia surgery. A CT scan is warranted to assess the extent of the lumbar hernia, the involved anatomical structures, the level of atrophy, and the possible content of the hernia. A laparoscopic pre-peritoneal approach is preferable in small, simple primary lumbar hernias leaving the open approach for the complex cases. Robot assisted procedures have also been described. ${ }^{36}$ Based on the review no recommendations could be made regarding mesh augmentation versus primary closure of the defect. As is the case with groin hernia repair, surgeons should use the technique they are most familiar with. ${ }^{37}$ However, as also shown in inguinal hernia repair, primary tissue repair is associated with increased recurrence rates in inexperienced hands. In light of the low incidence of primary lumbar hernias, few surgeons will have ample experience in tissue repair of primary lumbar hernias and, in general, a mesh augmentation seems the best choice.

Chapters 7 and 8 discuss the arcuate line hernia. The, to date, largest retrospective cohort study on the incidence of arcuate line hernia is presented. In this cohort, the incidence of arcuate line hernias (3.4\%) is almost double than earlier described. ${ }^{38} \mathrm{~A}$ significantly higher BMI was found in patients with arcuate line hernias, as well as more diabetes mellitus and more abdominal aortic aneurysms. An impaired connective tissue turnover and obesity could therefore have a role in the development of arcuate line herniation. ${ }^{39-45}$

Arcuate line hernias were rarely symptomatic in the study, which explains unfamiliarity of physicians with the arcuate line hernia; neither the treating physicians nor the radiologists considered or recognized arcuate line anomalies in this study at initial presentation. Assessment of abdominal CT scans with focus on the abdominal wall decreases likelihood of overlooking relevant abnormalities and should therefore be encouraged. 
Based on review of reported case reports, Montgomery et al. suggest a transabdominal laparoscopic approach in which the mesh is placed in the preperitoneal space after dissecting the peritoneum off the hernia sac. Afterwards, the peritoneum is closed over the mesh and defect and fixated with either tackers or sutures. ${ }^{46}$ Mesh augmentation of the defect is recommended to prevent early recurrence. All patients described in the review by Montgomery had no signs or recurrence or complaints at follow-up, which varied from 3.5 to 19 months after surgery.

\section{Future perspectives}

Unfortunately, not all surgeons universally adopt the current best evidence. The current survey did not query surgeons on the reason for use of a particular technique. In order to develop strategies for improved implementation of best evidence techniques for incisional hernia prevention, future research should first identify why surgeons are reticent to adopt current best evidence.

Another potential avenue for prevention of incisional hernia formation is to modify the patient related factor: It has been known that patients with impaired collagen turnover are at increased risk of ventral hernia development. ${ }^{47}$ If these patients can be identified before surgery, preventative measures can be taken. Exhaled Volatile Organic Compounds, which are metabolic end-products, can be analyzed using an electronic nose or eNose, to detect a number of diseases. ${ }^{48}$ If the eNose could be modified to detect impaired collagen disease, this would offer a good non-invasive tool to identify these patients.

A recent randomized trial showed improved collagen synthesis in patients undergoing Lichtenstein inguinal hernia repair that received supplemental nutrients, when compared to those that did not. ${ }^{49}$ This may also offer benefits in incisional hernia prevention.

The results of chapter 3 suggest that, with regard to incisional hernias, no difference between non-absorbable and slow absorbable sutures exist. Research on suture materials for abdominal wall closure is ongoing. Mesh-type sutures and elastic sutures, as well as ultra slow-absorbable suture materials may offer improved results in incisional hernia prevention in the future.

The TOMAS stoma appliance was found to be a safe appliance in the feasibility study described in chapter 4 . In the future, the appliance will be developed further to increase patient comfort. Patients with parastomal hernias who are not eligible for surgical repair of the hernia (due to comorbidity or patient preferences) seem to be the 
best target population use of the TOMAS appliance. Further research is needed to determine the exact role in stoma care.

Chapter 5 identified the combination of physical examination with ultrasonography as a reliable method for detection of incisional hernias in research settings. Future studies may use this combination of modalities as an alternative for computed tomography scans that use potentially harmful ionizing radiation. Because of the increasing availability of handheld ultrasonography devices, this diagnostic modality, performed by surgeons rather than radiologists, may become an extension of the clinical examination. In fields such as head and neck surgery and emergency trauma assessments this trend is already seen. ${ }^{50-52}$ However, training and assessment of these specialists is important, because ultrasonography is used-dependent with a potentially large interobserver variability. ${ }^{53}$ In order to facilitate comparisons between studies, future research should also use clear and comparable definitions for incisional hernia diagnosis.

Chapters 6 to 8 concern primary lumbar hernias and arcuate line hernias, both relatively rare entities. More research is needed to optimize treatment of these entities. Centralizing care for these hernias would increase specialization and produce the volumes needed for adequate research. Furthermore, cooperation between specialized abdominal wall centers would increase the awareness of these entities. 


\section{References}

1. Bloemen A, Van Dooren P, Huizinga BF, Hoofwijk AGM. Randomized clinical trial comparing polypropylene or polydioxanone for midline abdominal wall closure. Br J Surg. 2011;98(5):633-639.

2. Israelsson LA, Millbourn D. Prevention of incisional hernias. How to close a midline incision. Vol. 93, Surgical Clinics of North America. 2013:1027-1040.

3. Deerenberg EB, Harlaar JJ, Steyerberg EW, Lont HE, Van Doorn HC, Heisterkamp J, et al. Small bites versus large bites for closure of abdominal midline incisions (STITCH): A double-blind, multicentre, randomised controlled trial. Lancet. 2015;386(10000):1254-1260.

4. Israelsson LA, Jonsson T. Physical properties of self locking and conventional surgical knots. Eur J Surg. 1994;160(6-7):323-327.

5. Muysoms FE, Antoniou SA, Bury K, Campanelli G, Conze J, Cuccurullo D, et al. European Hernia Society guidelines on the closure of abdominal wall incisions. Hernia. 2015;19(1):1-24.

6. Rahbari NN, Knebel P, Diener MK, Seidlmayer C, Ridwelski K, Stöltzing H, et al. Current practice of abdominal wall closure in elective surgery - Is there any consensus? BMC Surg. 2009;9:8. Available from: http://www.pubmedcentral.nih.gov/articlerender.fcgi?artid=2687428\&tool=pmcentrez\& rendertype= abstract

7. Pereira JA, Lopez-Cano M, Marsal F, Feliu X. [Results of a national survey on abdominal wall closure]. Cir Esp. 2013;91(10):645-650

8. Dabrowiecki S. [Abdominal wall closure techniques--the results of the Polish surgeons' survey]. Pol Merkur Lekarski. 2005;19(113):646-650.

9. Jairam AP, Timmermans L, Eker HH, Pierik REGJM, van Klaveren D, Steyerberg EW, et al. Prevention of incisional hernia with prophylactic onlay and sublay mesh reinforcement versus primary suture only in midline laparotomies (PRIMA): 2-year follow-up of a multicentre, double-blind, randomised controlled trial. Lancet (London, England). 2017;390(10094):567-576.

10. Muysoms FE, Detry O, Vierendeels T, Huyghe M, Miserez M, Ruppert M, et al. Prevention of incisional hernias by prophylactic meshaugmented reinforcement of midline laparotomies for abdominal aortic aneurysm treatment: A randomized controlled trial. Ann Surg. 2016;263(4):638-645.

11. Thorup T, Tolstrup MB, Gögenur I. Reduced rate of incisional hernia after standardized fascial closure in emergency laparotomy. Hernia. 2019;23(2):341-346.

12. Tolstrup MB, Watt SK, Gögenur I. Reduced rate of dehiscence after implementation of a standardized fascial closure technique in patients undergoing emergency laparotomy. Ann Surg. 2017;265(4): 821-826.

13. Patel S V., Paskar DD, Nelson RL, Vedula SS, Steele SR. Closure methods for laparotomy incisions for preventing incisional hernias and other wound complications. Cochrane Database of Systematic Reviews. 2017;11:CD005661.

14. van 't Riet M, Steyerberg EW, Nellensteyn J, Bonjer HJ, Jeekel J. Meta-analysis of techniques for closure of midline abdominal incisions. Br J Surg. 2002;89(11):1350-1356.

15. Douglas DM. The healing of aponeurotic incisions. Br J Surg. 1952;40(159):79-84.

16. Outlaw KK, Richard Vela A, Patrick O'Leary J. Breaking strength and diameter of absorbable sutures after in vivo exposure in the rat. Am Surg. 1998;64(4):348-354.

17. Albertsmeier M, Seiler CM, Fischer L, Baumann P, Hüsing J, Seidlmayer $C$, et al. Evaluation of the safety and efficacy of MonoMax ${ }^{\circledR}$ suture material for abdominal wall closure after primary midline laparotomy - A controlled prospective multicentre trial: ISSAAC [NCT005725079]. Langenbeck's Arch Surg. 2012; 397(3):363-371.

18. Fortelny RH, Baumann P, Thasler WE, Albertsmeier M, Riedl S, Steurer W, et al. Effect of suture technique on the occurrence of incisional hernia after elective midline abdominal wall closure: Study protocol for a randomized controlled trial. Trials. 2015;16:52.

19. Dumanian GA, Tulaimat A, Dumanian ZP. Experimental study of the characteristics of a novel mesh suture. Br J Surg. 2015;102(10):1285-92.

20. Dumanian GA, Lanier ST, Souza JM, Young MW, Mlodinow AS, Boller AM, et al. Mesh sutured repairs of contaminated incisional hernias. Am J Surg. 2018;216(2):267-273. 
21. Lanier ST, Dumanian GA, Jordan SW, Miller KR, Ali NA, Stock SR. Mesh sutured repairs of abdominal wall defects. Plast Reconstr Surg - Glob Open. 2016;4(9):e1060.

22. Lambertz A, Vogels RRM, Busch D, Schuster P, Övel SJ, Neumann UP, et al. Laparotomy closure using an elastic suture: A promising approach. J Biomed Mater Res - Part B Appl Biomater. 2015;103(2):417-23.

23. Michel SA, Vogels RR, Bouvy ND, Knetsch ML, van den Akker NM, Gijbels MJ, van der Marel C, Vermeersch J, Molin DG, Koole LH. Utilization of flax fibers for biomedical applications. Journal of Biomedical Materials Research - Part B Applied Biomaterials. 2014;102(3):477-487.

24. Taneja C, Netsch D, Rolstad BS, Inglese G, Eaves D, Oster G. Risk and Economic Burden of Peristomal Skin Complications Following Ostomy Surgery. J wound, ostomy, Cont Nurs Off Publ Wound, Ostomy Cont Nurses Soc. 2019;46(2):143-149.

25. Black P. Peristomal skin care: an overview of available products. Br J Nurs. 2 2007;16(17):1048, 1050, 1052-4 passim.

26. Tam K-W, Lai J-H, Chen H-C, Hou W-H, Ko W-S, Chen S-L, et al. A systematic review and meta-analysis of randomized controlled trials comparing interventions for peristomal skin care. Ostomy Wound Manage. 2014;60(10):26-33.

27. Hodgson NCF, Malthaner RA, $\varnothing$ stbye T. The search for an ideal method of abdominal fascial closure: $A$ meta- analysis. Ann Surg. 2000;231(3):436-442.

28. Kingsnorth A, LeBlanc K. Hernias: Inguinal and incisional. In: Lancet. 2003;362(9395):1561-71.

29. Höer J, Lawong G, Klinge U, Schumpelick V. Factors influencing the development of incisional hernia. A retrospective study of 2,983 laparotomy patients over a period of 10 years. Der Chir. 2002;73(5): 474-480.

30. Osther PJ, Gjøde P, Mortensen BB, Mortensen PB, Bartholin J, Gottrup F. Randomized comparison of polyglycolic acid and polyglyconate sutures for abdominal fascial closure after laparotomy in patients with suspected impaired wound healing. Br J Surg. 1995;82(8):1080-1082.

31. Bosanquet DC, Ansell J, Abdelrahman T, Cornish J, Harries R, Stimpson A, et al. Systematic review and meta-regression of factors affecting midline Incisional hernia rates: Analysis of 14618 Patients. PLoS ONE. 2015;10(9):e0138745.

32. Israelsson LA, Jonsson T. Incisional Hernia after Midline Laparotomy: A Prospective Study. Eur J Surg. 1996;162(2):125-9.

33. Kroese LF, Sneiders D, Kleinrensink GJ, Muysoms F, Lange JF. Comparing different modalities for the diagnosis of incisional hernia: a systematic review. Hernia. 2018;22(2):229-242.

34. Beck WC, Holzman MD, Sharp KW, Nealon WH, Dupont WD, Poulose BK. Comparative effectiveness of dynamic abdominal Sonography for hernia vs computed tomography in the diagnosis of incisional hernia. J Am Coll Surg. 2013;216(3):447-53; quiz 510-1.

35. Winters H, Knaapen L, Buyne OR, Hummelink S, Ulrich DJO, van Goor H, et al. Pre-operative CT scan measurements for predicting complications in patients undergoing complex ventral hernia repair using the component separation technique. Hernia. 2019;23(2):347-354.

36. Kirkpatrick T, Zimmerman B, LeBlanc K. Initial Experience with Robotic Hernia Repairs: A Review of 150 Cases. Surg Technol Int. 2018;33:139-147.

37. Simons MP, Smietanski M, Bonjer HJ, Bittner R, Miserez M, Aufenacker TJ, et al. International guidelines for groin hernia management. Hernia. 2018;22(1):1-165.

38. Coulier B. Multidetector computed tomography features of linea arcuata (arcuate-line of Douglas) and linea arcuata hernias. Surg Radiol Anat. 2007;29(5):397-403.

39. Henriksen NA. Systemic and local collagen turnover in hernia patients. Dan Med J. 2016;63(7). pii: B5265.

40. Henriksen NA, Yadete DH, Sorensen LT, Ågren MS, Jorgensen LN. Connective tissue alteration in abdominal wall hernia. Br J Surg. 2011:98(2)210-219.

41. Henriksen NA, Mortensen JH, Sorensen LT, Bay-Jensen AC, Ågren MS, Jorgensen LN, et al. The collagen turnover profile is altered in patients with inguinal and incisional hernia. Surg (United States). 2015;157(2):312-321.

42. Rosch R, Junge K, Lynen P, Mertens PR, Klinge U, Schumpelick V. Hernia - A collagen disease? Eur Surg. 2003;35(1):11-15. 
43. Yamamoto M, Takakura Y, Ikeda S, Itamoto T, Urushihara T, Egi H. Visceral obesity is a significant risk factor for incisional hernia after laparoscopic colorectal surgery: A single-center review. Asian J Endosc Surg. 2018;11(4):373-377.

44. Aquina CT, Rickles AS, Probst CP, Kelly KN, Deeb AP, Monson JRT, et al. Visceral obesity, not elevated $\mathrm{BMI}$, is strongly associated with incisional hernia after colorectal surgery. Dis Colon Rectum. 2015;58(2):220-227.

45. Antoniou GA, Georgiadis GS, Antoniou SA, Granderath FA, Giannoukas AD, Lazarides MK. Abdominal aortic aneurysm and abdominal wall hernia as manifestations of a connective tissue disorder. J Vasc Surg. 2011;54(4):1175-1181.

46. Montgomery A, Petersson U, Austrums E. The arcuate line hernia: Operative treatment and a review of the literature. Hernia. 2013;17(3):391-396.

47. Henriksen NA, Mortensen JH, Lorentzen L, Ågren MS, Bay-Jensen AC, Jorgensen LN, et al. Abdominal wall hernias-A local manifestation of systemically impaired quality of the extracellular matrix. Surgery. 2016;160(1):220-227.

48. Farraia MV, Cavaleiro Rufo J, Paciência I, Mendes F, Delgado L, Moreira A. The electronic nose technology in clinical diagnosis. Porto Biomed J. 2019;4(4):e43.

49. Kjaer M, Frederiksen AKS, Nissen NI, Willumsen N, van Hall G, Jorgensen LN, et al. Multinutrient Supplementation Increases Collagen Synthesis during Early Wound Repair in a Randomized Controlled Trial in Patients with Inguinal Hernia. J Nutr. 2020 jan 3.

50. Mazzaglia PJ, Milas M. Ultrasound training among endocrine oncology surgeons: what is best practice? Int J Endocr Oncol. 2015;2(2).

51. Rozycki GS, Ochsner MG, Jaffin JH, Champion HR. Prospective evaluation of surgeons' use of ultrasound in the evaluation of trauma patients. J Trauma - Inj Infect Crit Care. 1993;34(4):516-526.

52. Carroll WW, Walvekar RR, Gillespie MB. Transfacial ultrasound-guided gland-preserving resection of parotid sialoliths. Otolaryngol - Head Neck Surg (United States). 2013;148(2):229-234.

53. Todsen T. Surgeon-performed ultrasonography. Dan Med J. 2017 Nov;64(11). 


\section{Chapter 10}

Summary

Samenvatting

Valorisation

Dankwoord

Curriculum Vitae

List of publications 



\section{Summary}

In chapter 1 the purpose and outline of this thesis is introduced: to investigate current aspects and challenges in preventative measures, diagnostics and treatment of common (incisional and parastomal hernias) and rare abdominal wall hernias (lumbar and arcuate line hernias).

\section{Part A}

\section{Prevention and treatment of iatrogenic abdominal wall hernias}

Incisional hernia, defined as any abdominal wall gap at the site of a previous surgical incision of the abdominal wall can occur in more than $20 \%$ of patients. Extensive research has been done on preventative measures to decrease the likelihood of incisional hernia formation. Because little is known about the actual clinical implementation of this research, in chapter $\mathbf{2}$ an online survey among Dutch surgeons on this subject is described. 402 surgeons participated in the survey, representing $97 \%$ of all surgical departments in the Netherlands. The survey found that implementation of the latest evidence regarding closure techniques of the abdominal wall is not widespread. Although nearly all surgeons use slow-absorbable suture materials, only $35 \%$ of surgeons close the abdominal fascia using a suture length to wound length ratio of 4:1. Surgical trainees, gastrointestinal and oncological surgeons are most familiar with the recommended technique and use it in their daily practice.

Chapter 3 describes a randomised controlled trial which investigated incidence of incisional hernia after midline laparotomy in patients after midline laparotomy. 456 patients were randomised and the abdominal fascia was closed with either nonabsorbable (polypropylene; Prolene ${ }^{\circledR}$ ) or absorbable (polydioxanone; PDS ${ }^{\circledR}$ ) suture material. During median follow-up of 32 and 31 months in both groups, no significant difference in the incidence of incisional hernia between the groups was detected: 20.2\% (45 of 223) for Prolene ${ }^{\circledR}$ and $24.9 \%$ (58 of 233) with PDS $^{\circledR}(P=0.229)$. KaplanMeier analysis showed a cumulative rate after 4 years of 23.7 and $30.2 \%$ for Prolene ${ }^{\circledR}$ and $\mathrm{PDS}^{\circledR}$ respectively $(P=0.222)$. The incidence of incisional hernia in both groups was thus higher than expected from previous literature.

Chapter 4 describes a safety and feasibility study on a new stoma dressing for patients with peristomal skin complications and parastomal hernias. The TOMAS dressing 
combines a rigid plastic ring, which is applied on the skin around the stoma, with an elastitic bandage, which keeps the ring in place. 23 patients (16 colostomas and 7 ileostomas), including 6 patients with parastomal hernia, participated in the study and wore the dressing continuously during four weeks. Readjustment of the bandage was necessary in nearly all participants and 16 participants discontinued early due to shifting or discomfort while wearing the dressing. Peristomal skin improved in the remaining patients. Patients with parastomal hernias experienced high comfort levels. Leakages decreased in all participants. Transient oedema of the stoma occurred in six patients. The dressing was found to be safe and of benefit to patients with parastomal hernias and skin erosions, as it allows omission of adhesives and inunctive treatment of skin erosions. Comfort levels need to be improved before widespread implementation is possible.

\section{Part B}

\section{Diagnosis and treatment of abdominal wall hernias}

In chapter 5, a comparison is made between two diagnostic modalities for detection of an incisional hernia: physical examination and ultrasonography, based on the randomised trial described in chapter 3. During the median follow-up of 31 months, 103 incisional hernias were found. A total of 82 incisional hernias were found by physical examination and an additional 21 with ultrasonography. Six of these additional hernias were symptomatic and only one of the additional hernias received operative treatment. The false-negative rates for physical examination and ultrasonography were 25.3 and $24.4 \%$, respectively. Interest variability was low, with a Kappa of 0.697 $(P<0.001)$. Standardized combination of ultrasonography with physical examination during follow-up yielded a significant number of, mostly asymptomatic, hernias, which would not be found using physical examination alone. This is especially relevant in research settings.

Chapter 6 describes a systematic literature review and makes clinical recommendations for proper diagnosis and treatment of the primarylumbarhernia. The lumbar abdominal wall hernia is a rare hernia in which abdominal contents protrude through a defect in the dorsal abdominal wall, which can be of iatrogenic, congenital, or traumatic origin. Two anatomical locations are known: the superior and the inferior lumbar triangle. 
Out of 670 eligible articles, 14 were included and additional single case reports were analysed separately. The average quality of the included articles was 4.7 on the MINORS index (0-16). Risk factors are related to increased intra-abdominal pressure. CT scanning should be performed during pre-operative workup. Available evidence favours laparoscopic mesh reinforcement, saving open repair for larger defects. Incarceration was observed in $30.8 \%$ of the cases and $2.0 \%$ had a recurrence after surgical repair.

Chapters $\mathbf{7}$ and $\mathbf{8}$ investigate another little known abdominal wall hernia: the arcuate line hernia. An arcuate line can occur if a sharp delineation of the arcuate line occurs and a peritoneal fold develops at this location. This abdominal wall hernia is an internal herniation, ie no full defect of the abdominal wall occurs. Little is known on the clinical relevance and incidence of this type of abdominal wall hernia. Chapter 7 describes a case report on this type of hernia, which alerted the authors to the existence of this type of hernia. Chapter 8 reports a retrospective study on the incidence of arcuate line hernia in patients presenting to the emergency department with abdominal complaints in who no initial diagnosis was found. Eight hundred and ten patients presented with abdominal complaints, 415 of these had CT scans available for review and were included in the study. In 47 patients (11.3\%), an arcuate line anomaly was found, and in 14 patients (3.4\%), a frank arcuate line herniation (grades 2 or 3) was found. Retrospective correlation with clinical complaints was found in $50 \%$ of these patients. Patients with arcuate line hernia had a significantly higher BMI, and diabetes mellitus and aortic aneurysm were more prevalent in these patients. 

Summary

\section{Samenvatting}

Valorisation

Dankwoord

Curriculum Vitae

List of publications 



\section{Samenvatting}

Hoofdstuk 1 beschrijft het doel en de opzet van dit proefschrift: het onderzoeken van de huidige uitdagingen met betrekking tot preventie, diagnostiek en behandeling van veel voorkomende (parastomale hernia's en littekenbreuken) en zeldzame buikwandherniaties (lumbale en linea arcuata hernia's).

\section{Deel A}

\section{Preventie en behandeling van iatrogene buikwand hernia's}

Littekenbreuken, gedefinieerd als elke onderbreking van de buikwand ter plaatse van een eerdere chirurgische incisie, hebben een incidentie van meer dan $20 \%$. Er is veel onderzoek verricht naar preventieve maatregels om het risico op ontwikkeling van een hernia cicatricalis te verkleinen. Omdat weinig bekend is over de daadwerkelijke implementatie van dit onderzoek, beschrijft hoofdstuk 2 een online enquête onder Nederlandse chirurgen over dit onderwerp. 402 chirurgen namen deel aan het onderzoek, waarmee $97 \%$ van de chirurgische afdelingen in Nederland zijn vertegenwoordigd. Vrijwel alle chirurgen gebruiken een langzaam oplosbaar hechtmateriaal om de buikwand te sluiten, maar slechts $35 \%$ van deelnemers sluiten de abdominale fascia met een hechtdraad-wondlengteratio van 4:1. Chirurgen in opleiding, abdominaal en oncologisch chirurgen zijn het meest bekend met de aanbevolen technieken en implementeren deze in hun dagelijkse praktijk.

Hoofdstuk 3 beschrijft een gerandomiseerde gecontroleerde studie die de incidentie van littekenbreuken na een mediane laparotomie onderzocht bij gebruik van verschillende hechtdraden om de abdominale fascie te sluiten. 456 patiënten werden gerandomiseerd in twee onderzoeksarmen waarin de fascia met een niet oplosbare hechtdraad (polypropylene; Prolene ${ }^{\circledR}$ ) of een langzaam oplosbare hechtdraad (polydioxanone; PDS $^{\circledR}$ ) werd gesloten.

Gedurende een mediane follow-up van 32 en 31 maanden in beide groepen werd geen significant verschil in incidentie van hernia cicatricalis gevonden: 20.2\% (45 van 223 deelnemers) voor Prolene ${ }^{\circledR}$ en $24.9 \%$ (58 van 233) voor $\operatorname{PDS}^{\circledR}(P=0.229)$. Een KaplanMeier analyse vond na vier jaar een cumulatieve incidentie van 23.7 en $30.2 \%$ voor respectievelijk Prolene ${ }^{\circledR}$ en and PDS $^{\circledR}(P=0.22)$. De incidentie van hernia cicatricalis was derhalve hoger dan op basis van eerdere literatuur werd verwacht. 
In hoofdstuk 4 wordt een pilotstudie beschreven die een nieuw type stomamateriaal onderzoekt met als doel peristomale huidcomplicaties te verminderen, in het bijzonder bij patiënten met parastomale hernia's. De TOMAS stoma-applicatie combineert een rigide plastic ring, die op de huid om het stoma wordt geplaatst en waaraan het opvangzakje wordt bevestigd, met een elastische buikband die de ring op zijn plek houdt. 23 patiënten (16 deelnemers met colostomas en 7 deelnemers met ileostomas) namen deel aan de studie, waaronder 6 deelnemers met een parastomale hernia. Hoewel de studie vier weken duurde, stopten 16 deelnemers voortijdig met deelname en moest de band bij nagenoeg alle patiënten worden bijgesteld. Peristomale huidcomplicaties en lekkages namen wel af onder de deelnemers. Patiënten met parastomale hernia's ondervonden veel comfort tijdens het gebruik van de applicatie. Voorbijgaand oedeem werd bij zes patiënten geobserveerd. De nieuwe applicatie was in deze pilotstudie veilig en mogelijke doelgroepen zijn patienten met peristomale huidcomplicaties en parastomalehernia's. Het comfort tijdens gebruik moet echter verbeterd worden voordat wijdverspreid gebruik mogelijk is.

\section{Deel B}

\section{Diagnose en behandeling van buikwand hernia's}

In hoofdstuk 5 worden twee diagnostische technieken (lichamelijk onderzoek en echografie) vergeleken om hernia cicatricalis op te sporen met gebruik van de dataset van de in hoofdstuk 3 beschreven studie. Gedurende de mediane follow-up van 31 maanden werden 103 littekenbreuken gedetecteerd. Hiervan werden 82 breuken gevonden met lichamelijk onderzoek en daarnaast nog 21 herniaties met echografie.

Van deze additioneel gedetecteerde breuken waren er zes symptomatisch en één ervan werd operatief behandeld. Het percentage vals-negatieve resultaten voor lichamelijk onderzoek en echografie was respectievelijk $25.3 \%$ en $24.4 \%$ De intertest variabiliteit was laag, met een Kappa van 0.697 ( $P<0.001)$. Gestandaardiseerde follow-up waarin lichamelijk onderzoek met echografie werd gecombineerd leverde dus een significant aantal extra gedetecteerde breuken op die voornamelijk asymptomatisch waren. Dit is bijzonder relevant voor toepassing in toekomstig onderzoek naar littekenbreuken.

Hoofdstuk 6 beschrijft een systematische literatuurreview naar primaire lumbale hernia's en geeft klinische aanbevelingen voor diagnostiek en behandeling hiervan. De lumbale hernia is een weinig voorkomende buikwandherniatie waarbij de inhoud van het abdomen door de dorsale buikwand hernieert. Het defect kan iatrogeen, 
congenitaal of traumatisch ontstaan. Twee anatomische locaties worden beschreven: de bovenste en onderste lumbale driehoek.

14 artikels werden geïncludeerd in de review en aanvullende casusbeschrijvingen werden apart geanalyseerd. De gemiddelde kwaliteit van de geïncludeerde studies was 4.7 op basis van de MINORS index (0-16). Risicofactoren voor het ontwikkelen van een lumbale hernia zijn gerelateerd aan een verhoogde intra-abdominale druk. CT scans van het abdomen moeten vervaardigd worden bij de preoperatieve oppuntstelling. De beschikbare evidence ondersteunt laparoscopische behandeling met een kunststof mesh, waarbij open herstel kan worden overwogen bij grotere defecten. Inklemming van de hernia werd gezien bij $30.8 \%$ van de onderzochtte patiënten en een recidief na chirurgisch herstel werd gevonden bij twee procent.

Hoofdstukken 7 en 8 beschrijven een andere weinig bekende buikwandhernia: de linea arcuata hernia. Deze hernia kan ontstaan wanneer er een scherpe demarcatie van de linea arcuata is waardoor aldaar een peritoneale plooi vormt. Omdat bij dit type buikwandhernia geen volledig defect van de buikwand optreedt, is er sprake van een inwendige hernia. Er is weinig bekend over de klinische relevantie en incidentie van dit type buikwandhernia. Hoofdstuk 7 beschrijft een case report over dit type hernia. Hoofdstuk 8 beschrijft een retrospectieve studie waarin de incidentie van linea arcuata hernia werd onderzocht bij patiënten die zich op de spoedeisende hulp presenteerden met buikklachten en waarbij geen initiële diagnose werd gesteld. 810 patiënten werden geidentificeerd. Hiervan waren bij 415 patiënten CT scans beschikbaar voor beoordeling. Bij 47 patienten (11.3\%) werd afwijkende anatomie van de linea arcuata gevonden en bij 14 patiënten (3.4\%) een duidelijke linea arcuate hernia (graad 2 of 3). Correlatie met klinische klachten werd bij de helft van deze patiënten gevonden. De BMI was significant hoger bij patiënten met linea arcuata hernia. Diabetes mellitus en aneurysma van de aorta waren meer prevalent onder deze patiënten. 

Summary

Samenvatting

Valorisation

Dankwoord

Curriculum Vitae

List of publications 



\section{Introduction}

Valorisation is the process of creation of value from knowledge, by making knowledge suitable and available for social and/or economic use and by translating knowledge into competitive products, services, processes and new commercial activities. This addendum discusses the social and economic value of the results described in this thesis for both the general patient population as well as the quality of life of the individual patient.

Health care providers may apply the findings of this thesis in their clinical and scientific practice. A final relevant target audience are health care managers, insurance companies and policy makers, as they can apply the findings to improve resource management and allocation within the health care system.

\section{Scope}

Several types of abdominal wall hernias are discussed in this thesis: incisional and parastomal hernias are more common and lumbar and arcuate line hernias are rare abdominal wall hernias.

Incisional hernia and parastomal hernia are iatrogenic types of hernias that can arise after abdominal surgery. Up to two in ten patients who had a laparotomy develop an incisional hernia and in certain types of ostomies, up to one in two patients develop a parastomal hernia. Presence of obesity and smoking increases the likelihood of hernia development. Each year approximately 5500 colostomies are created in the Netherlands and ventral abdominal hernia repair remains one of the most commonly performed surgical procedures; 3 million hernia repairs are performed each year in the world. Convalescence after abdominal wall hernia repair may be complicated by surgical site infections, bowel injury or recurrence of the hernia.

The incidence of lumbar hernias and arcuate line hernias is much lower. These types of abdominal wall hernias may well be classified as a rare disease as defined by the European Commission on Public Health: 'Life-threatening or chronically debilitating diseases which are of such low prevalence that special combined efforts are needed to address them.' Low prevalence is generally meant to be fewer than 1 in 2000 people. 


\section{Personal and societal impact}

Individual patients with abdominal wall hernias may experience bulging, discomfort or pain related to the hernia, as well as cosmetic complaints. Incarceration or strangulation of the hernia may occur, which can cause mortality if untreated. Parastomal hernias can cause leakage of effluent that leads to skin irritation and inflammation, besides incarceration also leading to mortality if not treated. These symptoms impair quality of life of patients and inhibit their ability to fully use their occupational potential, which may result in poorer employment opportunities. Surgical treatment of abdominal wall hernias is not without risks for the patient. Postoperative complications such as recurrence of the hernia, infection and in extreme cases mortality can occur. Lifestyle interventions such as preoperative weight loss and smoking cessation may decrease the risk of incisional hernia formation and decrease risk of postoperative complications. Shared decision making with patients is increasingly important in abdominal wall surgery.

Abdominal wall hernias burden the resources of society in several ways. First, patients with abdominal wall hernias have an impaired productivity, when compared to patients without abdominal wall hernias. Second, unemployed patients with abdominal wall hernias will also seek to gain disability benefits, which are provided by general society. Third, patients with incisional hernia and parastomal hernia seek relief and treatment for these complaints which leads to an increased health care consumption by increased health care consultations, use of supportive devices and surgical revision of the hernia. This in turn leads to a larger economic burden of the general health care system for society. In France, a multi-center study assessed the annual cost for ventral hernia repair at 45 million Euros. A saving of 4 million Euros was estimated if a $5 \%$ reduction of incisional hernia incidence could be achieved.

With these figures in mind, the potential gains of prevention of incisional hernia formation and improved supportive treatment of parastomal hernia are huge. Individual quality of life of patients will improve and general health care consumption will decrease. Part A of this thesis is focused on this subject.

\section{Prevention}

Chapter 2 is in essence a quality control audit of current implementation of best evidence techniques for prevention of incisional hernia development. Unfortunately, the findings are that for various reasons most surgeons do not currently use best 
evidence techniques for incisional hernia prevention. While incisional hernia development is dependent on a variety of reasons, surgical technique and materials are directly adaptable and these findings suggest that significant decreases in incisional hernia rates are achievable if all surgeons adapt the current best techniques.

Likewise, optimization of preventative strategies for incisional hernia formation will reduce the incidence and thus less socio-economic impact of this condition. Chapter 3 investigated a potential preventative strategy for incisional hernia formation by use of two different suture materials for closure of the abdominal fascia after midline laparotomy.

Chapter 4 focuses on a new ostomy dressing (TOMAS) that omits adhesive fixation on the skin. Less disposable materials are used in this dressing which leads to a smaller environmental and economic burden for patients and society. The exact economic impact of the device will have to be examined in future studies.

\section{Diagnosis and treatment}

In part B of this thesis, diagnosis and treatment of abdominal wall hernias is discussed. Chapter 5 found that the combined use of structured physical examination and ultrasonography yielded a significant number of, mostly asymptomatic, hernias which would not be found by physical examination alone. This is relevant for future research in incisional hernia to adequately detect all incisional hernias, which in turn leads to improved quality of research that can better be applied in clinical care for patients.

Chapters 6, 7 and 8 focus on more rare abdominal wall hernias, the arcuate line hernia and the lumbar dorsal hernia. While these types of abdominal hernias have a low incidence and have little general socio-economic impact, the consequences of having a symptomatic or even incarcerated rare abdominal wall hernia can be immense for individual patients. The research presented in these chapters can help patients suffering from one of these rare abdominal wall hernias. Furthermore, improving knowledge on diagnosis and treatment of these hernias can translate into future knowledge of more common types of hernias which affect larger number of patients.

\section{Conclusion}

Abdominal wall hernias, both common and rare, have a large socioeconomic impact on individual patients and society in general. The content of this thesis helps to prevent hernia formation and to optimize treatment of these hernias. Hopefully this benefits 
individual patients and decreases health care consumption. Ongoing research in this field is thus necessary and valuable. 
Summary

Samenvatting

Valorisation

Dankwoord

Curriculum Vitae

List of publications 
'If I have seen further, it is by standing on the shoulders of Giants.'

Isaac Newton 


\section{Dankwoord}

Ik ben veel mensen dank verschuldigd voor hun bijdrage aan de totstandkoming van dit proefschrift.

Vooraleerst gaat mijn dank uit naar de patiënten die zich belangeloos ter beschikking stelden voor deelname aan de onderzoeken waarop dit proefschrift is gebaseerd.

Mijn dank gaat uit naar mijn (co)promotoren, medeauteurs, leden van de beoordelingscommissie en overige leden van de promotiecommissie.

Professor doctor Bouvy, beste Nicole, ik kon mij geen betere promotor wensen. Je passie voor de chirurgie en de wetenschap straalt er vanaf en dat werkt aanstekelijk. Je opbouwende (subtiele) begeleiding, waarbij je mij alle ruimte liet om mijn eigen ideeën en projecten uit te werken, vormt een grote inspiratiebron.

Doctor Hoofwijk, beste Ton, de fundamenten van dit proefschrift zijn samen met jou gelegd. Dit proefschrift zou er nooit zijn gekomen zonder jouw kritische, intensieve begeleiding bij aanvang van mijn carrière als wetenschapper.

Doctor Aarts, beste Frits, we delen onze fascinatie voor de buikwand en ik kijk met veel plezier terug op onze discussies over dit onderwerp. Je bent voor mij een voorbeeld van de moderne specialist die niet alleen vakbekwaamheid, maar ook balans tussen carrière en gezinsleven hoog in het vaandel heeft staan.

Beste leden van de beoordelingscommissie, prof. dr. Laurents Stassen, prof. dr. Maarten Van Kleef, prof. dr. Niels Komen en dr. Simon Nienhuijs, hartelijk dank voor uw grondige en kritische beoordeling van dit proefschrift. Ik zie uit naar de gelegenheid om met $u$ van gedachten te wisselen over mijn doctoraat.

Beste leden van de vakgroep chirurgie en collega's van het VieCuri Medisch Centrum in Venlo, bedankt voor een fantastische en leerzame tijd die ik met jullie door mocht brengen. Ik stapte elke dag met veel plezier in mijn auto, met een nieuwe werkdag samen met jullie in het vooruitzicht.

Beste chirurgen en arts-assistenten van de dienst abdominale, kinder- en reconstructieve chirurgie van het Universitair Ziekenhuis Antwerpen, bedankt voor de 
mooie en leerzame tijd die ik als fellow bij jullie mocht doorbrengen. Jullie hebben mijn buitenlandse excursie tot een waar genoegen gemaakt.

Mijn Paranimfen, Jesse Habets en Rob Körver.

Jesse, amice, jij ging mij al voor en ik mocht bij jou als paranimf al proeven van het promoveren. Ik prijs me gelukkig dat jij mij deze wederdienst bewijst tijdens mijn verdediging.

Rob, vriend door dik en dun, ik hoop dat ik jou ooit op gelijke wijze mag bijstaan. Dit proefschrift bewijst dat niets onmogelijk is!

Waarde leden van de Heeren Jaarclub Numen, in je studententijd maak je vrienden, niet voor even maar voor de rest van je leven! Inmiddels getrouwd, gesetteld en met kinderen zijn we hard op weg naar ons vierde lustrum. Ik ben ervan overtuigd dat we lief en leed nog lang samen blijven delen.

Lieve vrienden en familie. Het lot kiest onze familie, wij kiezen zelf onze vrienden. Voor mij twee keer een schot in de roos.

Beste schoonfamilie Bauduin, lieve Eddy, Monique, Patrick, Babette, Felipe en Oliver, ik ben dankbaar dat ik deel van de familie mag uitmaken. Grazie Mille!

Beste ouders, lieve pappa en mamma, dank jullie voor alles. Ik ben trots dat ik jullie zoon ben.

Lieve Kasper en Nancy, dank jullie voor alle steun in de loop der jaren. Kasper, onze levenspaden nemen elk een andere richting, maar gelukkig lopen we als broers nooit ver van elkaar.

Nathalie, Veerle en Milou, ik heb de belangrijkste personen in mijn leven voor het laatst bewaard. Woorden schieten te kort om te beschrijven hoe dankbaar ik ben dat ik jullie echtgenoot en vader mag zijn.

Liefste Veerle en Milou, elk op je eigen manier, maar wat een pit zit er in jullie! Jullie zijn de zonnestralen in mijn leven. Elke dag is een nieuw avontuur voor jullie. Ik kan niet wachten om samen met jullie te ontdekken wat er in de wereld allemaal te beleven valt! 
Allerliefste Lie, jouw schroefjes en moertjes worden nooit saai om naar te luisteren en ik weet niet of ik de handleiding ooit helemaal zal begrijpen, maar ik kijk ernaar uit om dit de rest van mijn leven samen met jou te ontdekken. Ti amo! 

Summary

Samenvatting

Valorisation

Dankwoord

Curriculum Vitae

List of publications 



\section{Curriculum Vitae}

Arthur Bloemen was born on July 14th 1985 in Sittard, The Netherlands. He finished his secondary education (Gymnasium) at the Trevianum Scholengroep in Sittard in 2003 and started his medical studies at Maastricht University in the same year. In 2007 he began his clinical rotations, which included a traineeship in the Republic of South Africa and a senior rotation in the Orbis Medical Centre in Sittard-Geleen (now Zuyderland hospital). It was there that the foundation of the current thesis was made under supervision of dr. A.G.M. Hoofwijk.

After graduating in 2009, he worked as a resident not in training at the surgical departments of the VieCuri Medical Centre in Venlo (dr. H.M.J. Janzing) and the Maastricht University Medical Centre in Maastricht (prof. dr. L.P.S. Stassen). In 2013 he started surgical training, first in the Maastricht University Medical Centre, and again in the VieCuri Medical Centre from 2015 till 2019. Work on this thesis was continued under supervision of dr. F. Aarts and prof. dr. N.D. Bouvy.

After finishing his surgical training and registering as a general and gastro-intestinal surgeon, he continued with fellowship level training at the department of abdominal, pediatric and reconstructive surgery of the University Hospital of Antwerp, Belgium (prof. dr. G. Hubens).

In 2020 he decided to change his career path into social (insurance) medicine. He currently lives in Maastricht with his wife Nathalie and his two daughters, Veerle and Milou. 

Summary

Samenvatting

Valorisation

Dankwoord

Curriculum Vitae

List of publications 



\section{This thesis}

Bloemen A, Aarts F, Bouvy N, Nijhuis P. 'Evaluation of a new elastic ostomy appliance to decrease skin complications: results of a pilot study.' Journal of wound management and prevention. 2020;66:30-36

Bloemen A, Kranendonk J, Sassen S, Aarts F, Bouvy ND. 'Incidence of arcuate line hernia in patients presenting to the emergency department with abdominal complaints; a retrospective cohort study.' World Journal of Hernia and Abdominal Wall Surgery. 2019;23:1199-1203

Bloemen A, De Kleijn RJCMF, Van Steensel S, Aarts F, Schreinemacher M, Bouvy ND. 'laparotomy closure techniques: are surgeons following the guidelines?' International Journal of Surgery. 2019;71:110-116.

Bloemen A, Keijzers MJ, Konsten JLM, Aarts F, Vogelaar FJ. 'Clinical image: internal herniation of the abdominal wall.' Journal of Clinical Case Reports 2019;00:1-2

Van Steensel S, Bloemen A, Van den Hil LCL, Van den Bos J, Kleinrensink GJ, Bouvy ND. 'Pitfalls and clinical recommendations for the primary lumbar hernia based on a systematic review of the literature.' World Journal of Hernia and Abdominal Wall Surgery. 2019;23:107-117.

Bloemen A, Dooren van P, Huizinga BF, Hoofwijk AGM. 'Comparison of ultrasonography and physical examination in the diagnosis of incisional hernia in a prospective study'. World Journal of Hernia and Abdominal Wall Surgery. 2012;16:53-57

Bloemen A, Dooren van P, Huizinga BF, Hoofwijk AGM. 'Randomized clinical trial comparing polypropylene or polydioxanone for midline abdominal wall closure'. British Journal of Surgery. 2011;98:633-9

\section{Other}

Van Steensel S, Van den Hil LCL, Bloemen A, Gijbels MJ, Breukink SO, Melenhorst J, Lenaerts K, Bouvy ND. 'Prevention of incisional hernia using different suture materials for closing the abdominal wall: a comparison of PDS, Vicryl and Prolene in a rat model'. World Journal of Hernia and Abdominal Wall Surgery. 2020;24:67-78 
Bloemen A, Daniels AM, Samyn MG, Janssen RJ, Elshof JW. 'Electrocardiographic-guided tip positioning technique for peripherally inserted central catheters in a Dutch teaching hospital: Feasibility and cost- effectiveness analysis in a prospective cohort study' Journal of Vascular Access. 2018;19:578-84.

Van Heinsbergen M, Bloemen A, Konsten JLM. 'Darmresectie bij dunne darmischemie: altijd zwart-wit of soms door een roze bril bezien?'. Nederlands Tijdschrift voor Heelkunde. 2018;27:30-32

Konings K, Bloemen A, Hageman M, Schlatmann F. 'Ook doelmatigheid is jong geleerd, oud gedaan'. Medisch Contact. 2018;73:28-30

Bloemen A, Weber RJP. 'Man met pijnlijke pols na val'. Nederlands Tijdschrift voor Geneeskunde. 2012;156:A3085

Bloemen A, Testroote MJG, Janssen-Heijnen MLG, Janzing HMJ.' Incidence and diagnosis of heparin induced thrombocytopenia (HIT) in patients with traumatic injuries treated with unfractioned or low-molecular-weight heparin: a literature review'. Injury. 2012;43:548-52

Bloemen A, JMLG Gehlen. 'Buikpijn en target-sign'. Medisch Contact. 2011;66:1513

Bloemen A, Akker van den LHJM. 'Vrouw met pijn in de linker onderbuik.' Nederlands Tijdschrift voor Heelkunde. 2009; 18: 228-229 

s

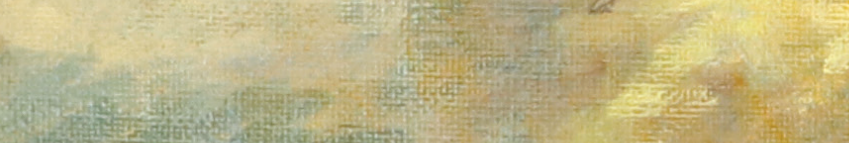

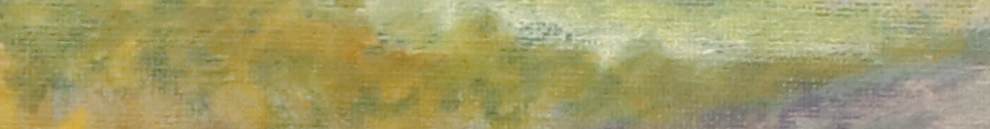

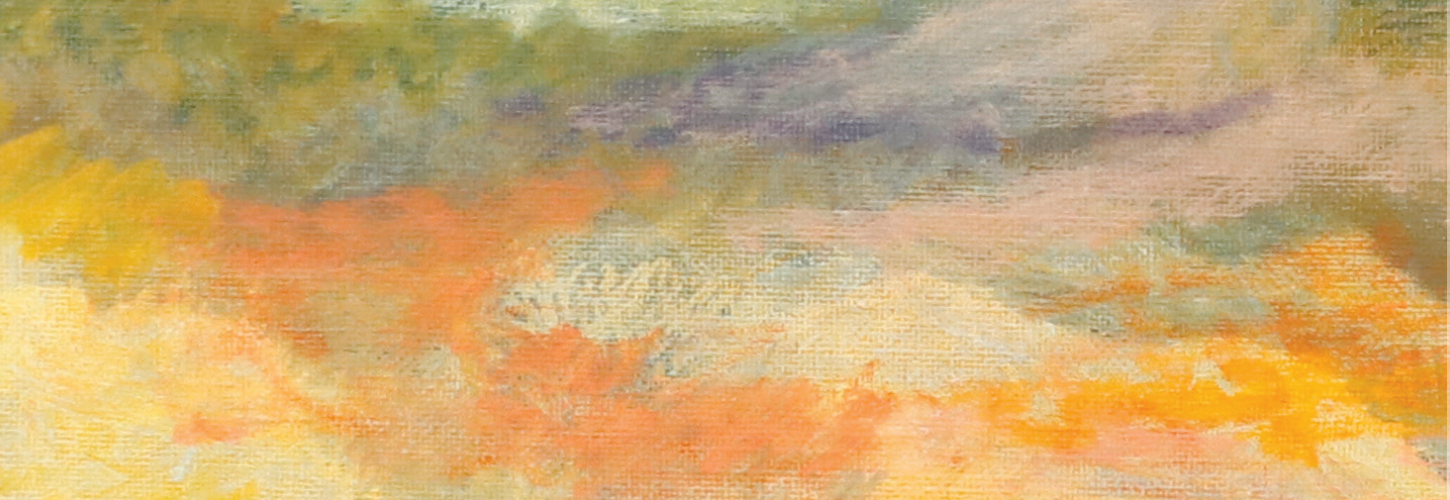

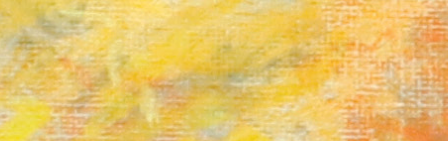

$-3 x^{2}+x^{2}$



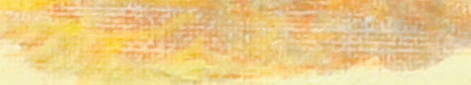

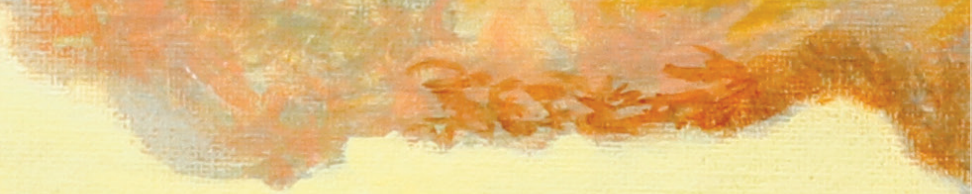

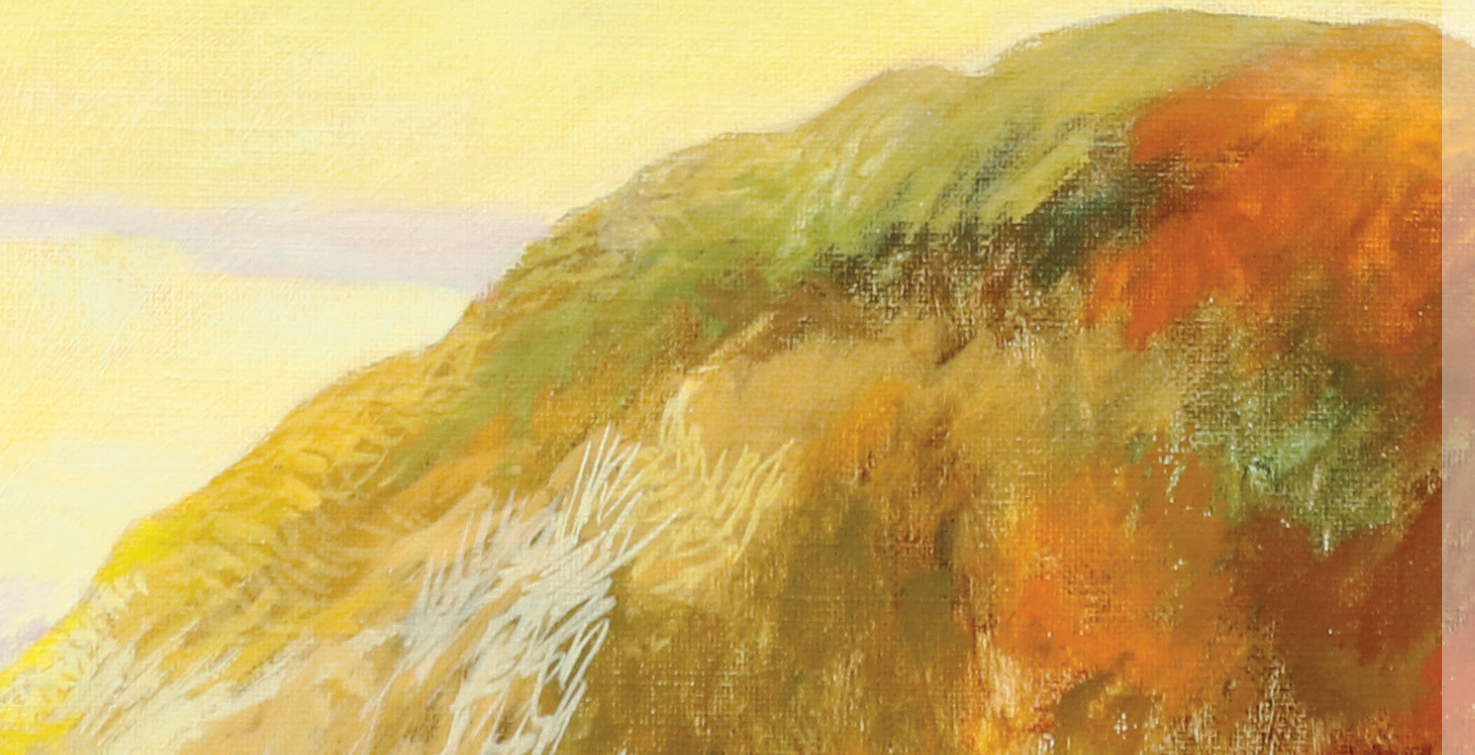

